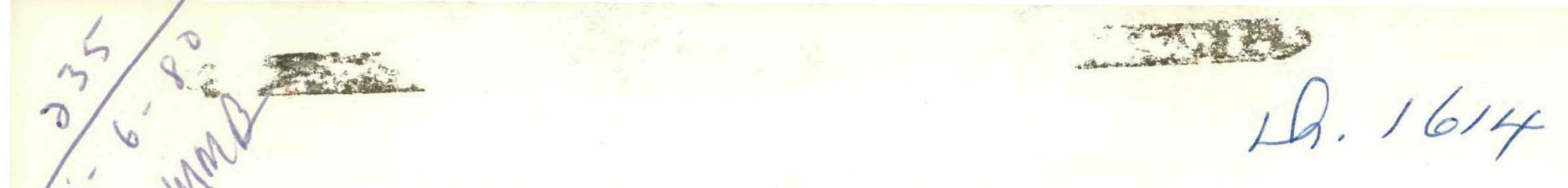

ORNL/Sub-7585/1

\title{
Life and Stability Testing of Packaged Low-Cost Energy Storage Materials
}

\author{
Galen R. Frysinger
}

\section{MASTER}

OPERATED BY

UNION CARBIDE CORPORATION

FOR THE UNITED STATES DEPARTMENT OF ENERGY 


\section{DISCLAIMER}

This report was prepared as an account of work sponsored by an agency of the United States Government. Neither the United States Government nor any agency Thereof, nor any of their employees, makes any warranty, express or implied, or assumes any legal liability or responsibility for the accuracy, completeness, or usefulness of any information, apparatus, product, or process disclosed, or represents that its use would not infringe privately owned rights. Reference herein to any specific commercial product, process, or service by trade name, trademark, manufacturer, or otherwise does not necessarily constitute or imply its endorsement, recommendation, or favoring by the United States Government or any agency thereof. The views and opinions of authors expressed herein do not necessarily state or reflect those of the United States Government or any agency thereof. 


\section{DISCLAIMER}

Portions of this document may be illegible in electronic image products. Images are produced from the best available original document. 


\section{Printed in the United States of America. Available from National Technical Information Service \\ U.S. Department of Commerce \\ 5285 Port Royal Road, Springfield, Virginia 22161}

NTIS price codes-Printed Copy: A07 Microfiche A01

This report was prepared as an account of work sponsored by an agency of the United States Government. Neither the U nited States Government nor any agency thereof, nor any of their employees, makes any warranty, express or implied, or assumes any legal liability or responsibility for the accuracy, completeness, or usefulness of any information, apparatus, product, or process disclosed, or represents that its use would not infringe privately owned rights. Reference herein to any specific commercial product, process, or service by trade name, trademark, manufacturer, or otherwise, does not necessarily constitute or imply its endorsement, recommendation, or favoring by the United States Government or any agency thereof. The views and opinions of authors expressed herein do not necessarily state or reflect those of the United States Government or any agency thereof. 
ORNL/Sub-7585/1

Dist. Category UC-94a

\section{LIFE AND STABILITY TESTING OF PACKAGED LOW-COST \\ ENERGY STORAGE MATERIALS}

Galen R. Frysinger

Date Published: July 1980

Report Prepared by

Institute of Energy Conversion

University of Delaware

Newark, Delaware 19711

Under Subcontract No. 7585

For

OAK RIDGE NATIONAL LABORATORY

Oak Ridge, Tennessee 37830

operated by

UNION CARBIDE CORPORATION

for the

DEPARTMENT OF ENERGY

Contract No. W-7/105=eng-26

DISCLAIMER

This book was prepared as an account of work sponsored by an agency of the United States Government Neether the United States Government nor any agency thereot, nor eny of their employees makes anv

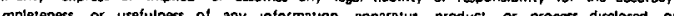
mesentis mmercial producy process or servose by trode name indemark manutacturer or orhermse does 
THIS PAGE

\section{WAS INTENTIONALLY \\ LEFT BLANK}




\section{$\underline{\text { ABSTRACT }}$}

The Institute of Energy Conversion, in cooperation with the Du Pont Company, has developed a low-cost laminated plastic film which is used to contain a Glauber's salt-based phase change thermal energy storage material in sausagelike containers called Chubs. This report describes the results of tests performed on the Chub packages themselves and on the thermal energy storage capacity of the packaged phase change material. From the test results, $\exists$ set of specifications have been drawn up for a film material which will satisfactorily contain the phase change material under anticipated operating conditions. Calorimetric testing of the phase change material with thermal cycling indicates that a design capacity of $45-50 \mathrm{Btu} / \mathrm{lb}$ for a $\Delta \mathrm{T}$ of $30^{\circ} \mathrm{F}$ can be used for the packaged material. 
THIS PAGE

\section{WAS INTENTIONALLY LEFT BLANK}


TABLE OF CONTENTS

Page

EXECUTIVE SUMMARY 1

INTRODUCTION - 4

1. PACKAGING MATERIAL AND THE CHUB PACKAGE 6

A. Film Characteristics' Specifications 6

B. Specification - Blue Film Laminate for Thermal Energy Storage Chubs 11

C. Test Methods 13

D. Moisture Vapor Retention Tests 14

E. Package Integrity Testing 29

F. Performance Cycle Testing 40

11. THERMAL STORAGE PERFORMANCE EVALUATION 55

A. Test Method 55

B. Air Calorimeter 56

C. Laboratory Calorimeter $\quad 71$

D. Differential Scanning Calorimeter 85

E. Chub Test Results 92

III. SPECIFICATION AND TESTING 98

A. For Blue Chubs Containing $55^{\circ} \mathrm{F}$
Phase Change Material

B. Qualified Chub Fabrication $\quad 104$ 


\section{EXECUTIVE SUMMARY}

The University of Delaware has developed a thermal energy storage system which uses a Chub package to contain the phase change thermal energy storage material. The chub is fabricated from a low cost laminated plastic film which has a low rate of water vapor transmission.

This report describes the results of testing performed on a phase change thermal energy storage material contained in Chubs. The first part of the report discusses the characteristics that the laminated film must have in order to successfully contain the phase change material for long periods of time and the second part describes calorimetric testing of the phase change material.

\section{Laminated Plastic Film and Chub Package}

A set of criteria defining acceptable characteristics of the laminated film are given with a brief discussion of the reason for each criterion. A list of test methods to ensure that the laminate meets the necessary criteria is given. A detailed discussion of a test program designed to measure the moisture retention properties of the qualified laminate is given and it is concluded that a laminate consisting of several layers of polyethylene and metallized polyethylene teraphthalate performs satisfactorily. 
A program was performed which tested the ability of the Chub package to withstand extremes of temperature, handling and transportation. The abovementioned laminated film was found to perform satisfactorily.

The Chub package was tested for its ability to withstand prolonged thermal cycling. Some problems were encountered with leakage at the end clips of the Chub in these tests. Several types of secondary seals of the end clips were tested and found to resolve the problem satisfactorily. Aside from tliis mechanical problem, which is due to shortcomings of thc packaging maclinilery, the laminate performed satisfactorily.

\section{Thermal Energy Storage Performance}

The phase change material that was tested is a mixture of sodium sulfate, water and other salts which nominally undergoes a phase change transition at $55^{\circ} \mathrm{F}$. The material was tested as a function of thermal cycling in threc different, complementary calorimeters:

1) A differential scanning calorimeter

2) A laboratory scale liquid calorimeter

3) A large scale air calorimeter

For convenience, all calorimetric measurements were normalized to a $\Delta T$ of $30^{\circ} \mathrm{F}$.

It was found that the results obtained from the differential scanning calorimeter were inconsistent and difficult to interpret. It was concluded that this method is not useful for measuring thermal energy storage capability with respect 
to thermal cycling. Nonetheless, the technique may be useful for quality control purposes such as might be necessary during large scale production of the Chub packages. Differential scanning calorimetry was also used to test the effects of prolonged vibration on the Chub packaged phase change material. It was concluded that no significant change in the performance of the material due to vibration could be determined from this test.

Test results from the liquid calorimeter correlated well with results obtained from the large scale air calorimeter. The material, with one exception, showed a decline in thermal energy storage capability with cycling. For use in design considerations, a nominal capacity of $45-50 \mathrm{Btu} / \mathrm{lb}$ is recommended.

The performance of the material with cycling can be improved as can be seen from two pieces of evidence:

1) In all cases, the capability of the material is greater than or equal to $70 \mathrm{Btu} / \mathrm{lb}$ for the first thermal cycles.

2) A batch of Chubs which had been cycled more than 400 cycles stored more than $70 \mathrm{Btu} / \mathrm{lb}$.

\section{Specification and Test Procedures}

A detailed listing of the specifications for the laminated plastic film, the chub package and the mixing phase change material is given. In addition, a series of test procedures are given to ensure that the Chubs are fabricated properly. 


\section{INTRODUCTION}

This report presents the results of the life and stability testing research performed at the Institute of Energy Conversion (IEC) during 1978-79 on a thermal energy storage phase change material. This work was performed as part of sub-contract \# 7585 between Oak Ridge National Laboratory and the Institute of Energy Conversion. As part of its thermal energy storage research program, the Institute is investigating a storage assisted air conditioning system which, with the aid of a thermal energy storage unit using a phase change material, will enable the user to defer the consumption of electrical power to off-peak hours. The advantages of such load shifting or load leveling are well known and will not be discussed here.

The thermal energy storage unit conslsts of a bin, approximately $125 \mathrm{ft}^{3}$ in volume, filled with a $52^{\circ}-55^{\circ} \mathrm{F}$ Glauber's salt based phase change material packaged in sausage-type packages called Chubs. The energy storage bin is connected into the ductwork of a residence and suitable thermostatic controls are employed to allow the unit to operate in the desired manner. Workers at the IEC have tested this concept in various configurations in several different installations over the past few years and over this period of time the Chub package for the phase change material was developed. 
The purpose of the project reported here was to test the capability of the Chub package to contain the phase change material under simulated operating conditions for an adequate period of time. The research was divided into two major areas: testing and qualification of the laminated plastic film and the Chub package; and testing of the thermal energy storage capability of the Chub package filled with the phase change material. In addition, a detailed list of specifications from the Chub package and laminated plastic film is given.

The report discusses these two objectives in detail; the first part deals with the development and qualification of the laminated plastic film and the Chub package which has been developed in conjunction with E. I. du Pont de Nemours Company (Du Pont) and the second describes the results of testing the phase change material under various conditions.

The successful development of a thermal energy storage package which is long lived and has a large energy storage density will have a significant impact on the solution of the energy problem facing the United States today because it makes load leveling feasible. The ability to defer power consumption to off-peak hours is desirable because it can reduce the consumption of imported petroleum and reduce future capital investments needed for power generation facilities. 


\section{PACKAGING MATERIAL AND THE CHUB PACKAGE}

This section describes the characteristics of the thin laminated plastic film, developed with help from the Du Pont Company, which is used to package the phase change thermal energy storage material. A series of tests were performed which were designed to test the material's capability to successfully contain the phase change thermal energy storage material in Chub packages under a variety of extreme conditions. On the basis of these tests, a set of specifications for the plastic laminate have been generated. The Chubs are prepared by a machine manufactured by Kartridg-Pak of Davenport, lowa. The machine is used extensively in the food industry for packaging sausages, cheese, etc. Therefore, the laminated film described in this section must be compatible with the operating requirements of the Chub machine.

\section{A. Film Characteristics' Specifications}

The laminated film used to package the thermal energy storage material represents about one percent by weight of the tinished Chub, yet this thin film (thickness about 102 micrometers, or 0.004 inches) must possess a number of critical properties if the finished Chub is to be fully functional. These film characteristics are:

Ability to form a heat seal - To perform satisfactorily on the Chub machine, the film must be capable of forming a strong, uniform seal when first heated and then cooled on one side by a jet of hot or cold air. To do this, the inner and outer layers of the laminate must have similar melting points and 
viscosities at temperatures just above the film's melting point, however, its melting point must be lower than the peak temperature attained at the film interface. These criteria limit the maximum film thickness which in turn limit production on the Chub machine.

Low density polyethylene film, made from resin with a density close to $0.92 \mathrm{~g} / \mathrm{ml}$ (range 0.919 to 0.922 ) is preferred for the inside and outside layers of the laminate.

Proper slip - The level of slip (related to the inverse of the coefficient of friction) of the inner and outer plies of polyethylene film in the laminate must be properly controlled. If the slip is too high (coefficient of friction <0.5) difficulty will be experienced in forming and holding the film tube in position during the heat sealing operation. The presence of surface active additives in high or medium slip film will also interfere with treatment of the polyethylene film that is required to achieve adequate adhesion between the polyethylene layer and the polyester film layer using suitable adhesives.

The low density polyethylene outside layers should be treated for adhesion on one side, and should have a kinetic coefficient greater than 0.50 , as measured by ASTM Test Method ASTM D1894.

Physical strength - The 48 or 50 gauge oriented polyethylene teraphthalate film used as the core of the laminated $\mathrm{film}$ imparts the desired impact strength, puncture resistance, and stiffness to the laminate. The water vapor transmission rate of polyester film of this thickness, while good, can be further improved by adding a film of vacuum deposited aluminum to its surface. This metallized polyester film provides a composite with acceptable water vapor transmission rates. 
Adhesion between layers - The overall performance of the laminate is dependent upon good adhesion between adjacent layers. In laminates of polyethylene film and biaxially oriented polyester film, the stress-strain characteristics of the two films are very different. The polyethylene film has relatively low tensile modulus, yield point, and tensile strength at break, but high elongations on the order of 100 to 600 percent. In contrast, the polyester film has a high tensile modulus, high yield point, and high tensile strenqth at break, but low elonqations on the order of 5 to 25 percent at break. The desirable combination of good impact resistance, high tear strength and high tensile strength of the laminate depend on the level of adhesion achieved between the adjacent film layers.

In the Chub package, good adhesion is required over a temperature range of $0^{\circ}$ to $65^{\circ} \mathrm{C}\left(150^{\circ} \mathrm{F}\right)$. Adhesion must not be adversely affected by exposure of the cut edge of the laminate to the contents of the chub. The effectiveness of many common film adhesives depends on completion of a chemical curing reaction before full adhesive strength is achieved. Thus adhesives used in the film laminate, if not adequately cured, may allow penetration of salt solutions into the $f i l m-f i l m$ interface, leading to destruction of the adhesive bond. Permeation of salt solutions into the metallic layer will cause disintegration of the metallic vapor barrier coating and result in an increase in the water vapor transmission rate of the laminate.

As a practical test for adequate adhesion, the film is stretched uniformly beyond the yield point in both machine and transverse directions. Visible separation of the $\mathrm{film}$ layers after release of the tensile stress is an 
indication of inadequate adhesion. To determine the sensitivity of the adhesive joint in the laminate to chemical attack, a sample of the laminate with freshly cut edges is stored in a hot $\left(150^{\circ} \mathrm{F}\right)$ saturated slurry of water, sodium sulfate and borax for several days. If adhesion is acceptable, there will be no visual evidence of delamination or attack of the metallic barrier coating adjacent to the cut edges of the laminate.

Water vapor transmission rate - To obtain a reproducible measure of the moisture vapor transmission rate of the laminate, film samples of known exposed areas are used to seal demineralized water in an aluminum cup. The sealed cup is then placed in a dessicator in a thermostatically controlled oven at $100^{\circ} \mathrm{F}$, so that the effective humidity difference across the film is from 100 percent to zero percent. A plot of loss in gross weight with time permits calculations of the film's water vapor transmission rate (WVTR), normally expressed in grams lost per 24 hours per $100 \mathrm{in}^{2}$ of exposed area at $100^{\circ} \mathrm{F}$ and 100 percent water vapor pressure differential. ASTM Test Method E-96, "Test for Water Vapor Transmission of Materials in Sheet Form," provides a detalled procedure for determining the WVTR.

The film laminate should have a WVTR below $0.10 \mathrm{~g} / 24 \mathrm{hrs} / 100 \mathrm{in} / 100^{\circ} \mathrm{F}$ and 100 percent RH. High quality laminates with multiple metallized layers should have WVTR values close to $0.03 \mathrm{~g} / 24 \mathrm{hrs} / 100 \mathrm{in}^{2} / 100^{\circ} \mathrm{F}$ and 100 percent $\mathrm{RH}$.

Abrasion resistance - The abrasion resistance of the Chubs is provided by the exterior polyethylene film layer. For polyethylene films in general, abrasion resistance is improved by an increase in the resin density. However, 
an increase in resin density increases the resin melting point and decreases film impact resistance. To retain the desired heat seal characteristics, a resin density of $0.920 \pm 0.001$ represents an acceptable compromise. The use of a thicker outer layer of polyethylene film is another method that can improve the abrasion resistance. For the present chub film laminate, the polyethylene $\mathrm{film}$ thickness is 38 micrometers $(0.0015 \mathrm{in})$ for both the inner and the outer layers so that the total laminate thickness is about 102 micrometers $(0.004 \mathrm{in})$. With this laminated film thickness, heat seals of good uniformity and strength can be produced consistently on the KartridgPak Chub machine at acceptable production rates. The inside layer of polyethylene $\mathrm{film}$ in the Chub package protects the polyester layer(s) from attack by the aqueous salt solution in the Chub.

Sheet flatness - Production of consistently strong and uniform heat seals on the Chub package is dependent on precise positioning of the overlapping films as the heat seal is made. If the laminate used is not flat, but is stretched along one or both edges as it is unwound from the roll, the precise positioning of $\mathrm{film}$ in the heat seal area becomes difficult to maintain. As a result, variations in heat seal width, puckers and transverse wrinkles in the seal area may occur. Such defects in the chub heat seal may lead to leakage of the liquid chub contents through narrow capillaries across the seal area. In an extreme case, openings in the seal area may lead to catastrophic leakage of the Chub contents.

A specification on sheet flatness may be necessary to ensure acceptable film tracking and sealing on the Chub machine. 
Color - Chub color, achieved by pigmentation of the outside polyethylene film layer, serves as a convenient method of identifying Chub contents. A standard "Blue" color has been selected for Chubs containing the $55^{\circ} \mathrm{F}$ material used in cooling applications.

B. Specification - Blue Film Laminate for Thermal Energy Storage Chubs The laminated film structure defined by this specification shall have, in order, the following components:
a) 38 micrometers $(.0015-i n)$ blue polyethylene film
b) adhesive
c) metallized 48 or 50 -gauge oriented polyester film
d) adhesive
e) metallized 48 or 50-gauge oriented polyester film
f) adhesive
g) 38 micrometers $(.0015-i n)$ clear polyethylene film

\section{Specifications}

a. The 38 micrometers $(0.0015-i n)$ thick opaque blue polyethylene film shall be produced from $0.92 \mathrm{~g} / \mathrm{ml}$ density polyethylene resin, and shall be pigmented blue to provide an approximate match to the standard sample afler lamination. Film color shall be uniform.

b. The adhesive shall be effective at temperatures from $-18^{\circ} \mathrm{C}$ to $82^{\circ} \mathrm{C}$ $\left(0^{\circ} \mathrm{F}\right.$ to $\left.+180^{\circ} \mathrm{F}\right)$ without delamination of any of the interfaces involved. It shall be uniformly applied at a coverage of $2.5 \mathrm{~g} / \mathrm{m}^{3}(1.5$ ib per ream) for each interface. 
c. The 48 or 50 -gauge oriented polyester film shall be metallized uniformly to a resistivity of $2-3$ ohms per unit square.

d. The 38 micrometer $(0.0015$-in thick) clear polyethylene shall be produced from 0.92 density polyethylene resin.

e. The finished laminate shall have a water vapor transmission rate of 0.03 to 0.06 grams per $100 \mathrm{in}^{2}$ per $24 \mathrm{hr}$ at $38^{\circ} \mathrm{C}\left(100^{\circ} \mathrm{F}\right)$ and $90-100$ percent relarlve humidicy. ASTM Standard Method D-1653-72 "Moisture Vapor Permeability of Organic Coating Films", or an equivalent method, shall be used to measure the WVTR of the laminate.

f. The finished laminate shall be capable of being soaked at $65.6^{\circ} \mathrm{C}\left(150^{\circ} \mathrm{F}\right)$ for seven days in a saturated water slurry of sodium sulfate and borax, with no visible evidence of delamination.

g. The finlshed laminate shall be free of blocking, and shall have adequate slip to perform satisfactorily on a Kartridg-Pak "Chub" machine.

h. The finished laminate width shall be $177.8 \pm 1.6 \mathrm{~mm}(7.00 \pm 1 / 16 \mathrm{in})$.

i. The finished laminate shall be supplied in rolls not larger than $356 \mathrm{~mm}$ (14.0 in) 0.D. on $76 \mathrm{~mm}(3.0 \mathrm{in})$ I.D. cores with end plugs. Each roll shall be individually wrapped with kraft paper. Rolls shall be packed in boxes or on pallats so as to prevent domage during ihipping. 


\section{Test Methods}

Many of the test methods and specifications applicable to the Chub laminate and its components are standard procedures as defined by the American Society for Testing and Materials (ASTM). A list of the relevant ASTM test methods is given for reference:

a) ASTM D2103-73 - Standard Specifications for Polyethylene Film and Sheeting

b) ASTM 0374 - Test for Thickness of Solid Electrical Insulation

c) ASTM D1505 - Test for Density of Plastics by the Density Gradient Technique

d) ASTM D1604 - Test for Flatness of Plastic Sheet or Collapsed Tubing

e) ASTM D1893 - Test for Blocking of Plastic Film

f) ASTM D1894 - Test for Static and Kinetic Coefficients of Friction of Plastic Film and Sheeting

g) ASTM D2578 - Test for Wetting Tension of Polyethylene and Polypropylene Films

h) ASTM D3418-75 - Standard Test Method for Transition Temperatures of Polymers by Thermal Analysis

i) ASTM E-96 - Test for Water Vapor Transmission of Materials in Sheet Form

j) ASTM E-252-67 - Test Method For Thickness of Thin Foil and Film by Weighing 


\section{Moisture Vapor Retention Tests}

The ability of the Chub package to retain moisture is a critical requirement of an effective packaging system. The amount of water present in the thermal energy storage material is sufficient to form the sodium sulfate decahydrate at the transition temperature. Consequently, any loss of moisture during the life of the Chub may result in a decrease in its effective thermal storage capacity.

A development program was undertaken with Du Pont to evaluate different laminated films for the Chub package and to investigate the effect of various end closures. In the course of the six-month program, a total of 1303 Chubs, representing 24 variations, were supplied by Du Pont. Properties of these Chubs, and identification of the intended packaging variations, are summarized in Table 1. Data on the average values and the standard deviations for Chub weight and length were recorded to give a measure of the process reproducibility. The results of a series of moisture vapor retention tests are also recorded.

Chubs selected at random from the lots were stored at room temperature $\left(72^{\circ} \mathrm{F}\right)$ and in Blue $M$ circulating ovens maintained at 120.150 and $180^{\circ} \mathrm{F}$. The Chubs were removed periodically and weighed to within \pm 0.01 grams on a Mettler PL1200 automatic balance. 
TABLE I

\section{2-INCH CHUBS FROM DU PONT}

\begin{tabular}{|c|c|c|c|c|c|c|c|c|c|c|}
\hline \multirow{2}{*}{$\begin{array}{l}\text { CHUB } \\
\text { Lot } \\
\text { No. }\end{array}$} & \multirow{2}{*}{$\begin{array}{c}\text { No. } \\
\text { of } \\
\text { CHUBS }\end{array}$} & \multicolumn{2}{|c|}{ Weight-g } & \multicolumn{2}{|c|}{ Length-cm } & \multicolumn{3}{|c|}{ Wt. Loss-g/1000 } & hrs & \multirow{2}{*}{ Comments } \\
\hline & & $\bar{x}$ & $\sigma$ & $\bar{x}$ & $\sigma$ & $180^{\circ} 1$ & $\mathrm{~F} 150^{\circ} \mathrm{F}$ & $120^{\circ} \mathrm{F}$ & $72^{\circ} \mathrm{F}$ & \\
\hline A & 31 & 773.4 & 22.2 & - & - & 22.0 & 9.0 & - & 0.51 & Clip elosure only \\
\hline B & 31 & 770.4 & 16.8 & - & - & - & - & - & - & Clip \& wax \\
\hline $\mathrm{C}$ & 35 & 767.7 & 18.0 & - & - & - & - & 3.1 & - & Clip \& ultra-sound \\
\hline D & 64 & 769.1 & 19.1 & 31.3 & 3.9 & - & - & - & - & \\
\hline $\mathrm{E}$ & 109 & 856.5 & 26.1 & - & - & - & 5.5 & 3.0 & 1.2 & \\
\hline F & 13 & 863.1 & 26.8 & - & - & - & - & - & - & Poor heat seals \\
\hline $\mathrm{G}$ & 87 & 870.6 & 35.9 & 31.0 & 0.74 & - & 4.32 & 1.56 & 0.34 & \\
\hline $\mathrm{H}$ & 10 & 890.6 & 28.2 & 32.4 & 1.0 & - & 18.0 & 6.3 & 1.4 & Delaminated \\
\hline I & 20 & 853.4 & 55.4 & 30.8 & 1.7 & - & 12.8 & 3.5 & 1.0 & \\
\hline $\mathrm{J}$ & 15 & 762.0 & 23.6 & 33.1 & 0.3 & - & 5.4 & 1.1 & - & \\
\hline $\mathrm{K}_{1}$ & 15 & 773.0 & 10.1 & 30.2 & 0.6 & - & 3.1 & 0.90 & 0.21 & Plain clip \\
\hline $\mathrm{K}_{2}^{1}$ & 65 & 862.5 & 36.7 & 32.6 & 1.1 & - & 2.7 & 1.0 & 0.33 & Flamed end \\
\hline $\mathrm{L}$ & 68 & 865.8 & 29.4 & 31.8 & 0.8 & - & - & - & 1.1 & \\
\hline M & 48 & 867.9 & 41.3 & 32.5 & 1.4 & - & - & 1.8 & - & \\
\hline $\mathrm{N}$ & 8 & 854.0 & 42.7 & 32.1 & - & - & 5.2 & - & 0.15 & Thicker clay mix \\
\hline 0 & 17 & 788.3 & 35.7 & 30.7 & 1.1 & - & - & - & - & \\
\hline $\mathbf{P}$ & 118 & 836.0 & 22.1 & 30.6 & 0.8 & - & - & - & - & Clip pressure 9 \\
\hline$Q$ & 64 & 869.4 & 39.1 & 32.6 & 1.3 & - & - & - & - & Clip pressure 8 \\
\hline $\mathbf{R}$ & 29 & 825.4 & 20.2 & 30.9 & 0.6 & - & - & - & - & Clip pressure 8 \\
\hline $\mathrm{s}$ & 89 & 856.2 & 25.2 & 32.3 & 0.9 & - & - & - & - & \\
\hline $\mathrm{T}$ & 36 & 860.4 & 18.3 & 31.9 & 0.8 & - & - & - & - & Clip pressure 9 \\
\hline $\mathrm{U}$ & 43 & 860.6 & 25.7 & 31.8 & 0.5 & - & - & - & - & Clip pressure 8 \\
\hline $\mathrm{V}$ & 78 & 891.4 & 16.4 & 32.3 & 0.6 & - & 3.3 & 1.2 & .47 & Clip pressure $6,7,8,9$ \\
\hline W & 57 & 932.1 & 73.2 & 34.3 & 2.6 & - & - & - & - & \\
\hline $\mathrm{X}$ & 153 & 906.7 & 99.1 & 33.9 & 0.6 & - & - & - & - & \\
\hline $\mathrm{Y}-1$ & 578 & 806.7 & 13.1 & 30.3 & 0.48 & - & 2.3 & 0.68 & 0.085 & Qualification \\
\hline $\mathrm{Y}-2$ & 327 & 790.5 & 9.8 & 29.8 & 0.31 & - & - & - & - & Lots \\
\hline $\mathrm{Y}-3$ & 220 & 794.5 & 17.0 & 30.0 & 0.32 & - & - & - & - & \\
\hline
\end{tabular}


The loss in weight with time of the Chubs at each of the test temperatures was recorded. The data for each of the lots were plotted for each test temperature. Figure 1 is a plot of cumulative weight loss (grams) vs. time (hours) for a representative set of Chubs held at $150^{\circ} \mathrm{F}$. From this and similar graphs, values of weight loss per 1,000 hours were obtained for each of the test temperatures. These were plotted as a graph of log "weight loss per 1,000 hours" vs. the reciprocal of the absolute temperature in deqrees $K$. Figure 2 is an example of this type of plot for lot $G$.

As a reference point, weight loss per 1,000 hours was measured at $72^{\circ} \mathrm{F}$ (room temperature). Initial data obtained during the first six-ten weeks of testing of samples selected from the Du Pont Chubs indicated a weight loss range of $0.35-0.55 \mathrm{~g} / 1,000 \mathrm{hrs}$ for the standard $12^{\prime \prime} \times 2^{\prime \prime}$ (length $\times$ diameter) research Chub. This represents a percentage weight loss of from $0.04-0.07$ percent in the 1,000-hour period at room temperature.

An accumulated weight loss of from $0.35-0.55 \mathrm{~g} / 1,000$ hrs at $72^{\circ} \mathrm{F}$ extrapolates to a 10-year weight loss of from $3.5-6$ perrent. This is estimated to be equivalent to a reduction of $I U$ - is percent of the phase change material's energy storage capacity assuming that all of the weight loss is water needed for the formation of the sodium sulfate decahydrate.

Figures 3 and 4 show equivalent data for other Chub lots obtained from Du Pont as part of the qualification program. 


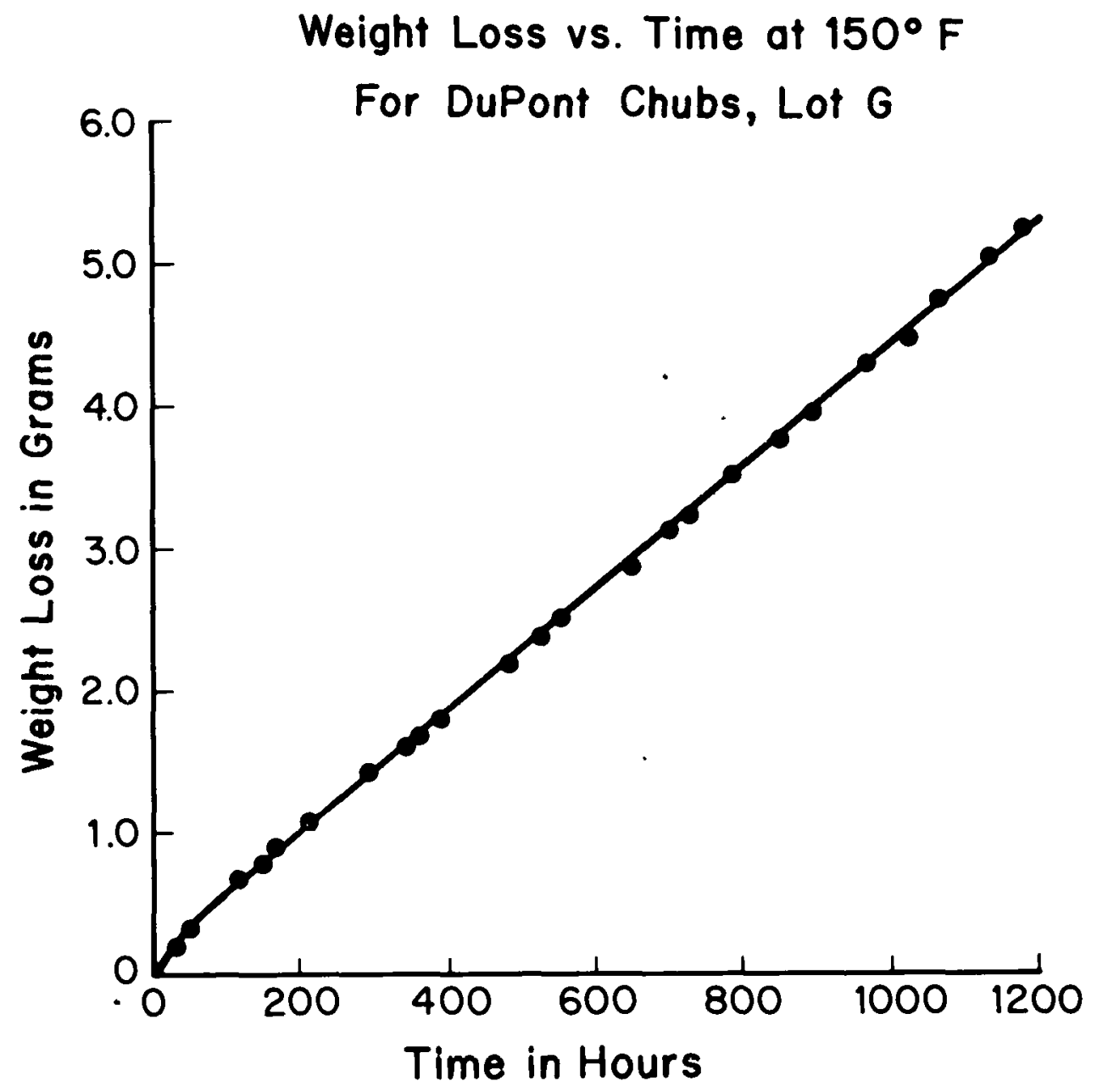

IEC79127

FIGURE 1 
Effect of Temperature on Weight Loss Rate

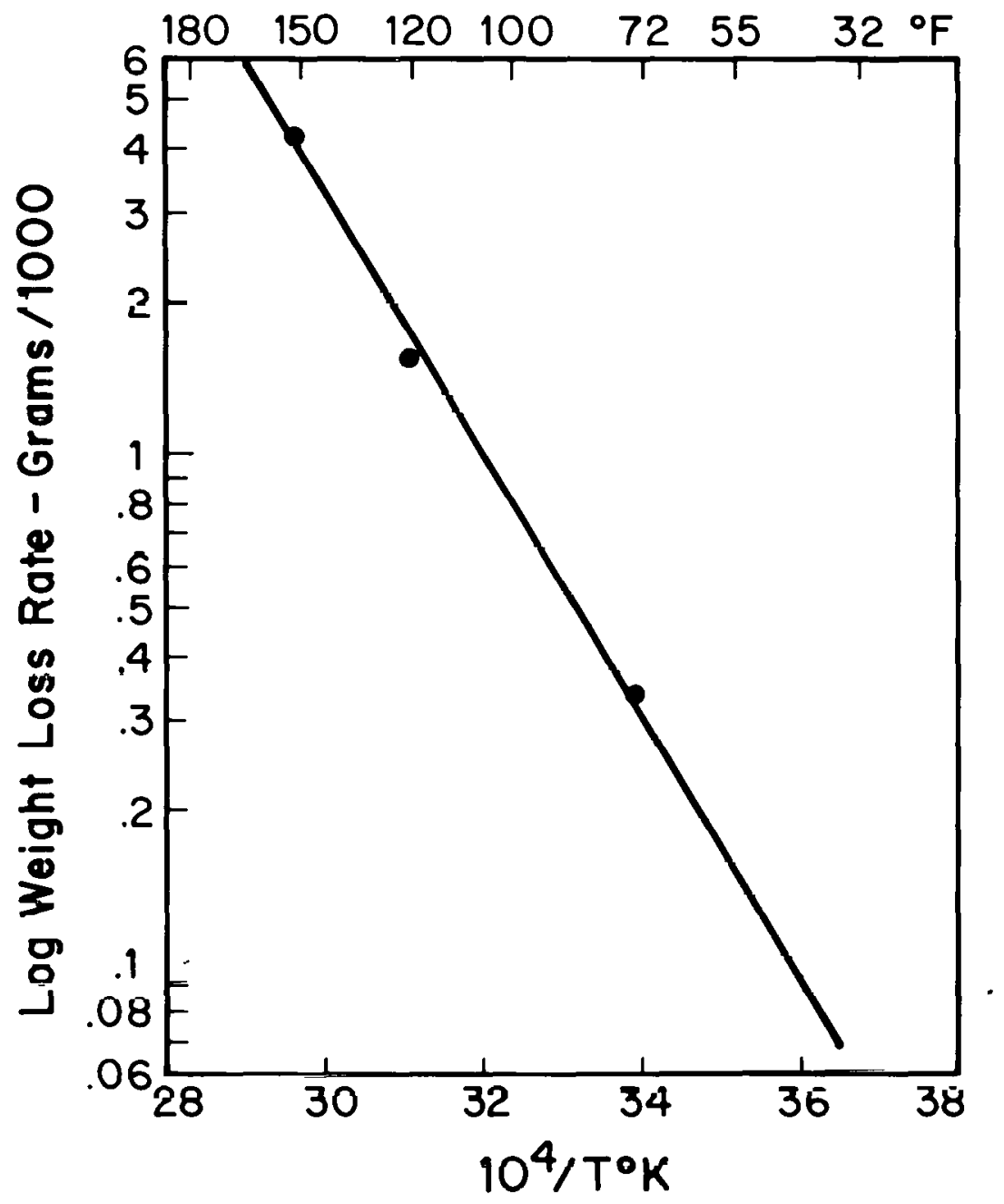

IEC79128

FIGAIIRE ? 
Log Weight Loss Rate - Grams/1000 hrs.

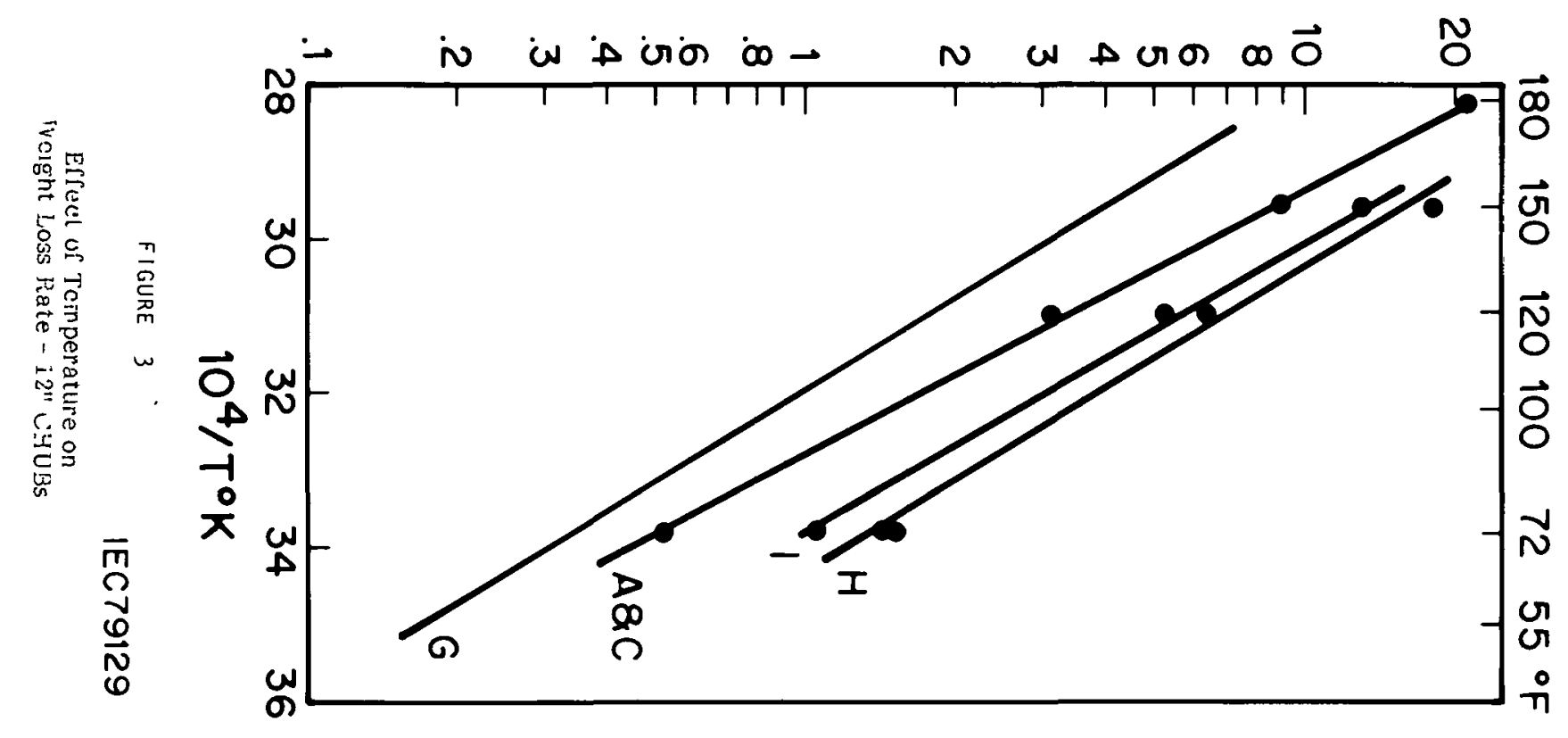


Log Weight Loss Rate - Grams/1000 hrs.

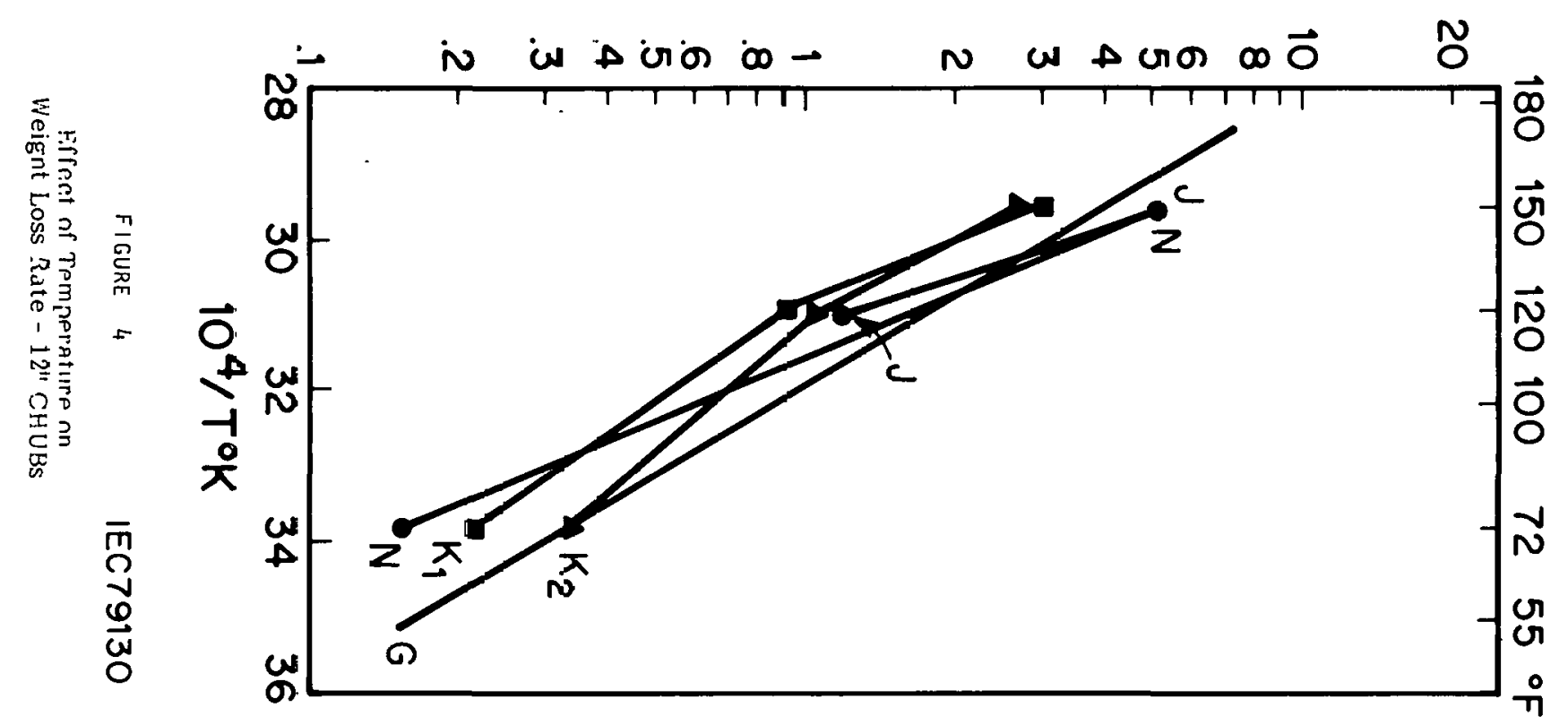


In a number of cases, weight loss tests were continued beyond 1,000 hours. The plots at $120^{\circ} \mathrm{F}$ remained linear out to times in excess of 5,000 hours. Higher test temperatures have induced changes in the laminate thus obscuring long-term data.

In the extended tests of weight loss at room temperature, the observed rate of weight loss frequently decreased with time. The mechanism for this behavior is not understood. One possibility is that, since the chubs at room temperature are under relatively low internal pressure, the capillaries, which may have existed in the end closure, filled with crystallized salt and effectively sealed themselves.

From the data, it is clear that Chubs, which are normally used at room temperature $\left(72^{\circ}\right)$ or lower, should lose weight less rapidly than predicted from the tests at high temperatures.

Long term test data (to 5,000 hrs) are shown for lot G in Figures 5, 6 and 7 for test temperatures of $150^{\circ} \mathrm{F}, 120^{\circ} \mathrm{F}$ and $72^{\circ} \mathrm{F}$.

After the qualification program was completed, three qualification lots, designated as $Y-1, Y-2$ and $Y-3$, were produced at the University of Delaware as the standard 12-inch long, 2-inch diameter research Chubs. 


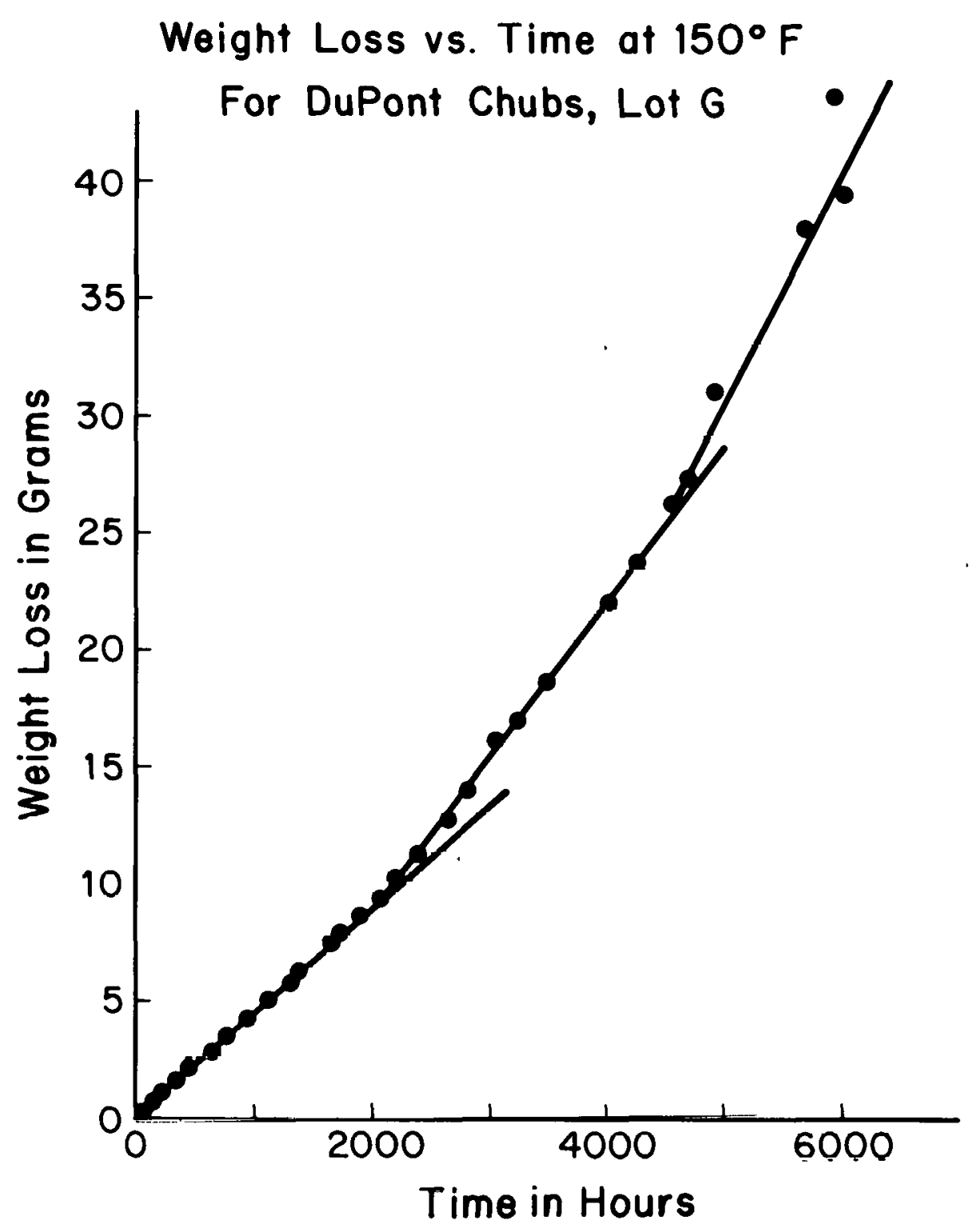

IEC.79124

FIGURE 5 
Weight Loss vs. Time at $120^{\circ} \mathrm{F}$

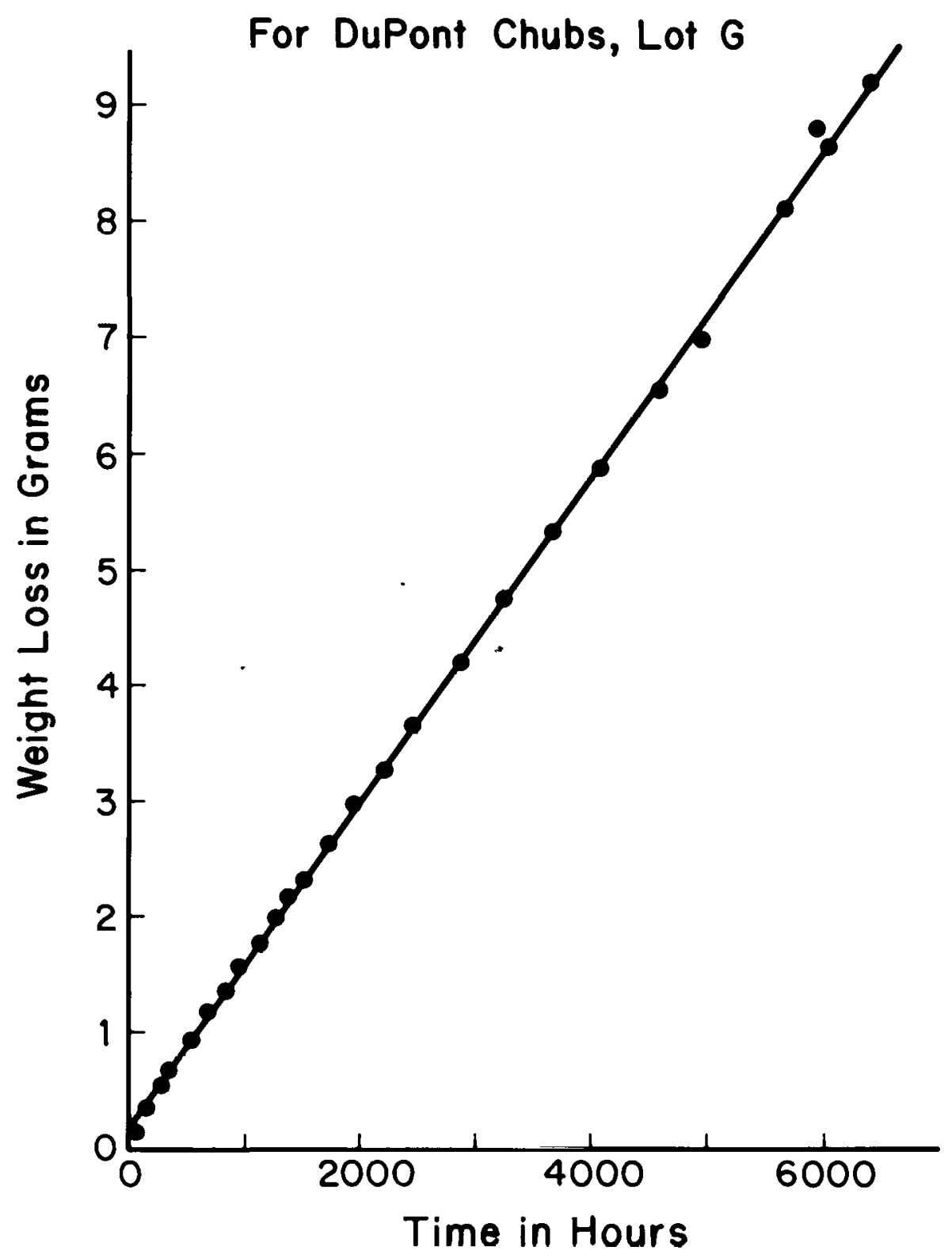

FIGURE 6

IEC79125 


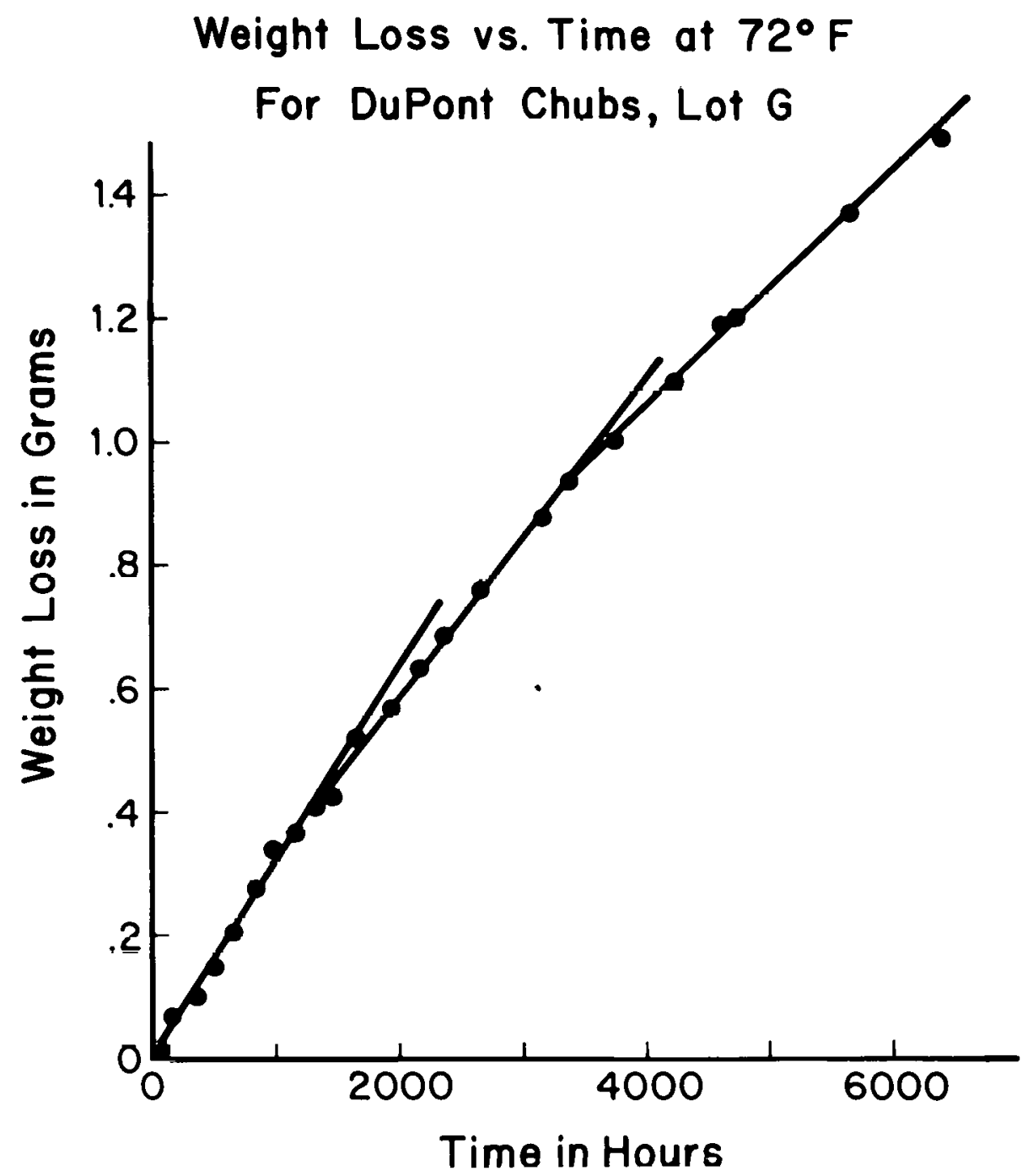

FIGURE 7

IEC79126 
Data on weight loss vs. time were obtained for these qualification Chubs using the standard procedure. The weight loss rates vs, temperature are plotted in Figure 8. To allow for convenience, the data have been normalized to a constant weight $(1,000 \mathrm{~g})$ of phase change material. The qualification Chubs, (lot $Y-1)$ exhibited lower weight loss rates than most of the Du Pont lots. This was probably due to the following factors:

a) Uniformly high quality laminate.

b) Strong uniform heat seals, as a result of careful adjustment of the heat sealing mechanism during extended production runs.

c) Well-formed end closures produced under optimized machine conditions.

The weight loss rate data on the qualification lot extrapolate to a room temperature moisture weight loss of about 0.92 percent in ten years, corresponding to a theoretical efficiency reduction due to water loss of 2.0 percent (see Table 11 ).

For comparison, weight loss data are plotted on thermal energy storage material packaged in a 1-1/2 inch diameter black polyethylene tube with a 0.040 inch wall thickness. The data are normalized to a fixed weight of 1,000 grams of thermal energy storage material. The weight loss data for the best Chub package, at a wall thickness of 0.004 inches, are comparable to those for the polyethylene tube. 
Effect of Temperature on Weight Loss Rate

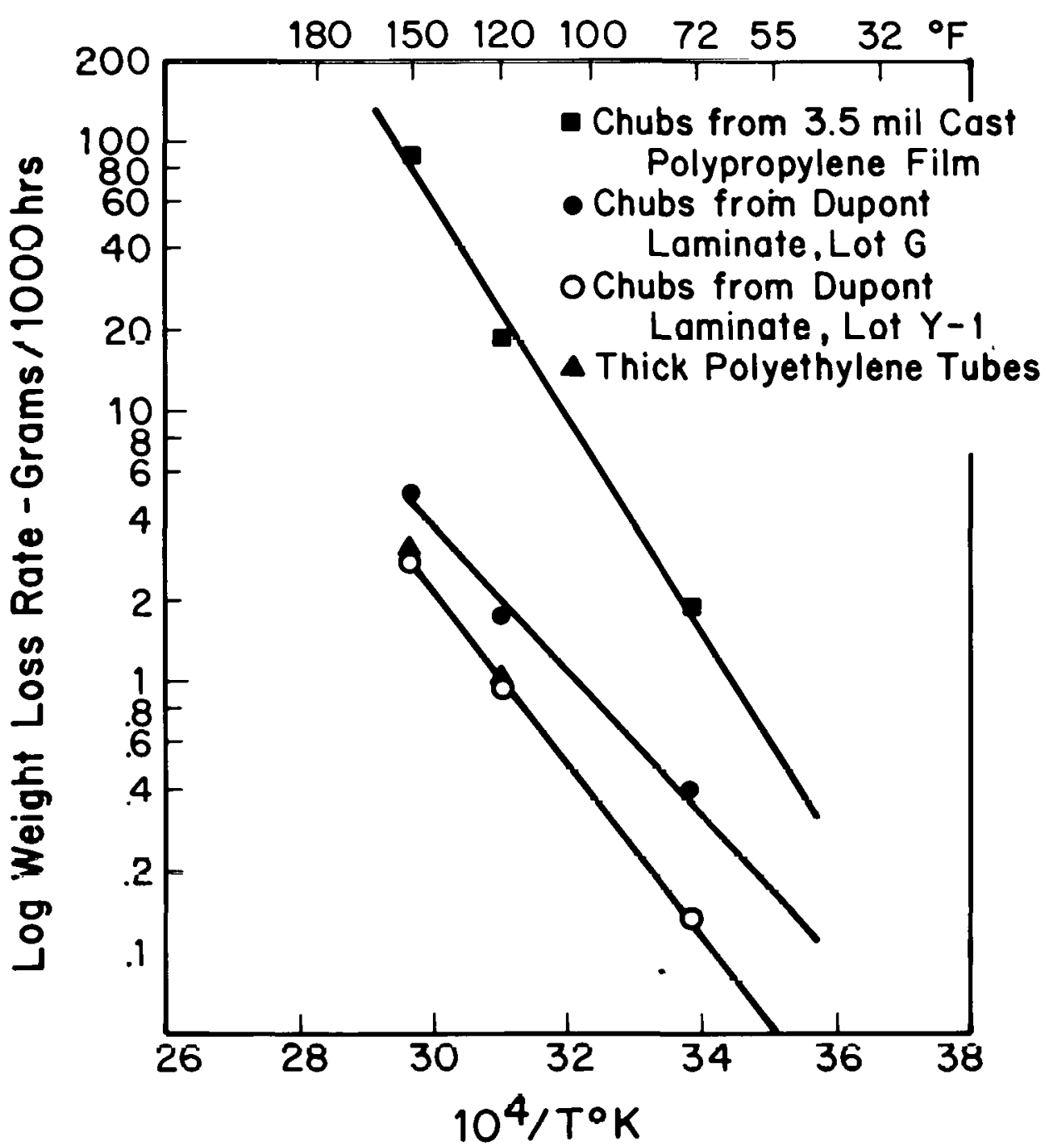

IEC79131 
TABLE |

\section{CHUB WEIGHT LOSS}

12-Inch CHUBs

Lot $G$

Early Du Pont

Prototype

ot $\mathrm{Y}-1$

First

Qualification Lot

Wt. Loss - G/1000 Hrs .

$\begin{array}{lll}150^{\circ} \mathrm{F} & 4.30 & 2.30 \\ 120^{\circ} \mathrm{F} & 1.55 & 0.68 \\ 72^{\circ} \mathrm{F} & 0.34 & 0.085\end{array}$

Wt. Loss - 1000 Hrs.

$$
72^{\circ} \mathrm{F}
$$

$.0105 \%$

Wt . Loss - 10 years

$\%$ of initial weight

3.72

.92

\% Efficiency lost Assuming all weight loss is water

8.6

2.0 
The water vapor permeability of several plastic films were experimentally measured using the permeability cup method, ASTM D-1653-72.

$\mathrm{Fi}$ Im

Nominal

Thickness

$$
\text { (micrometers) }
$$

Chub Laminate

Cast Polypropylene

oriented Pọlyethylene
102

89

107
Water Vapor

Permeability*

* (grams of water transport/24 hrs across $100 \mathrm{in}^{2}$ at $38^{\circ} \mathrm{C}$ and $100 \%$ relative humidity difference)

It is clear from these data that the laminate film has significantly better water vapor permeation properties than the single-ply materials. 


\section{E. Package Integrity Testing}

Since the object of these tests was to examine the integrity of the Chub package, no attempts were made to correlate these tests with the thermal energy storage capability of the package. Consequently, no calorimetric testing was performed in conjunction with the tests described in this section.

\section{Temperature Stability}

The Chub package is made from a polyethylene/polyethylene teraphthalate (PET) film laminate. The adhesive used to form the laminate is of a type used in the preparation of retortable food packages. After adequate curing, the adhesive/PET structure will withstand oven temperatures up to $205^{\circ} \mathrm{C}$ $\left(400^{\circ} \mathrm{F}\right)$. The oriented PET film will retain its integrity at still higher temperatures. The polyethylene films, which constitute the inner and outer surfaces of the Chub package, are heat sealable at temperatures above their crystalline melting points of 112 to $130^{\circ} \mathrm{C}\left(234\right.$ to $\left.266^{\circ} \mathrm{F}\right)$. The outer polyethylene layer will undergo some softening at $100^{\circ} \mathrm{C}\left(212^{\circ} \mathrm{F}\right)$, but pouches with well-formed heat seals in polyethylene/PET laminates are used to contain frozen foods in "heat-in-the-pouch" packages during storage and during cooking in boiling water. Thus, the components of the present chub package can hold the Chub contents at temperatures well above those encountered in actual use. The Chub package has been used to contain thermal energy storage materials in accelerated weight loss tests at $150^{\circ} \mathrm{F}\left(65.6^{\circ} \mathrm{C}\right)$ for more than 6,000 hours without any evidence of package deterioration as determined by visual inspection. 
The Chub package components also have excellent low temperature characteristics, as illustrated by their extensive commercial use for packaging frozen foods. The brittleness temperatures of polyethylene films, oriented PET films and the cured adhesive are well below $-40^{\circ} \mathrm{C}$ $\left(-40^{\circ} \mathrm{F}\right)$. Filled chub packages have been stored in a refrigerator at temperatures below $14^{\circ} \mathrm{F}\left(-10^{\circ} \mathrm{C}\right)$ for more than 7,000 hours without adverse effects on the film packages as determined by visual inspection.

The laminate used in the Chub package is thus capahle nf withatanding the stresses encountered over normal temperature ranges. When the Chub contents are fluid, localized stresses from rough handling or dropping will be distributed over the Chub surface, and absorbed by reversible stretching of the flexible film. However, when the chub contents are solid, the film is effectively locked in place so that it will not be free to stretch to absorb the stress. A localized impact may then cause breaks and pinholes In the tilm. For example, Chubs which have undergone temperature cycling may contain large crystals with sharp edges. If the chub is undisturbed, the crystal edges will not puncture the film because of the high tensile strength of the oriented PET layers and the tear resistance of the polyethylene layers. If the frozen Chub is squeezed or dropped, however, the sharp crystal edges may be forced through the film, causing pinholes.

In the case of the blue Chubs with a $55^{\circ} \mathrm{F}$ transition temperature for cooling applications, the Chubs will normally be handled while in the fluid condition at ambient temperatures, thus precluding the above type of handling problems. 


\section{Stability During Field Handling}

a. Drop Tests

The mechanical tests as outlined in Section 2 a of the Statement of Work consist of a series of drop tests with a filled $12-i n c h(30.5 \mathrm{~cm})$ Chub. A total of 20 Chubs as prepared by Du Pont were dropped from a height of one meter successively in each of four orientations. The orientations for the drop test consisted of a horizontal drop with the heat seal up and alternately with the heat seal down and a vertical drop on each of the package's ends. A successful drop test meant the package retained its contents without leakage. None of the qualified Chubs which were tested showed any leakage for the first ten successive drops. The number ten was chosen to represent extremes in rough handling that might be encountered during unloading or assembly of the Chubs into the Chub thermal energy storage bin. Extension of the tests beyond the qualification point for mechanical testing to a sequential set of 20 drops indicated that of the 20 Chubs tested, 12 of them were capable of sustaining 20 drops without any leakage. The type of failures noted on the non-surviving Chubs were splits along the heat seal and puncture of the laminate by the end clip.

Eight of the Chubs in the test sample were taken from a lot in which difficulties were encountered in making a satisfactory heat seal. These had been rejected by the normal quality assurance procedures. On testing, 
however, it was found that four of the eight survived the total 20 drops, two failed after drops 17 and 18, and two failed on the fourth drop. The heat seal, which is critical in making the Chub, cannot be directly related to loss of mechanical integrity.

\section{b. Vibration}

The Chub should be capable of absorbing mechanical energy in the form of vibration during transportation or use while maintaining its integrity. Likewise, the gelled contents should be capable of maintaining their performance and function after exposure to vibration.

Transportation - A laboratory apparatus called the Du Pont Travelometer was used to simulate the effects of vibration on the Chubs. The travelometer was developed by the Fabrics and Finishes Department of E. I. du Pont de Nemours and Company. It has been used by them to test (Du Pont TM-228-A) the settling of pigments and other particulates in paints and enamels since 1948. The travelometer used in the present work is located in the Annex of the Marshall Laboratory of E. I. du Pont de Nemours and Company, 3500 Grays Ferry Avenue, Philadelphia, PA. The travelometer provides horizontal elliptical vibrations with an amplitude of about $0.3 \mathrm{~mm}$ and a frequency of 12 cycles per second. Vibration of particulate-containing paints on the travelometer for 24 hours is thought by Du Pont personnel to be comparable to transportation for five to seven days in a railway car, followed by a year in storage on a store shelf; thus allowing for rail shipment to, and storage at, any warehouse in the continental United States. 
To evaluate the effects of vibration on the Chubs and their contents, corrugated cardboard trays containing eight Chubs each $12^{\prime \prime} \times 2^{\prime \prime}$ (length $x$ diameter) were placed horizontally on the travelometer tray, with the Chubs parallel to the short side of the tray. After being vibrated for specified times at room temperature, the bottom sides of the Chubs were checked for evidence of abrasion and leakage. The physical integrity of the packages was checked at intervals. After predetermined vibration times, the individual Chubs were frozen quickly in dry ice in their original orientation in order to retain the position and physical structure of the Chub contents. These frozen Chubs were cross-sectioned into 5-6 $\mathrm{mm}$ thick slices, and examined visually and microscopically. The sections were then allowed to thaw at room temperature, with visual observations continuing during the thawing process. Selected portions of the Chub cross-section were analyzed by differential scanning calorimetry (see Section $(1-A-(3))$.

There was no evidence of leakage or abrasion damage in the individual Chubs tested on the travelometer over a period of five months (254 million cycles). Packaging materials and techniques, therefore, are deemed adequatc to pass transportability test considerations.

To exaggerate the effects of vibration on the Chub contents, a sample Chub was vibrated on the travelometer for 166 hours ( 7 million cycles). The cross-section of the frozen Chub was then compared visually with that of a control Chub frozen without prior vibration. The frozen vibrated Chub 
had a band of loosely consolidated crystals across the top, comprising about $10-15 \%$ of the cross-sectional area. The balance of the crosssectional area was uniform in appearance, with clear crystals of about $1 \mathrm{~mm}$ diameter imbedded in a gray matrix. The control chub had a thin band of loose crystals across the top, comprising about $1 \%$ of thc cross sectional area. A similar Chub, which had been thermally cycled in the cooling system at Solar One, the University of Delaware's model solar house, also had a thin band of loose crystals across the top. This evidence suggests that the effects of vibration on the Chub contents during normal shipping, which usually involves only a few days of vibrationlike motion, are minimal.

It is conceivable that in practical field installations, vibration from the motors and fans of air handling equipment could be transmitted to stacks of the thermal energy storage materials, thereby subjecting them to long-term vibration. Our limited practical experience with field applications indicates that this vibration transmission, if any, would be blight. It is expected that the results would be no different than those obtained in the limited transportability test, and that the only cumulative results may be a slight stratification because of density differences. Since this would probably be an effect less pronounced than the same type of effects due to thermal cycling, it was decided to concentrate upon an analysis of thermal cycling effects instead of undertaking a long-term study of the effects due to vibration. 


\section{c. Transportation by Common Carrier to Field Sites}

A box of 24 Chubs was prepared and shipped to the Oak Ridge National Laboratory for two reasons: first as an example of the preparation of the materials based on the specifications of the qualified Chub laminate, and second as a demonstration of the transportability of the materials. The box was sent by a common carrier trucking company without any additional protection. A report of the receipt of these materials and their condition is given in the following pages.

Similarly, 5,400 pounds of Chubs were sent in boxes placed upon pallets to the Pacific Gas \& Electric Company test location in California. Also included is their letter detailing the condition of the shipped thermal energy storage material as it was received in California. 


\section{OAK RIDGE NATIONAL LABORATORY \\ OPERATED BY \\ UNION CARBIDE CORPORATION \\ NUCLEAR DIVISION \\ CANION \\ POST OFFICE BOX $Y$ \\ OAK RIDGE, TENNESSEE 37830 \\ September 5, 1979}

Mr. Galen P. Frysinger

University of Delaware

Institutc of Encrgy Conversion

One Pike Creek Center

Wilmington, DE 19808

Dear Galen:

On August 24 we received the box of 24 CHUBs you sent to us by common carrier. They arrived on an Interstate truck. The outside of the box was fairly heavily worn. The tape on the bottom was worn through in several places, apparently as a result of extensive sliding. Virtually all the edges and corners of the box were rounded. Attached are several photographs taken before the box was opened. On the inside we found all the CHUBs to be intact, although one CHUB leaked. The leak was very small and located in one of the creases formed by the end closure. This particular CHUB was located at the edge of the box, thus the leak may have resulted from stresses associated with the rounded edges of the box. It was noted on several of the CHUBs that the outside layer of blue film had worn away, exposing the aluminum at the tip of the end closure creases. We were unable to determine if the aluminum was penetrated. Finally, we weighed all the CHUBs (to the nearest gram), and these are tabulated on the attached data sheets.

sincerely yours,

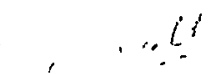

Rubert J. Kedl

Low-'Temperature 'I'hermal Energy

Storage Program

$\mathrm{RJK}: \mathrm{nr}$

Attachment

CC: D. M. Eissenbery

H. W. Hoffman 


\begin{tabular}{|c|c|c|c|}
\hline Group & Item No. & Weight (Grams) & Weight (Pounds) \\
\hline \multirow[t]{4}{*}{29177} & 1 & 1487 & 3.28 \\
\hline & 2 & 1453 & 3.20 \\
\hline & 3 & 1465 & 3.23 \\
\hline & 4 & 1455 & 3.21 \\
\hline \multirow[t]{10}{*}{2.907} & 1 & 1443 & 3.18 \\
\hline & 2 & 1477 & 3.26 \\
\hline & 3 & 1452 & 3.20 \\
\hline & 4 & 1464 & 3.23 \\
\hline & 5 & 1438 & 3.17 \\
\hline & 6 & 1462 & 3.22 \\
\hline & 7 & 1458 & 3.21 \\
\hline & 8 & 1463 & 3.23 \\
\hline & 9 & 1462 & 3.22 \\
\hline & 10 & 1460 & 3.22 \\
\hline \multirow[t]{4}{*}{29170} & 1 & 1524 & 3.36 \\
\hline & 2 & 1473 & 3.25 \\
\hline & 3 & 1463 & 3.23 \\
\hline & 4 & 1450 & 3.20 \\
\hline 2.908 & 1 & 1449 & 3.19 \\
\hline \multirow[t]{3}{*}{29171} & 1 & 1477 & 3.26 \\
\hline & 2 & 1479 & 3.26 \\
\hline & 3 & 1480 & 3.26 \\
\hline 2916 (?) & 1 & 1366 & 3.01 \\
\hline No Number & 1 & 1444 & 3.18 \\
\hline TOTAL & 24 & $\begin{array}{l}35044 \mathrm{G} \\
35.044 \mathrm{KG}\end{array}$ & $77.261 \mathrm{bs}$ \\
\hline
\end{tabular}




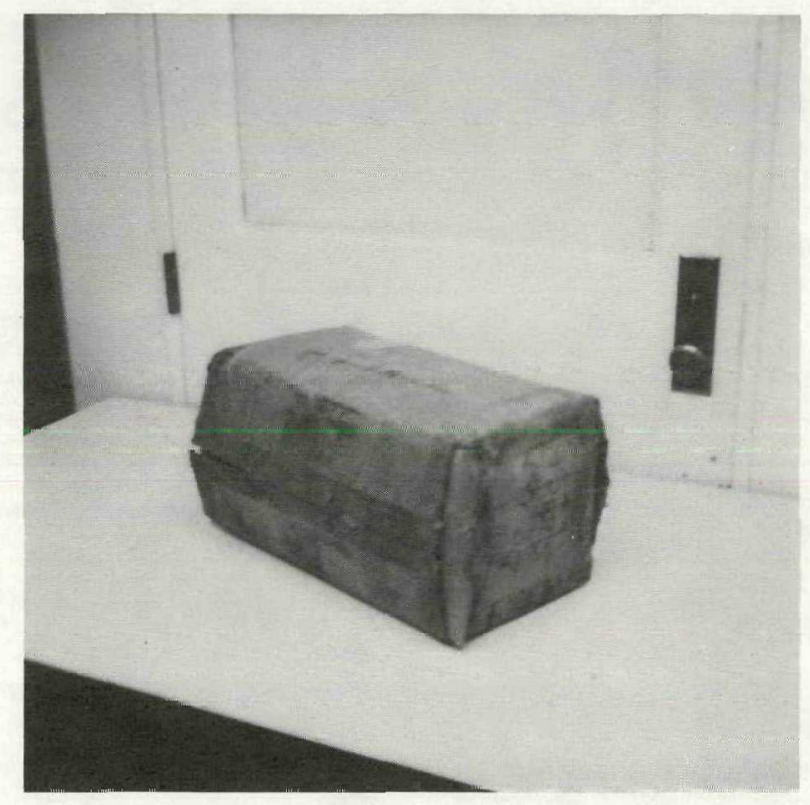

FIGURE 9

Photo of Package of 24 CHUBs as Received by ORNL After Common Carrier Shipment 


\section{PAOIFIO GAS AND EIEOTRIO OOMPANY}

IDG + DEPARTMENT OF ENGINEERING RESEARCH • $3400 \mathrm{CROW}$ CANYON ROAD • SAN RAMON, CALIF. 94583 • (415) 820-2000

September 10, 1979

Mr. Galen R. Frysinger

Manager, Energy Systems

Institute of Energy Conversion

University of Delaware

One Pike Creek Center

Wilmington, Delaware 19808

Dear Mr. Frysinger:

In response to our recent telephone conversation, I am writing to confirm our receipt of the CHUB thermal energy storage materials. We have received 78 boxes of the CHUB materials, each containing approximately 23 individual CHUB packages. The materials were received in good condition, and have since been unpacked and installed in the storage bin. The stacking hardware was received several days prior to the CHUB materials, and while the boxes were in poor condition, the contents were not damaged.

As I have indicated above, the CHUB materials have been installed and the system is now in operation. Data are now being collected for determination of system performance, and I will keep you informed on our findings as operation continues.

$$
\begin{aligned}
& \text { Sincerely, } \\
& \text { E.9. Dillbara } \\
& \text { E. G. D'Albora }
\end{aligned}
$$




\section{F. Performance Cycle Testing \\ 1. Preliminary $100-$ Cycle Test}

From April 12 to May 22, 1979, an array of $22812^{\prime \prime}$ long Chubs were cycled in an experimental bin (Figure 10). The bin was 12 Chubs deep by 19 Chubs high. The Chubs selected for this initial accelerated cycle test were from the lots prepared by Du Pont and received by the Institute of Energy Conversion as part of the qualification program. Those on the left in Figure 10 had a black polyethylene outer layer and those on the right had a clear outer polyethylene layer, which gave them a metallic appearance due to the inner metallized layer.

A fan was mounted (Figure 11) to exhaust air through the experimental test bin at the rate of approximately 1,000 CFM. The temperature of the room air drawn through the test bin was tempered by the use of the inside coil of a heat pump (shown in Figure 11 in the upper left). A York Model CHP030 heat pump was used which had a cooling capacity of 29,500 Btu's per hour at an EER of 8.1 , and a heating capacity of 30,500 Btu's per hour at a COP of 3.0 for a rating point of $47^{\circ} \mathrm{F}$ outside air temperature. For convenience in use, the compressor portion of the heat pump was placed in the laboratory (Figure 12).

The bin containing 228 Chubs had a total of approximately 400 pounds of phase change salts, with a rated capacity of approximately 20,000 Btu's. A thermistor placed on the air trailing side of a Chub in the bin was used to monitor the Chub's skin temperature during the freeze and thaw cycle. To be certain that the Chub's skin temperature was monitored instead of the air 


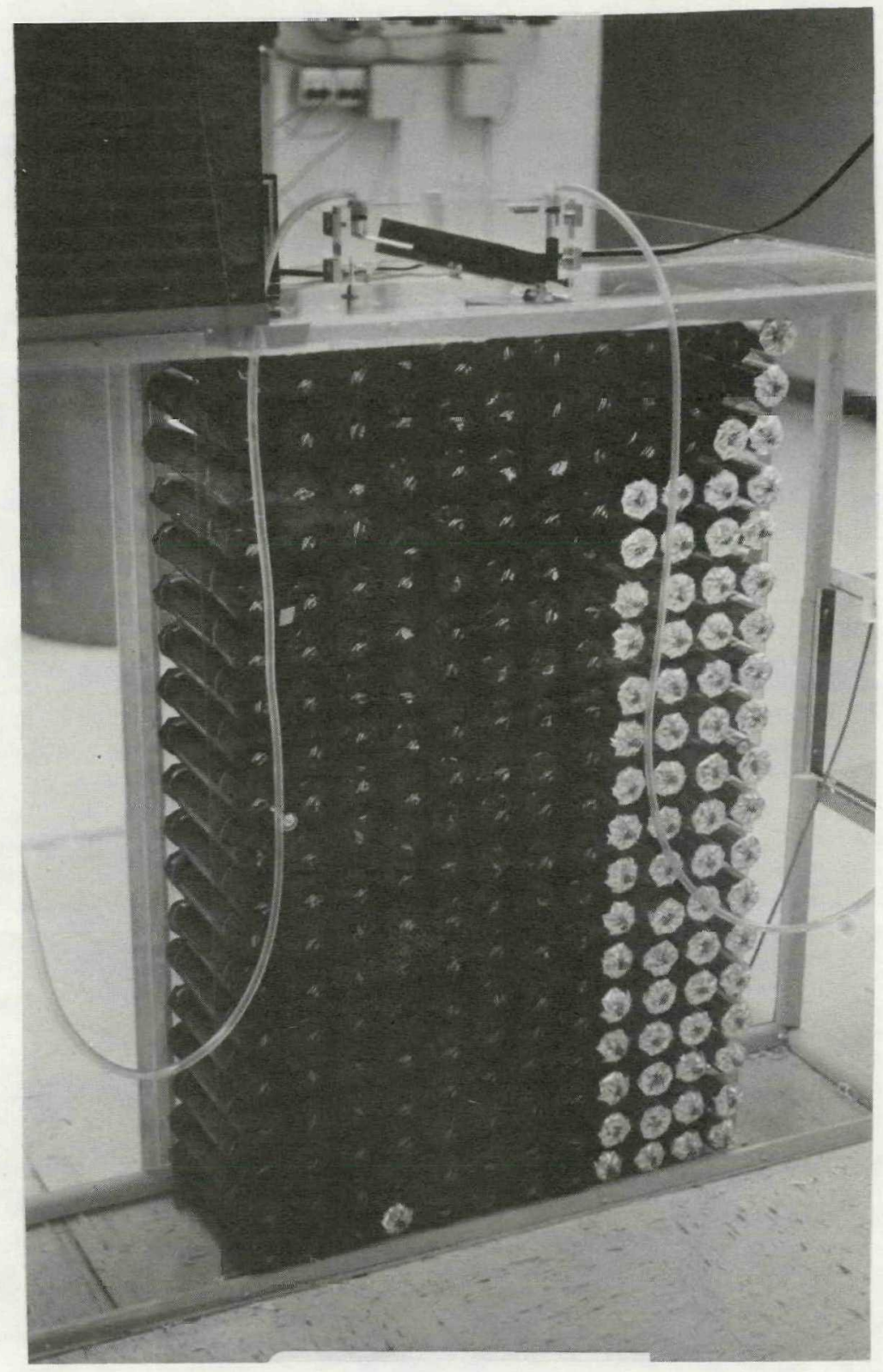

FIGURE 10

Preliminary 100-Cycle Test Bin 


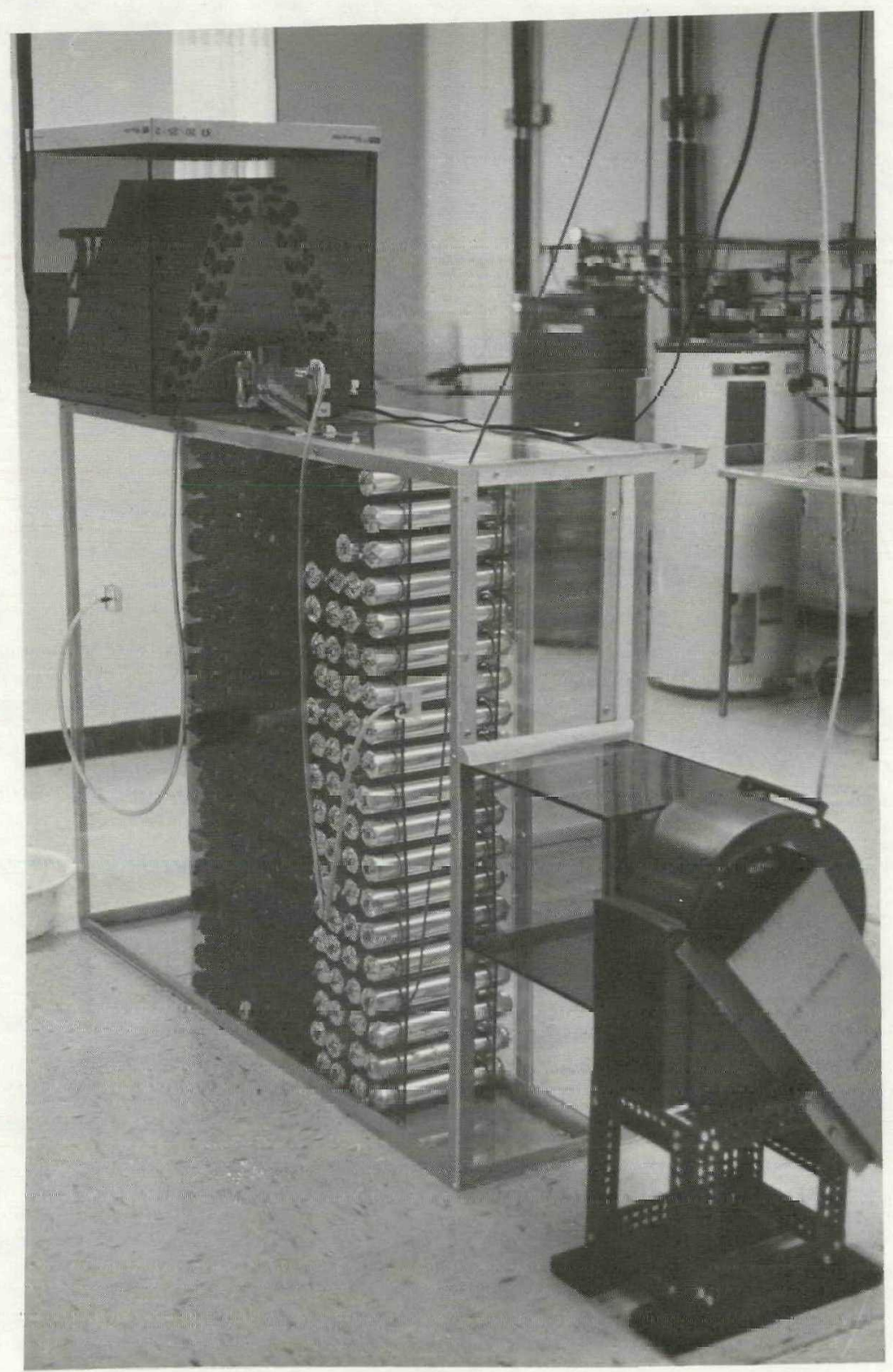

FIGURE 11

Test Apparatus for Preliminary 100-Cycle Test 


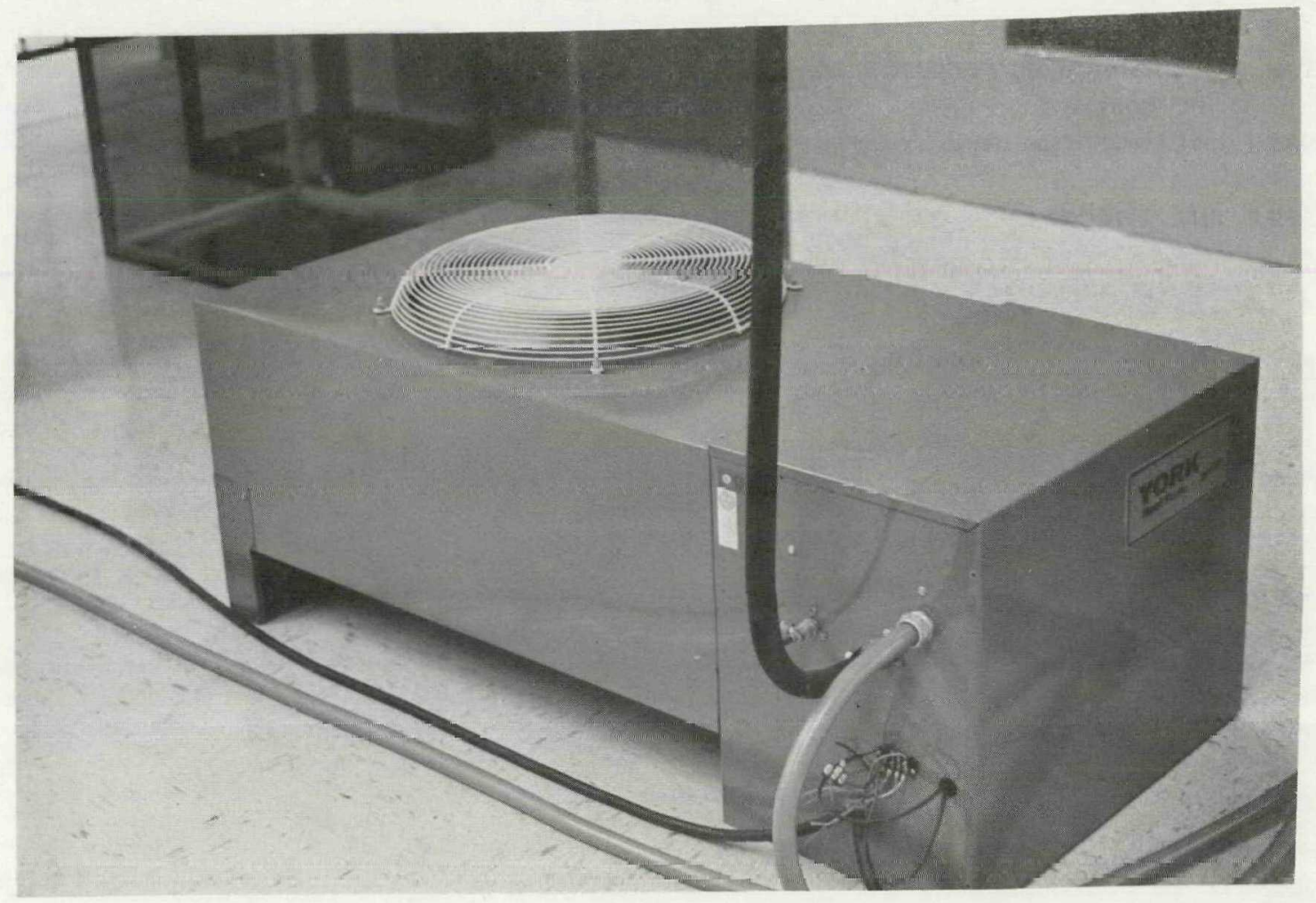

FIGURE 12

Compressor Section of York Heat Pump 
temperature within the bin, the thermistor probe was taped to the Chub and a 1/2-inch thick layer of urethane pipe insulation was placed over the thermistor.

The cycling was initiated by drawing cooled room air across the Chubs in the experimental bin (Figure 11). This was continued until the temperature of the reference Chub was reduced to less than $50^{\circ} \mathrm{F}$ as measured by the thermistor. At this point the cooling was stopped and room temperature air was drawn through the bin until the Chubs were thawed. When the temperature of the reference Chub was at room temperature, the cooling cycle was again initiated. This cycling was continued for 100 cycles, with a number of interruptions due to other activities in the laboratory. The average cycle time was less than four hours. In later cycles, the heating operation of the heat pump was used to increase the temperature of the air being drawn through the chub bin. This decreased the time required for thawing the Chubs, and also subjected them to higher air temperatures during the thawing operation.

Since the Chubs tested included over one dozen variations in the type of $\mathrm{film}$, adhesive, and manufacturing conditions, no attempt was made to correlate packaqe inteqrity with the particular Chub characteristics. As would be expected, these unqualified Chubs produced the normal type of deficiencies that were noted trom the general work in the qualification proyrdIII. These were:

a) Une of the Chubs, out of the 228 tested, showed separation of the film-to-film heat seal in a section about $1 / 8$-inch long where the heat seal was visibly non-uniform. 
b) Two out of the 228 Chubs showed large salt deposits at the end closure after 100 cycles. The leakage was judged to be due to inadequate pressure when the clip was applied.

c) 29 out of the 228 Chubs tested exhibited white salt deposits around the end closure due to the small amount of Glauber's salt mixture which was compressed in the area around the end clip during its manufacture. The amount of salt was weighed and found to be insignificant in relation to the total contents and probably has little effect on the performance of the material.

One of the interesting observations on the basis of this limited $100-c y c l e$ test was the appearance of a different consistency in about $1 / 3$ of the Chubs contained in the bin which was noticed when the bin was disassembled. Table III indicates the placement of the Chubs within the $19 \times 12$ test matrix. Those Chubs indicated by an " $X$ " exhibited a "crunchy" consistency. Examination of the contents of one of the "crunchy" Chubs indicated that large crystals were formed over the two-month cycling test, which gave the Chub a "crunchy" feel. As is seen from Table 111 , the Chubs with this crystal growth were located along the exit of the array and in the lower front corner.

While disassembling the experimental test bin, it was noted that under severe handling conditions the crystals penetrated the film and caused the Chub contents to leak. When the Chubs were removed and examined, four of them were found to be perforated. Note that this did not happen during the freeze-thaw cycling, but occurred when the Chubs were handled after cycling. 
TABLE III

CONSISTENCY VS. BIN POSITION FOR PRELIMINARY 100-CYCLE TEST

$\begin{array}{llllllllllll}1 & 2 & 3 & 4 & 5 & 6 & 7 & 8 & 9 & 10 & 11 & 12\end{array}$

1

2

3

4

5

6

7

8

9

10

11

12

13

18

19

1
14

15

16

17

4

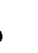

7

8

9

0

13

18

9

$X$ is the symbol for "Crunchy" CHUBs 
In later tests using qualified Chubs $(71$ cycles for daily test schedule and 405 cycles for the accelerated test schedule) the "crunchy" consistency was not common. Only 2 out of 456 Chubs exhibited this behavior. This phenomenon is tentatively attributed to poor mixing of the materials (stirrer in a barrel) used in filling the Du Pont research sample Chubs. The mixing and dispersion of material components at the University of Delaware's prototype fabrication facility was done in an Agi-Mixer (Figure 22) whose high speed head was used to form the thixotropic gel. The tentative conclusion is that proper mixing of the phase change material can mitigate the appearance of the "crunchy" consistency.

Air calorimetry was not performed on these Chubs because the instrument was not yet operational when these tests were performed. 


\section{Diurnal Cycle Tests}

A thermal energy storage bin containing 456 Chubs was constructed adjacent to the Institute of Energy Conversion's $1 / 4$-House test facility (Figure 13). This bin, containing approximately 800 pounds of salt hydrate material having a nominal capacity of 40,000 Btu's of thermal energy storage with a phase transition of $55^{\circ} \mathrm{F}$, was operated on a daily cycle. During the "on-peak" portion, the heaters were turned on in the interior space of lle 1/4-House facility for a fixed time to simulate the daytime heat gain of the living space. During this period, and for an hour after the heaters were turned off, the ran, under thermostatic control, removed air from the room, pulled it across the precooled Chub thermal energy storage bin and returned it to the ruoll. At the end of the "on-peak" period, the 1/4-House temperature was at its initial control temperature. At the onset of the "off-peak" period, the air curdiliunel was I un continuously for a set period with the circulation fan on. After this period the fan was run continuously for two hours and the air conditioner compressor was cycled off and on as required under thermostatic control to maintain the set 1/4-House chamber temperature. The system was then ready for a new "onpeak" cycle.

Because of the results trom the initial 100-cycle tests, it was considered important in the one season procedure (100 days of diurnal cycling) to incorporate not only full freeze-thaw cycles, but also a significant amount of shallow cycling where the Chubs are only partially thawed before being refrozen. 


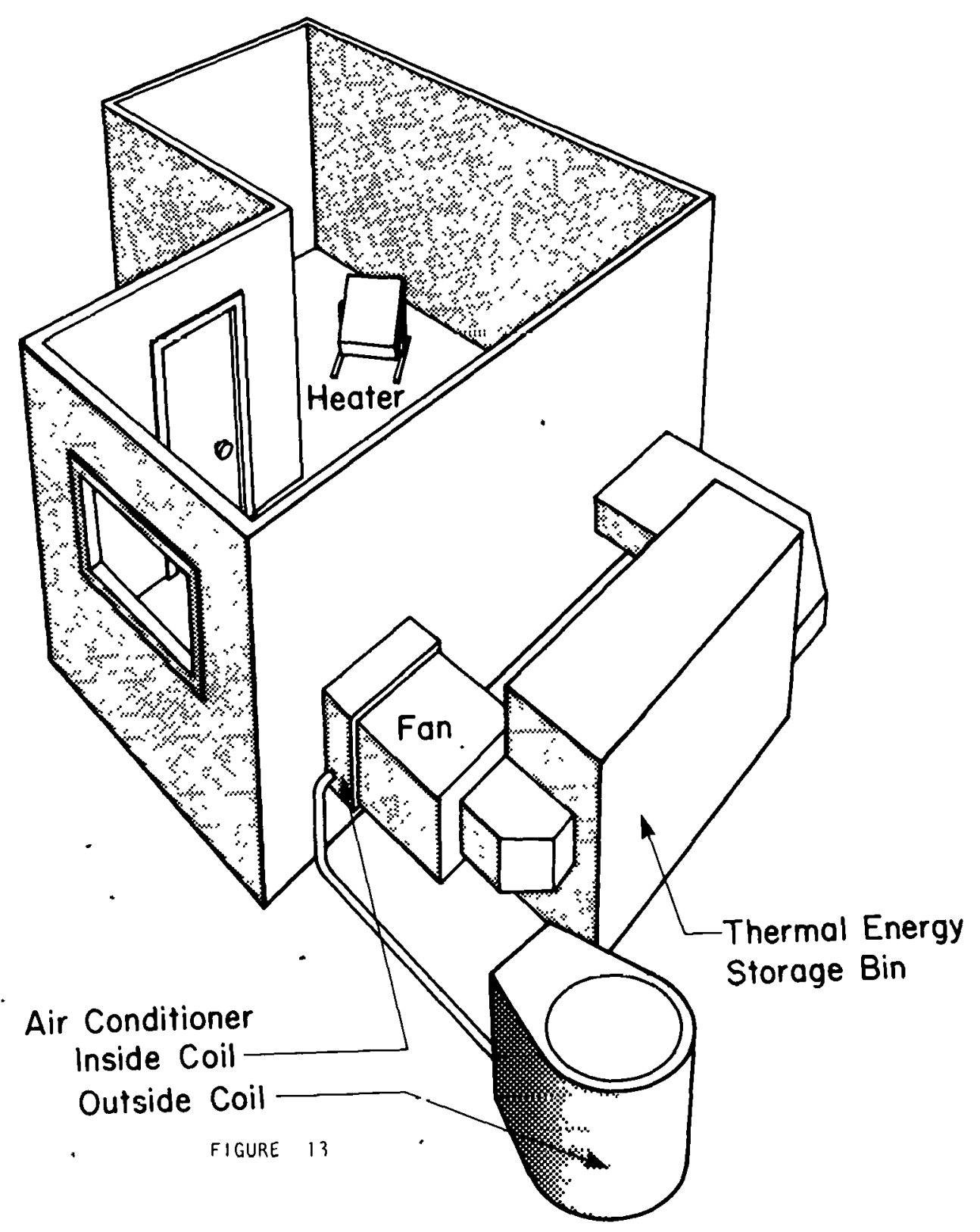

\section{1/4 House}


Therefore, a regimen was devised whereby an amount of heat equivalent to 60$80 \%$ of the bin storage capacity was injected into the test chamber. This was accomplished by using one of the heaters with a three-hour on-time over a sixhour period to simulate the daily heat gain. This was later extended to eight hours at the suggestion of the ORNL representative. During the corresponding refreeze period, the air conditioner was run for a two-hour fixed period, and then on demand, to maintain the test chamber temperature.

The initial cool down of the diurnal test cycle Chubs was accomplished on June 10, 1979. After stabilization and check-out of the system, the first cycle was initiated on June 16, 1979. After completion of 37 cycles (July 24 , 1979 ), the heat load was reduced from approximately $80 \%$ to approximately $60 \%$ $(25,000$ Btu's). Forty-five cycles had been accumulated by the first of August with completion of the cycle scheduled for September 25, 1979.

The testing was discontinued on August 27 , after 71 cycles so that the Chubs could be tested in the air calorimeter. These data are included in Section $11-C$. The air calorimeter only became available for testing towards the end of June 1979. When the above testing program was being set up, a decision had to be made as to whether or not to delay the start of the cycling program until the air calorimeter was ready. Due to uncertainties in the amount of time that would be required to have the air calorimeter operational, it was decided not to delay the test program. As a consequence, calorimetric data was obtained for Chubs that were cycled in the 1/4-House test facility and 
in the later accelerated test program (see below). When the air calorimeter became available it was realized that a measurement in the calorimeter takes at least one work week. Thus it became clear that the test program would be thrown even further off schedule if calorimetric measurements were made every 25 cycles as stated in the work statement. Therefore, measurements every 25 cycles were not made.

\section{Accelerated Life Testing}

Using the same test fixture employed in the preliminary 100 -cycle test, accelerated life testing was initiated in June 1979 using qualified Chubs fabricated at the University of Delaware. This was the same series of Chubs prepared for testing in the diurnal cycle sequence. 228 Chubs containing approximately 400 pounds of salts were loaded into the experimental test bin for the accelerated life test. Initially, five rows of Chubs (19 Chubs high) were involved in the test (Figure 14). These Chubs were identical except for six different variations in secondary end closures. This secondary end seal may be required since small amounts of the salt mixture are compressed in the area around the end clip during manufacture and this is slowly released. The standard procedure adopted for this preparation of the Chubs uses an epoxy-type sealant first placed in a small plastic end cap which is then pressed against the $c l i p$ and extended material of the Chub end seal to form an effective bond. The variations of secondary end closures involved in this accelerated life test include: several materials into which 


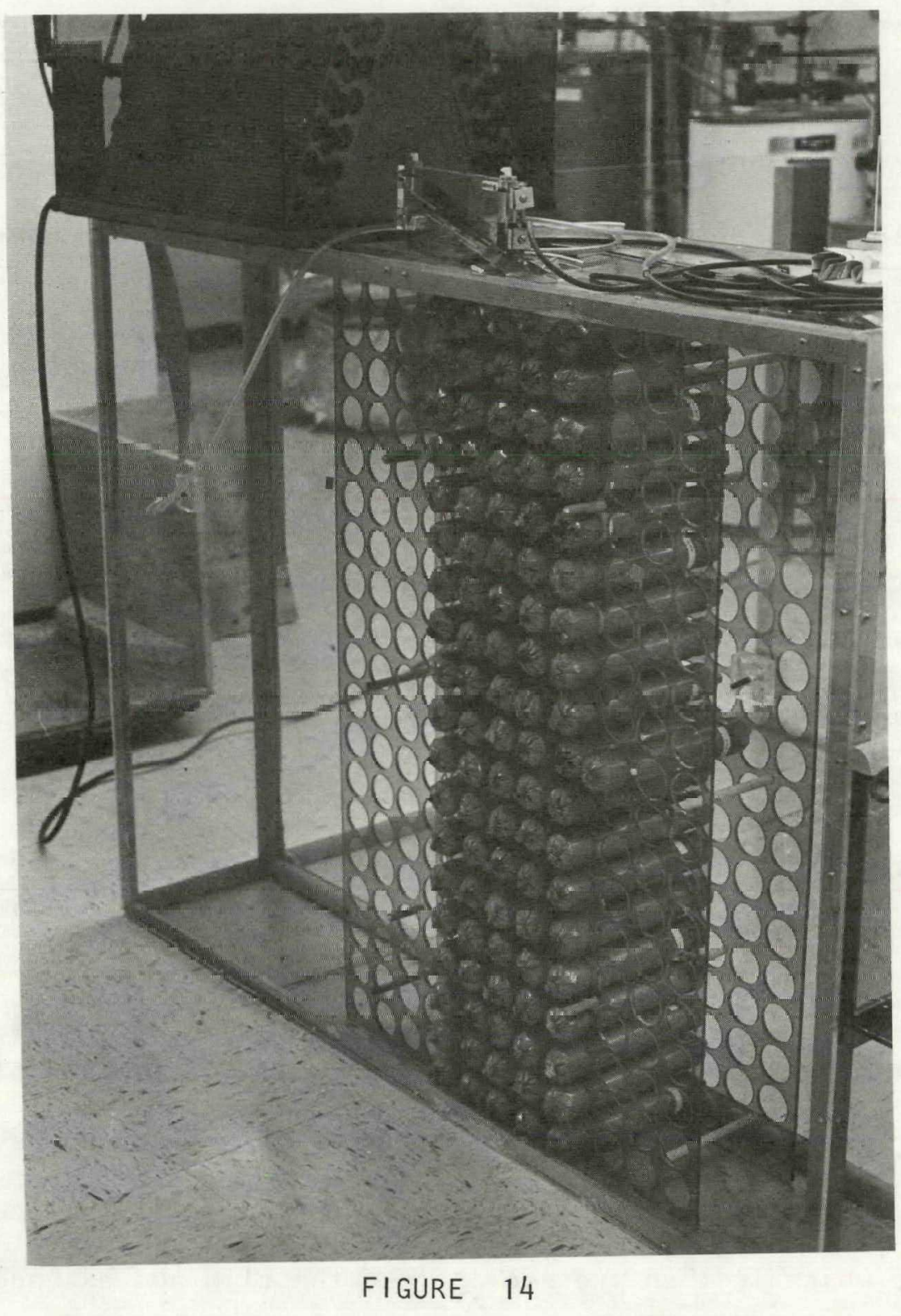

Initial Confiquration for Accelerated Life Test 
the end clip was dipped and coated, a secondary mechanical clip and the use of different elastomers or epoxies with a plastic cap. Several control Chubs were also placed in the array for comparison evaluation. When the cycling was started, it was thought that additional trial secondary end closures would be added to the test chamber. After approximately 150 cycles, however, most of the above-described end seal procedures appeared satisfactory and therefore the bin was completely loaded with additional control chubs and the cycling resumed.

The test procedure was based on a time schedule of three hours cooling and one hour heating $\left(105^{\circ} \mathrm{F}\right.$ from the heat pump) using a timeclock controlled by the laboratory computer. In this manner, six freeze-thaw cycles were completed in a 24-hour day.

The cycling was stopped on September 6 at 405 cycles so that performance data could be obtained in the air calorimeter. These data are presented in Section II-C. The calorimetry was not performed as outlined in the work statement for the reasons described abonve.

\section{Analysis of Laminate After Being Exposed to Cycle Testing}

From results on the cycle testing, the laminated film, prepared in accordance with the specification for the qualified Chub, performed as desired. The film was fully functional in the Chub cooling storage application using $55^{\circ} \mathrm{F}$ phase change material. The cut edges of the laminate which were exposed to the hydrated salts showed no visible evidence of attack or 
delamination. There was no evidence of degradation of flexibility or damage from normal abrasion. The critical parameters in producing a qualified film package are the package machinery and its ability to create the proper heat seal and end closure using the metallic clip. Punctures of the laminated film are possible, but the 0.004 -inch thick laminate is judged to be a good choice for cooling applications where normal handling can be accommodated by the laminate's abrasion resistance. Increased thickness not only increases cost, but also creates machinery problems and appears not to be warranted for the cooling applications. Where the Chubs are normally handled in a frozen condition (e.g., mixtures which have a transition point above room temperature), increased polyethylene film thickness for abrasion purposes may be desirable. 


\section{THERMAL STORAGE PERFORMANCE EVALUATION}

\section{A. Test Methods}

In the final analysis, the property that is of most interest in a thermal energy storage material is its energy storage capacity. The most direct measure of that capability is calorimetry. Three different complementary calorimeters have been used to characterize the thermal energy storage materials.

(1) The air flow calorimeter measures the thermal performance of the material on a scale approaching that of the anticipated end use. Thus it measures the material as packaged into the Chub under conditions approximating the full scale end use. As its name suggests, conditioned air is blown over the sample and the energy is transferred to or from the Chubs depending on whether the Chubs are being cooled or thawed. However, a half cycle can take as long as 24 to 48 hours to be completed and thus testing with this calorimeter is a slow process.

(2) The laboratory calorimeter yields information under conditions which give a quantitative measure of the amount of energy stored in the material of interest. The sample size $(150 \mathrm{~g})$ eliminates the problem of representative sampling since the sample is tested in its entirety. However, due to heat loss considerations, it is feasible to perform measurements on the heat storage (i.e., melting) half cycle only since the freezing process takes too long to be measured by this method. 
(3) The differential scanning calorimeter allows samples to be tested rapidly (in a matter of minutes to hours) because of the small size of the samples. It is a useful technique for screening a large number of samples and for attaining complete thermal cycling data in short times. However, because of the small sample sizes one must be careful to choose a representative sample.

\section{B. Alr Calorlmeter}

A calorimeter using air as the heat transfer fluid was constructed to allow testing of 100 to 200 lbs of phase change materials under well characterized conditions. The unit's design is based on ASHRAE Standard 94-77.

\section{Description of Apparatus}

The calorimeter (shown in Figure 15) consists of: (1) a test chamber containing the material to be tested; (2) a duct system to convey the air in a closed loop; (3) a heater and cooler to condition the air; (4) a blower; (5) a damper; (6) a flow measuring device; (7) a controller for the air conditioning system (not shown); (8) a differential thermopile to measure the temperature change of the air passing through the test chamber (not shown) and thermocouples to measure the temperatures of the storage material and air. The system design was based on ASHRAE Standard 94-77 (ANSI B199.1-1977), 'Methods of Testing Thermal Storage Devices Based on Thermal Performance." The 


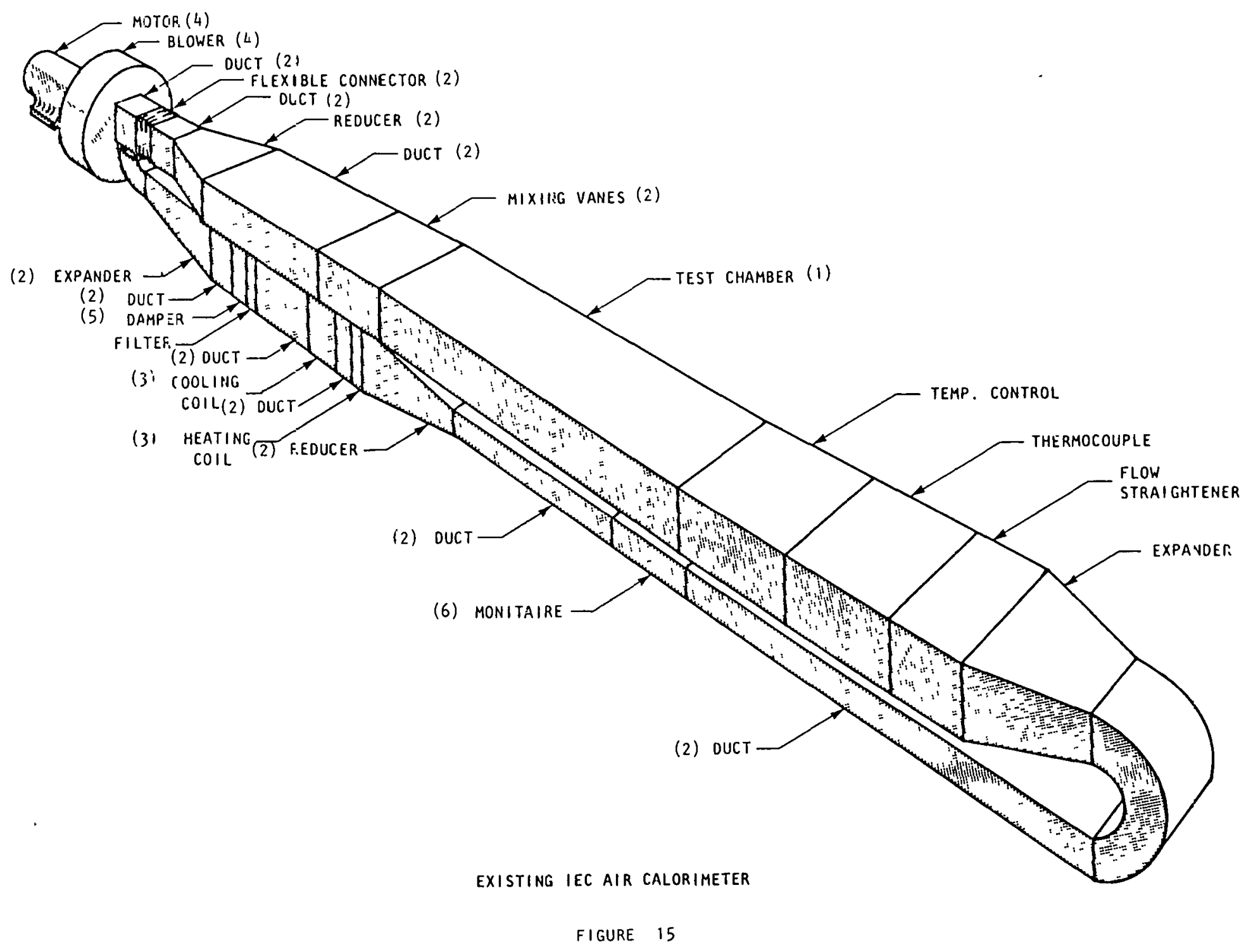


only major deviations from this standard were in the use of a MonitAire multiple pitot tube device to measure air flow and R-19 insulation on the test chamber and duct between the hot and cold junctions of the thermopile. The MonitAire was chosen as an accurate air-flow-measuring device in the range of expected flows; it is comparable to a flow nozzle in accuracy and is readily available from its manufacturer, the Air Monitor Corp. R-19 insulation was deemed more than adequate since temperature transients are controlled with this thickness of insulation.

The test chamber has been designed to hold as much as 250 lbs of thermal energy storage material. Any container which will fit into the available $5-3 / 8^{\prime \prime} \times 24-1 / 2^{\prime \prime} \times 76^{\prime \prime}$ test chamber can readily be accommodated. The operating specifications for the air calorimeter are given in Table IV.

\section{Test Procedures (Air Calorimeter)}

A weighed amount (between 100-250 lbs) of storage material is placed in the test chamber and the air is turned nn. The air flow rate and tempcraturc are adjusted to the desired level. When the storage material has reached a constant temperature, the temperature controller is set at a new level either above the former level if the storage material is to be heated, or helow if the storage material is to be cooled. The air flow rate, air temperature, temperature difference across the test chamber and storage temperature are recorded as a function of time while the storage temperature approaches the newly set 
air temperature. Because of the closed-loop design, significant humidity changes are not expected to be observed. Methods for monitoring the sample's temperature have been provided.

The data are then digitized and reduced by means of a computer program which has been specially written for this purpose. A listing of the program is given in Table $V$. From the data, the amount of energy transferred by the air to or from the storage material is calculated with appropriate corrections for heat losses to the atmosphere and the calorimeter itself. As a check on the accuracy and precision of the data, frequent calibration runs are made with an identical test configuration in which water has been substituted for the storage material. We estimate the precision to be $\pm 5 \%$ and the accuracy $\pm 10 \%$.

\section{Sample Calculation}

The equation of interest for the air calorimeter involves a heat balance between the material being tested and the circulating air with appropriate corrections for losses to the surroundings and the calorimeter ilself.

$Q_{\text {sample }}=Q_{\text {air }}+Q_{\text {heat loss }}-Q_{\text {calorimeter }}$

The value for $Q_{a i r}$ is given as:

$$
Q_{a i r}=\int t \dot{M} c_{a i r}\left(T_{i}-T_{0}\right) d t
$$


TABLE IV

AIR CALORIMETER

System Specifications

Min. $\quad \underline{\text { Max. }} \quad \underline{\text { Variations }}$

Air Flow

$200 \mathrm{cfm}$

$440 \mathrm{cfm}$

$+5 \%$

Cold side Temperature

$35^{\circ} \mathrm{F}$

$150^{\circ} \mathrm{F}$

$\pm 1 \%$

Hot Side Temperature

$35^{\dot{\cup}} \mathrm{F}$

$150^{\mathrm{U}} \mathrm{F}$

$\pm 1 \%$

Test Chamber Capacity

Up to $10^{4}$ cubic inches of material

Not applicable

Accurac̄y Precision

Air Flow Measurement

$\pm 15 \mathrm{cfm} \quad \pm 5 \mathrm{cfm}$

Differential Temperature Measurement

$\pm 5 \% \quad \pm 1 \%$ 
TABLE $V$

PROGRAM LISTING FOR AIR CALORIMETER

P CALC1

AFILE (13530)CALC1 ON PACK

9000 FILE 1 (KINII=IISKFACK, TITLE=LATA, MAXRECSIZE=14, BLOCKSIZF=4, TD)

9500 FILE 6 (KINII=FEMOTE, MYUSE $=I 0, M A X R E C S I Z E=22)$

10000

11000

12000

IIIMENSION MU(999), CF(999), CFH(999), TC:SIJI, 999$), T 1551999)$

DIMENSION CFAUE(999), M(999), SIMFUL (999), BTU( 999$)$

IIIMENSION SECTOT (20), TBTULE (20), FAFA (999)

13000

14000

DIMENSION DIT(999), QT (999), QFHDE(999), SFLIITU(999)

15000

DIMENSION TC141JC (999)

INTEGEF TM, TM2, THYY2

REAL MU,M1,M2,M3, M

16050 WRITE $(6,104)$

16060

FEAII $(1, /)$ FAGE, NE, IIATE

16070

17000

$\pm 7010$

18000

19000

20000

20010

21000

22000

23000

23010

23011

24000

25000

25005

25010

25011

25015

26000

WRITE $(\zeta, * /)$ FAGE, NE, DATE

FEAD $(1, /)$ SECTS, AIRTTYP, AMSAL, CFFHOE

102 FOFMAT $\left(F_{1} 14,3, F_{14}, 3\right)$

WRITE $(6, * /)$ SECTS, AIRTMF, AMSAL, CFFHOE

DO $75 K=1$, SECTS

REAL $(1, /)$ TOTMIN, BAF, TRODM, DK

103 FOFMAT (F14,3,F14.3,F14,3,F14,3)

WFITE(,$* \# /)$ TOTMIN,BAF, TFIOOM, UX

TM=TOTMIN/DX+1

WRITE $(6, * /)$ TM

WFITE $(6,207)$

207. FORMAT $/ / / 20 X$, 'EXFERIIMEITTAL IIATA', ///)

IIO $4 \quad I=1$, TM

$\operatorname{READ}(1, /)$ EARA(I), MU(I),TC15UC(I), TC1.4IJC(I)

CFM(I) $=20.55 * S Q R T$ (BARA (I))

WRITE $(S, 208) C T M(I), H U(I), T C 15 U C(I), T C 1$ IJIS (I), BAFFA (T)

206 FOTMAAT $(4(5 X, F 14,3))$

208 FORMAT $(5(5 X, F 14.3))$

4 CONTINUE 


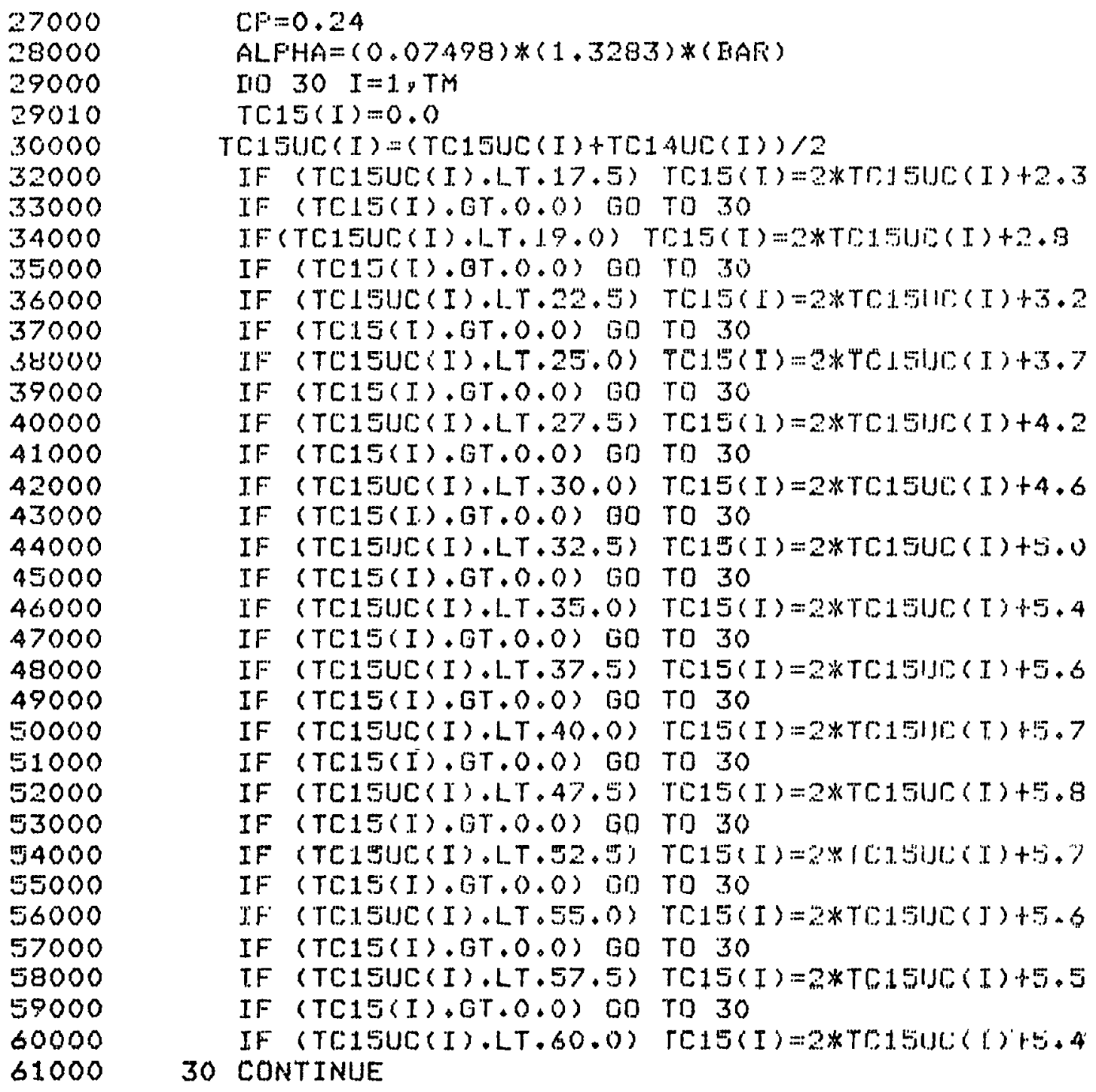




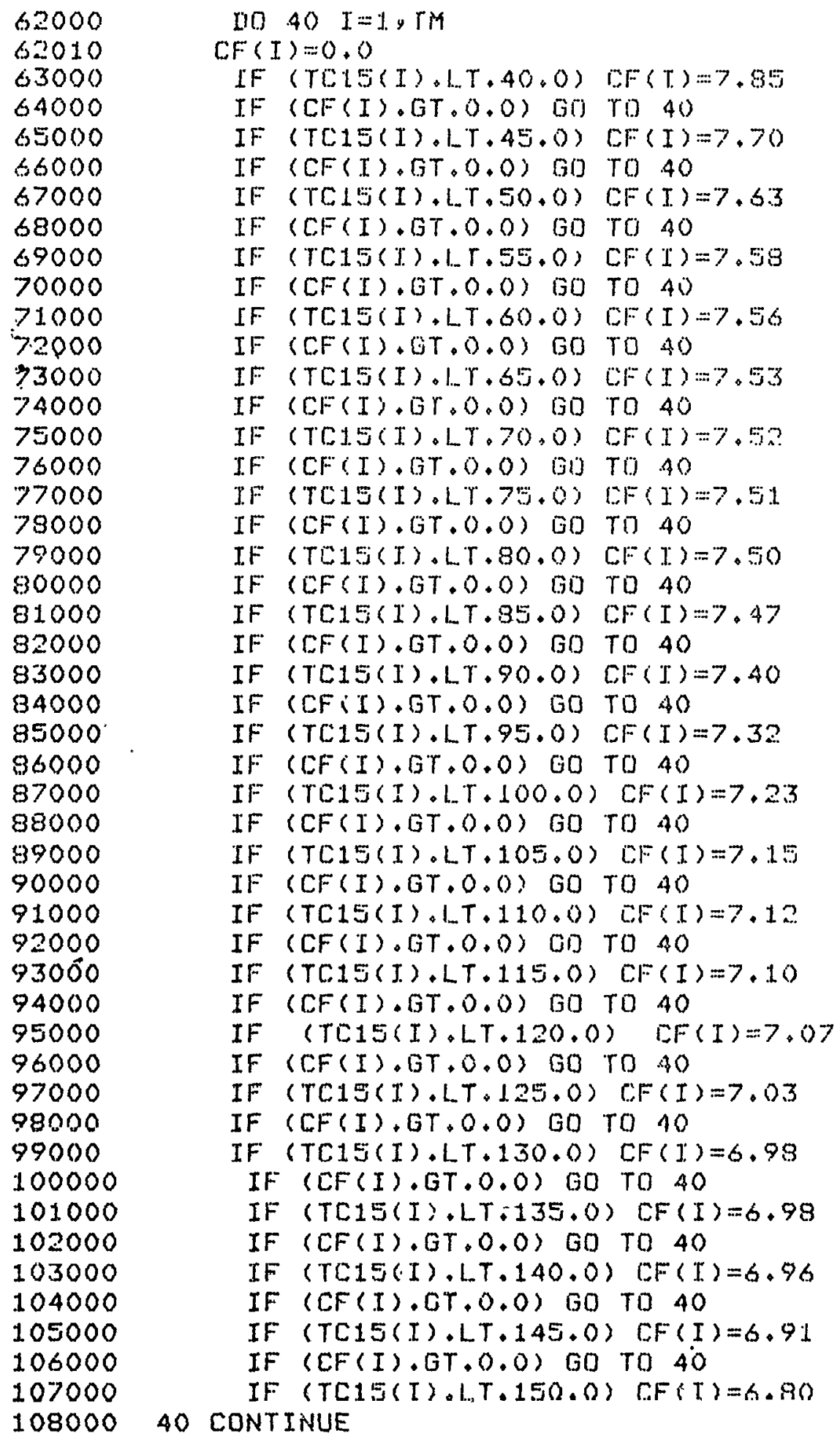


1.08001 1.09002 108010 108020 1. 08021 1.08030 1.08031 108035 1.08036 108040 1.08042 :108043 108045 108046 1.08050 1.08052 1.08053 108055 109000 109010 1.09030 1.09090 110000 1. 11000 112000 113000 1. 1.4000 115000 116000 1. 1.7000 118000 118050 119000 119010 127000 127010 127030 127050 128000
WFI ITE $(6,201)$

201 FOFMAT $/ /, 10 X^{\prime}$ 'AUG BIN TEMF" ,30X, 'COFFN FACTDF" $/ 1 /$ )

DO $20 \quad L=1, T M$

WFITE (6,202) TC15(L) y C.F (L.)

202 FUFMAT $\left(6 X, F_{14} .3,22 X, F 14,3\right)$

20 CONTINUE

IF (K.GT.O)GO TO 25

TBIN $=\left(T C 15(T M)+T C 15(T\right.$ TH -1$)+T C_{1} 15(T M-2)+T C 15(T$ TH -3$)+T C 15(T M-4)$

$*+T C 15(T M-S)) / 6.0$

TAVE: $=$ TFOOM-TBIN

CFNEW $=(C F=(T M)+C F(T M-1)+C F(T M-2)+C F(T M-3)+C F(T M-4)+C F(T M-5)$ $* 16.0$

AMDOT $=($ CFM $($ TM $)+C F M(T M-1)+C F M(T M-2)+C F M(T M-3)+C F M(T H-4)$

$\left.*+C F M\left(T H-T_{j}\right)\right) / 6.0$

AFLO=AMDOT $60.0 * S Q F T$ (ALFHA/ (THIN+460))

$* 16.0$

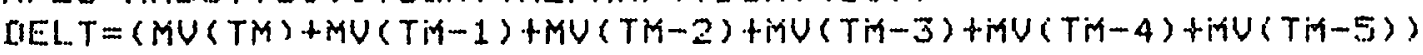

$A H A=A B S((C F * A F L O * I E L T * C F N E W) /(T A U E))$

2 GONT CONUE

$A H A=3.0$

$J=0$

TMMTOTM T

I10 $50 \quad I=1, T M M 2,2$

$J=J+1$.

SIMFUL $(J)=(I X X / 3) *(M U(I)+(4 * M U(I+1))+M U(I+2))$

CFAVE $(J)=(C F(I)+C F(I+1)+C F(I+2)) / 3$

$M 1=C F M(I) * S Q R T(A L F H A /(T C 15(J)+460))$

$M 2=C F M(I+1) * S R F T(A L F H A /(T C 15(I+1)+460))$

$M 3=C F M(I+2) * S R F T(A L F H A /(T C 15(I+2)+460))$

$M(J)=(M 1+M 2+M 3) / 3$

ETU $(J)=S \mathrm{TMFUL}(J) *$ CFAUE (\rfloor$) * M(\jmath) * C F$

$\operatorname{DT}(I)=T$ TROOM-TC15(I)

IT $(I+1)=$ TROOM-TC15 $(I+1)$

IIT $(I+2)=T F O O M-T C 15(I+2)$

QT $(J)=(D X / 3) *(D T(I)+4 * \Pi T(I+1)+\Pi T(I+2)) * A H A / 50.0$

IF ((AIFTMP-TC15 (TMM2)).GT.0.0) QT (J)=-QT $(J)$

SALETU $(J)=E T U(J)+R T(J)$

101 FOFIMAT $(5 X, F 14,3,5 X, F 14,3,5 X, F=14,3,5 X, F 14,3)$

SO CONTINUE 


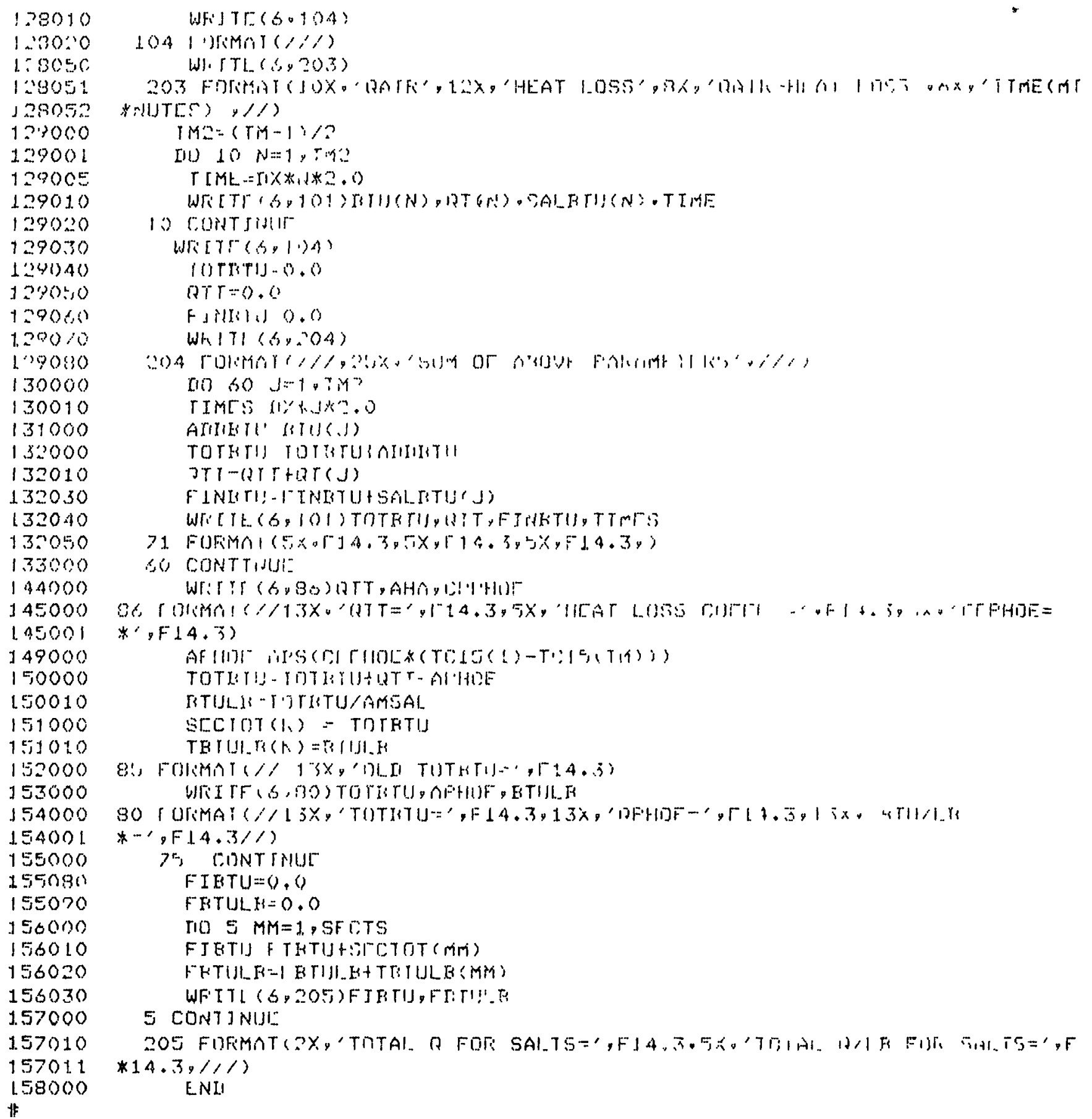


where $\dot{M}$ is the mass flow rate of the air, $C_{a i r}$ is its heat capacity, $T_{i}$ is the inlet temperature, $T_{0}$ is the outlet temperature of the air and $t$ is time.

$$
\begin{aligned}
& Q_{\text {heat loss }} \text { is calculated as follows: } \\
& Q_{\text {heat loss }}=\int_{t} K_{1}\left(T_{r}-T_{b}\right) d t
\end{aligned}
$$

where $K_{1}$ is a constant, $T_{r}$ is the average room temperature and $T_{b}$ is the average air temperature in the sample chamber during the time $d t$. Values of $K_{1}$ are computed from the data for each run by assuming that after a sufficiently long time the sample has come to equilibrium with the air flowing in the calorimeter; then $Q_{a i r}=Q_{\text {hed }}$ loss

$$
\text { Qcalorimeter is calculated from calibration data. Included in }
$$
$Q_{\text {calorimeter }}$ are the effects of the packaging material and the hardware used to support the test sample in the calorimeter. The data are obtained by performing a series of calorimeter runs in which all experimental conditions are the same as in a test run, except that the phase change material has been replaced by water. In this way an effective product of heat capacity and mass for the calorimeter, packaging materlal and supporting hardware is calculated:

$$
Q_{\text {calorimeter }}=K_{2}\left(T_{f}-T_{i}\right)
$$

where $K_{2}$ is the above-mentioned product, and $T_{f}$ and $T_{i}$ are the final and initial temperatures of the air in the sample chamber of the calorimeter. 
The data are reduced by means of a computer; a sample output is shown in Table VI. The program performs the integration in equations (1) and (2) at convenient time intervals to achieve optimum precision. The data are presented as a table of values in which $Q_{a i r}$ and $Q_{\text {heat }}$ loss are tabulated for each integration interval. Then the summation is performed and tabulated. Finally, the correction for $Q_{\text {calorimeter }}$ is applied, the values for each integration segment are summed and represented in a convenient form. QAIR is $Q_{\text {air }}$, HEAT LOSS is $Q_{\text {heat loss, and the }}$ right two columns are self-explanatory. In the table headed SUM OF ABOVE PARAMETERS, the corresponding quantities are summed. At the end the summed values of TOTAL Q FOR SALTS and TOTAL Q/LB FOR SALTS are listed for each section that was integrated. QPHOE is Q calorimeter, HEAT LOSS COEFF is $K_{1}$, CPPHOE is $K_{2}$, TOTBTU is $Q_{\text {sample for the given }}$ integrated section, BTU/LB is $Q_{\text {sample }}$ divided by the mass of the sample and QTT is the summed value of $Q_{\text {heat }}$ loss for the given integrated section. The last values of TOTAL $Q$ FOR SALTS and TOTAL Q/LB FOR SALTS in Table VI is' the sum total for that particular run. For increased precision, the data were digitized in two parts, the first four hours of the run were digitized every four minutes and the remainder of the data were digitized every hour. This is because the graph of temperature differential vs time changed very rapidly during the first four hours and then changed very slowly. The first part of Table VI gives the results for data digitized every hour and the second half shows the results of the data digitized every four minutes. 
QAIR

2585.288

1807.735

1251.987

560.969

190.127

117.106

$-23.727$

75.907

HEAT LOSS

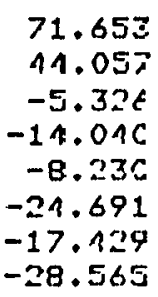

11.057

$-5.326$

$11.01 \mathrm{C}$

$-28 \cdot 565$

C.AIR-HEAT LOSS

2656.941

1851.793

1216.661

543.929

181.896

122.114

$-11.156$

47.342
TIME (MI NUTES)

120.000
240.000
350.000
400.000
600.000
720.000
910.000
960.000

SUM OF AEJUE PARAHETERS

$$
\begin{array}{r}
71.653 \\
115.711 \\
110.385 \\
96.345 \\
88.111 \\
63.123 \\
45.991 \\
17.429
\end{array}
$$
2656.941
1508.731
5755.395
6302.324
6194.221
S506.635
55<5. 470
6512.922

120.000

240.060

$3 \leq 0.000$

490.060

600.060

720.060

840.060

$930.0 \mathrm{CO}$
17.429

HEAT LOSS COEFF =
11.524

TOTATU

6392.122

QPHOE =

CFFHOE =

0.1 .000

RTU/LR =

29.27 


531.071
600.280
547.099
501.121
475.892
446.258
421.554
404.607
388.725
374.793
366.328
351.117
343.336
332.636
325.801
318.960
310.253
302.665
295.539
290.027
282.868
276.201
269.693
265.792
261.570
254.764
251.835
247.953
241.158
237.157
229.901
226.377
221.887
213.586
212.296
210.361
205.622

13.315

23.626

19.331

16.493

14.524

13.588

12.523

12.104

11.716

11.329

10.912

10.587

10.361

9.973

9.586

9.231

9.037

8.844

8.350

8.156

7.910

7.682

7.488

7.294

7.101

6.907

6.713

6.681

6.520

6.326

6.291

6.132

5.939

6.036

5.874

5.681

5.497
574.386

623.906

566.432

520.614

190.417

459.846

434.077

116.711

400.441

386.112

377.270

361.701

353.697

312.609

335.387

328.191

319.291

311.509

301.189

298.183

290.808

283.883

277.181

273.097

268.670

261.672

258.548

254.634

247.678

243.483

236.198

232.510

227.825

219.621

218.170

216.011

211.108
8.000 16.000

21.000

32.000

10.000

18.000

56.000

61.000

72.000

80.000

89.000

96.000

101.000

112.000

120.000

128.000

136.000

144.000

152.000

160.000

158.000

176.000

184.000

182.000

200.000

208.000

216.000

224.000

232.000

210.000

218.000

256.000

261.000

272.000

200.000

289.000

296.000 
SUM OF AHOUE FIAFIAMETEKS

531.071

1131.351

1678.450

2182.570

2659.163

3.104 .721

3523.275

3930.983

4319.60 ?

4694.390

5060.719

5411.836

$5755 \cdot 172$

6097.909

6113.309

6732.569

7042.822

7345.487

7641.026

7931.053

8213.921

8440.122

$87: 59.816$

$90 \div 5.605$

9287.179

g:jA1. PA?

9793.777

10041.730

1028.2 .397

10520.014

10749.949

10976.326

11108.212

11111.798

I1624.094

11834.454

12040.076

\section{$\mathrm{OTT}=$}

TOTETU

TOTAL O FOR SALTSN

TOTAL O FOR SA!-TS.

\begin{tabular}{|c|c|}
\hline $\begin{array}{l}13.315 \\
63.941 \\
93.275\end{array}$ & $\begin{array}{r}574.386 \\
1199.292 \\
1764.724\end{array}$ \\
\hline $\begin{array}{l}10 \% .739 \\
117.295\end{array}$ & $\begin{array}{l}2295.238 \\
2775.755\end{array}$ \\
\hline 130.900 & $3.235,601$ \\
\hline 143.404 & 3669.679 \\
\hline 155.507 & 4086.390 \\
\hline 167.234 & 1486.031 \\
\hline 170.53 & 1072.942 \\
\hline 199.494 & $5: 50.212$ \\
\hline 200.091 & 5611.916 \\
\hline 210.442 & 5965.614 \\
\hline 220.115 & 6300.223 \\
\hline 2.30 .001 & $6, G A Z, 609$ \\
\hline 239.232 & 6971.901 \\
\hline 248.269 & 7291.092 \\
\hline $257.11 x$ & $76,02.601$ \\
\hline 265.763 & $790 \mathrm{~A} .784$ \\
\hline 274.220 & 020.5 .273 \\
\hline 282.114 & 3496.080 \\
\hline 289,941 & 8779.964 \\
\hline 297,329 & $40.5 \% .115$ \\
\hline 304.624 & $4.80 .2 \geq 2$ \\
\hline 311,725 & $9598.00: 2$ \\
\hline 319.632 & 9960.574 \\
\hline ت34.324. & 10119.122 \\
\hline 332.026 & 10373.756 \\
\hline 330.546 & $106,21.431$ \\
\hline $3 \wedge A, D 7: 2$ & :00s4.417 \\
\hline 351.166 & 11101.114 \\
\hline יפי29. & 11333.624 \\
\hline 363.230 & 11561.950 \\
\hline 369.27 .3 & 11781.071 \\
\hline 375.149 & 11999.241 \\
\hline 380.028 & 12215.292 \\
\hline 383.315 & 12423.391 \\
\hline
\end{tabular}

$396,3: 5$ HEAT LOSS COEFF =

QFHOF =

6332.122

TOTAL $3 / L$ FOF SALTS

11.524

24.24.900

TOTAL O/LA FOR SALTS=

9.000

16.000

.1 .000

32.000

40.000

49.000

53.000

64.000

72.000

90.000

80.000

96.000

101.000

$11 . .000$

120.000

128.000

13.6 .000

$14 . .000$

1.52 .000

150.000

1.38 .000

173.000

194.000

192.000

200.000

209.000

$\therefore 16.000$

224.000

232.000

210.000

249.000

256.000

2.5. 000

2.72.000

280.000

208.000

296.000

16301.012
CFFHOE =

64.000

29.270

RTU/LE

15.77 


\section{Laboratory Calorimeter}

The calorimetric measurements have been obtained with a calorimeter which was assembled and tested in the Institute's laboratories. It consists of a two-liter silvered Dewar flask which is filled with about $1200 \mathrm{~g}$ of water. In addition, there is a slow speed stirrer, an ASTM approved precision thermometer which can be read to $0.01^{\circ} \mathrm{C}$ and a bayonet-type 100-Watt DC heater. The heater is powered by a Sorenson DCR 150-68 voltage regulator and the current and voltage are monitored by appropriate meters to a precision of $0.1 \%$. The Dewar flask and associated equipment are covered with a styrofoam cap with appropriate holes for the various accessories and a port for introducing the sample.

An experimental run consists of charging the Dewar flask with a known mass of water and heating it to a known initial temperature of ca $32^{\circ} \mathrm{C}$ with the stirrer operating throughout the run. At this point, the sample (ca $150 \mathrm{~g}$ of material whose temperature is accurately known, contained in a closed plastic container) is dropped into the water in the Dewar flask and the temperature is recorded as a function of time. When the decrease in temperature with time has reached a predetermined rate, the system is considered to be at thermal equilibrium. The electric heater is then switched on and the voltage and current are recorded during the heating of both the sample and the water in the flask. When the temperature of the flask's contents are close to the temperature of the water in the Dewar flask at the beginning of the experiment the heater is switched off and the temperature is recorded as a function of time for about twenty more minutes. From these data, the heat content of the sample can be calculated in two ways: 
1. By a balance between the heat lost by the water and that gained by the sample with appropriate corrections for heat losses to the surroundings, etc.

2. From the amount of electrical heat required to raise the temperature of the flask's contents back to the initial temperature an enthalpic balance is made, again corrected for heat losses to the surroundings, etc.

To determine the extent of thermal losses such as heat absorbed by the walls of the calorimeter, sample container, etc., several calibration runs were made with water as the sample. On the basis of the calibration, we estimate our results to be accurate to within $5.0 \%$ with a precision of $\pm 7.5 \%$. The data are reduced by means of a computer program which was specially written for this purpose. A listing of the program is qiven in Table VII.

Laboratory Calorimeter - Sample Calculations

The basic equation is a heat balance between the heat lost by the sample and its container and that gained by the water in the calorimeter and the Dewar flask plus a correction for losses to the surroundings.

$$
Q_{\text {sample }}=Q_{\text {water }}+Q_{\text {Dewar }}+Q_{\text {heat loss }}-Q_{\text {container }}
$$


TABLE VII

Program (FORTRAN) Lur inalysis of Data from the Laboratory Calorimeter

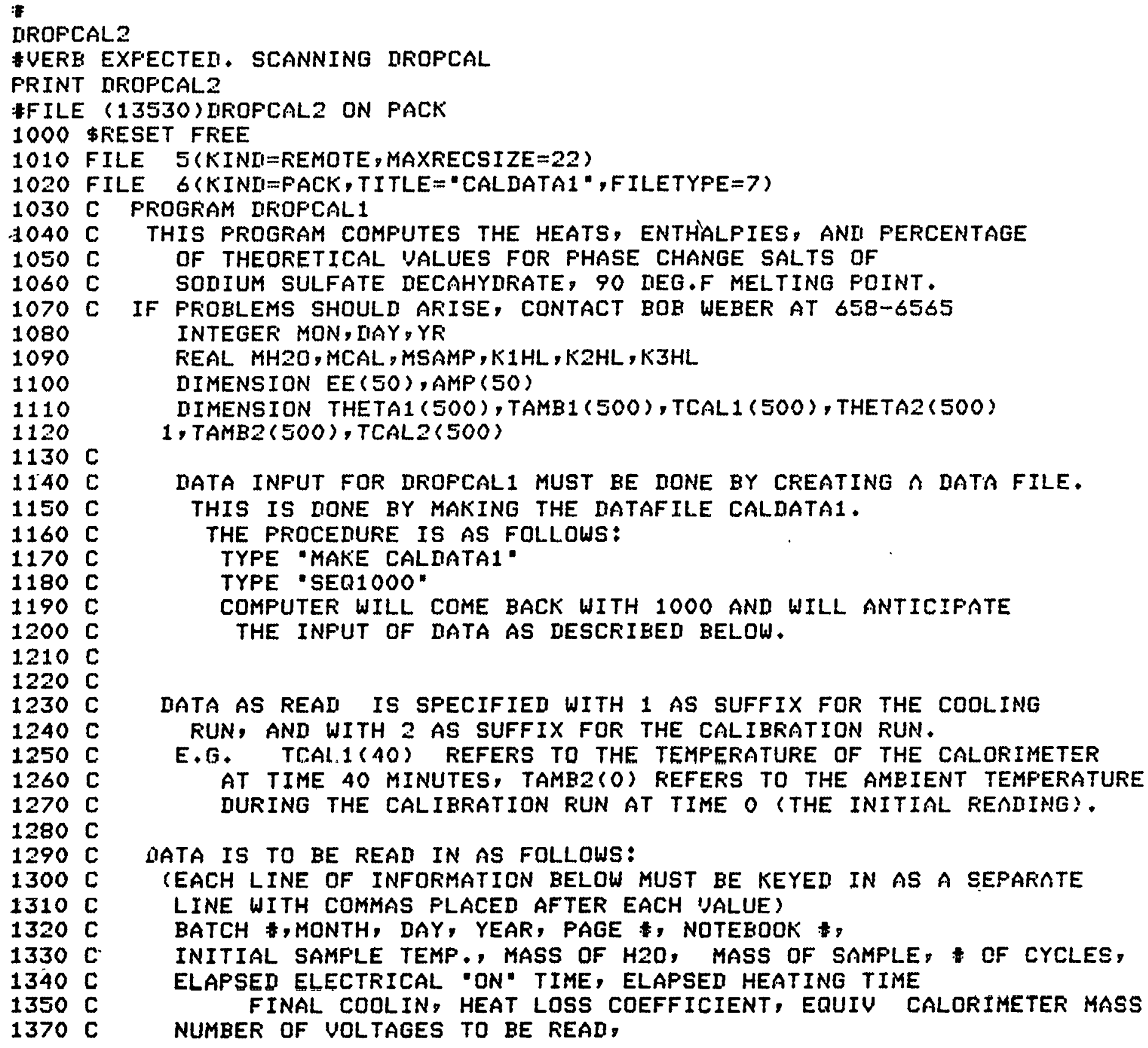

DATA INFUT FOR DROFCAL1 MUST BE DONE BY CREATING $\cap$ DATA FILE. THIS IS DONE BY MAKING THE DATAFILE CALDATA1.

DATA AS READ IS SPECIFIED WITH 1 AS SUFFIX FOR THE COOLING RUN, AND WITH 2 AS SUFFIX FOR THE CALIBRATION RUN.

E.G. TCAL1(40) REFERS TO THE TEMPERATURE OF THE CALORIMETER AT TIME 40 MINUTES, TAMB2(O) REFERS TO THE AMEIENT TEMFERATURE DURING THE CALIBRATION RUN AT TIME O (THE INITIAL RENDIMG).

IATA IS TO BE READ IN AS FOLLOWS:

(EACH LINE OF INFORMATICN BELOW MUST BE KEYED IN AS A SEPAFINTE LINE WITH COMMAS PLACED AFTER EACH UALUE)

BATCH *,MONTH, DAY, YEAR, PAGE , NOTEBOOK *

INITIAL SAMFLE TEMP., MASS OF H2O, MASS OF SAMPLE, CF CYCLES, ELAPSED ELECTRICAL "ON" TIME, ELAPSED HEATING TIME

FINAL COOLIN, HEAT LOSS COEFFICIENT, EQUIU CALORIMETER MASS NUMBER OF VOLTAGES TO BE READ, 


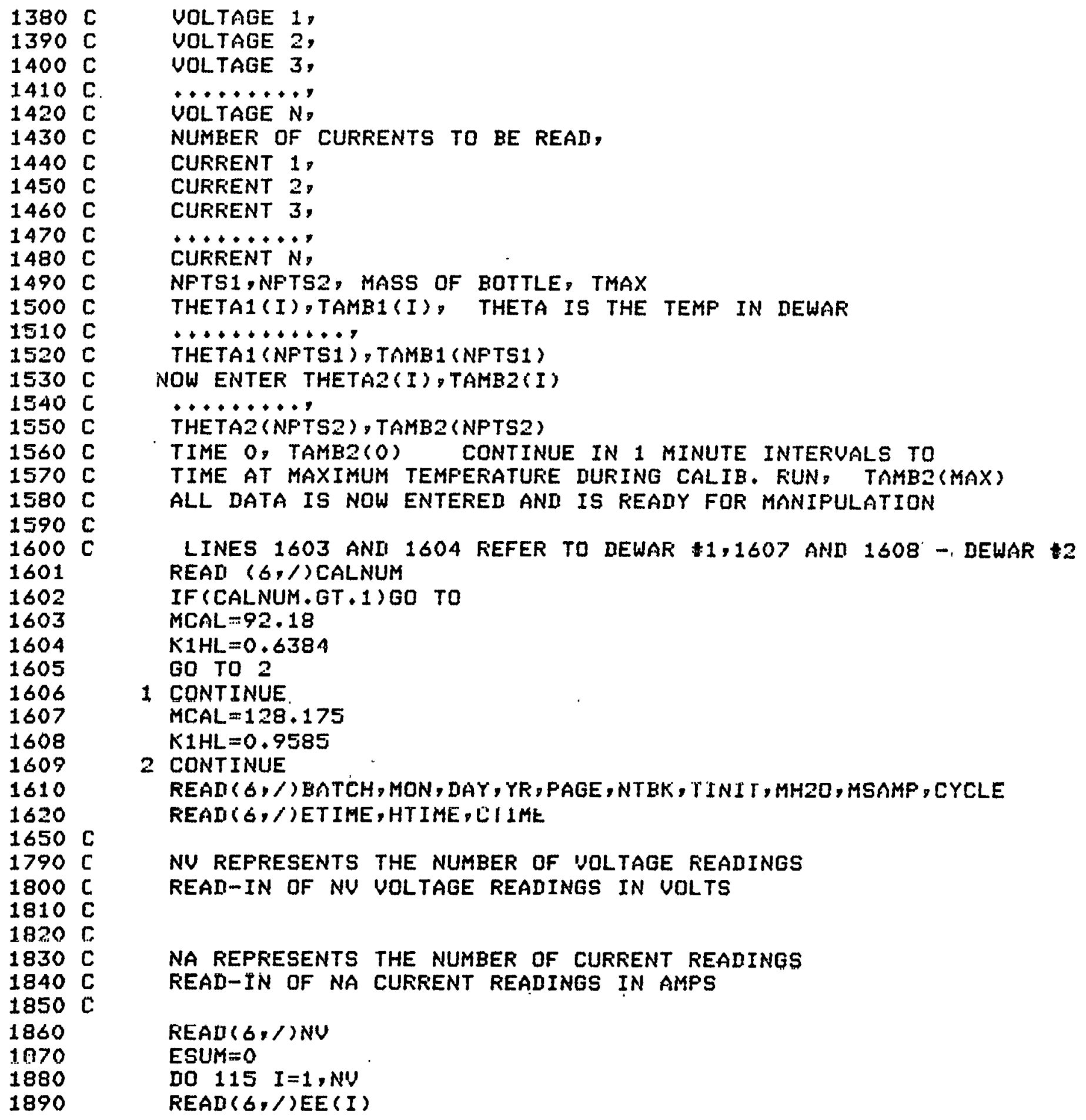




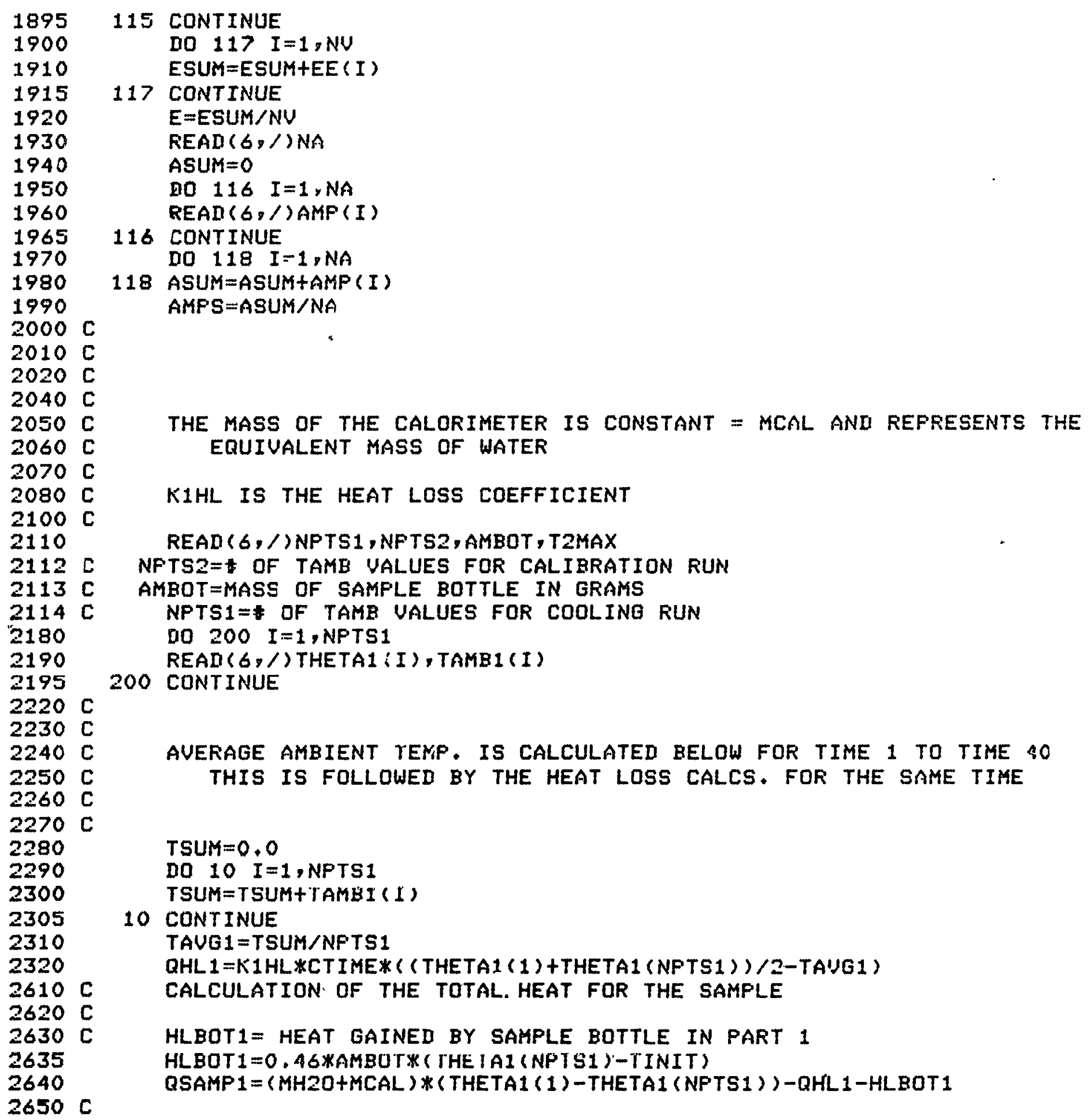

THE MASS OF THE CALORIMETER IS CONSTANT = MCAL AND REFRESENTS THE EQUIUALENT MASS OF WATER

K1HL IS THE HEAT LOSS COEFFICIENT

READ (6,/)NPTS1,NFTS2, AMBOT, T2MAX

NFTS2 $=$ \# OF TAMB UALUES FOR CALIBRATION RUN

AMBOT=MASS OF SAMPLE BOTTLE IN GRAMS

NPTS1=* OF TAMB UALUES FOR COOLING RUN

DO $200 \mathrm{I}=1$, NPTS 1

READ( 6 , /)THETA1:I), TAMB1(I)

200 CONTINUE

AUERAGE AMBIENT TEMP. IS CALCULATED BELOW FOR TIME 1 TO TIME 40 THIS IS FOLLOWED BY THE HEAT LOSS CALCS. FOR THE SAME TIME

TSUM $=0.0$

DO $10 \mathrm{I}=1$, NPTS 1

TSUM $=$ TSUM+TAMBI ( 1 )

10 CONTINUE

TAVG1 $=$ TSUM/NFTS1

QHL1 =K1HL*CTIME* ((THETA1(1)+THETA1 (NPTS1))/2-TAUG1)

CALCULATION OF THE TOTAL. HEAT FOR THE SAMPLE

HLBOT1= HEAT GAINED BY SAMPLE BOTTLE IN PART 1

HLBOT $1=0$. 46*AMBOTK ( THE IAI (NPISI) -TINIT)

QSAMP1 $=(M H 2 O+M C A L) *($ THETA1 (1)-THETA1 (NPTS1) $)-$ QHL1-HLBOT1 
$2660 \mathrm{C}$ $2670 \mathrm{C}$ $2680 \mathrm{C}$ $2690 \mathrm{C}$ 2700 2710

2720

2725

2730

2740

2750

2755

$2760 \mathrm{C}$ $2770 \mathrm{C}$ 2780 C 2790 C $3800 \mathrm{C}$ 2810 $2820 \mathrm{C}$ $2830 \mathrm{C}$ 2840 C 2850 C $2860 \mathrm{C}$ 2870 $2880 \mathrm{C}$ $2890 \mathrm{C}$ $2900 \mathrm{C}$ $2910 \mathrm{C}$ $2920 \mathrm{C}$ 2930 $2940 \mathrm{C}$ 2950 C 2960 C $2970 \mathrm{C}$ $2980 \mathrm{C}$ 2985 2990 $3000 \mathrm{C}$ $3010 \mathrm{C}$ $3020 \mathrm{C}$ $3030 \mathrm{C}$ $3010 \mathrm{C}$ 3050 $3060 \mathrm{C}$ $3070 \mathrm{C}$ $3080 \mathrm{C}$ $3090 \mathrm{C}$ $3100 \mathrm{C}$
CALCULATION OF THE TOTAL HEAT PER GRAM OF THE SAMfLE

QPERG1 $1=$ QSAMF $1 /$ MSAMP

DO $45 \mathrm{I}=1$, NFTS2

REAI ( 6,1$)$ THETA2 (I), TAKB2 (I)

45 CONTINUE

TSUM $=0.0$

no $40 \quad I=1$, NFTS2

TSUM $=$ TSUMH TAMB2 (I)

40 CONTINUE

CALCULATION OF AUERAGE AMEIENT TEMF. DURING ELECT. HEATING

TAUG $4=$ TSUM/NPTS2

CALCULATION OF ELECTRICAL HEAT INFUT TO THE CALORIMETER

QELEC $=E * A M P S * E T I M E * 60 / 4,184$

CALCULATIUN OF HEAT LOSS DURING COOLING BY METHOD 2

Q2HL $=$ QHL 1+K゙1HL*HTIME*( (T2MAX+THETA2(1))/2-TAUGA)

CALCULATION OF TOTAL HEAT FOR SAMFLE BY METHOD 2 HL.ROT2- HENT FINTNEN FY SAMPIF RITTIF TN PART a

HLBOT2 $=0.46 * A M B O T *(T 2 M A X-T I N I T)$

QSAMF2 =QQELEC-Q2HL+ $(M H 20+M C A L) *(T H E T A 1(1)-T 2 M A X)-H L E O T 2$

CALCULATION OF HEAT PER GRAM OF SAMPLE BY METHOD 2

QPERG2 =QSAMP2/MSAMP

CALCULATION OF THE THEORETICAL HEAT OF THE SAMPLE BY METHOD 1 FOLLOUED BY FRACTION 1 (F1) 


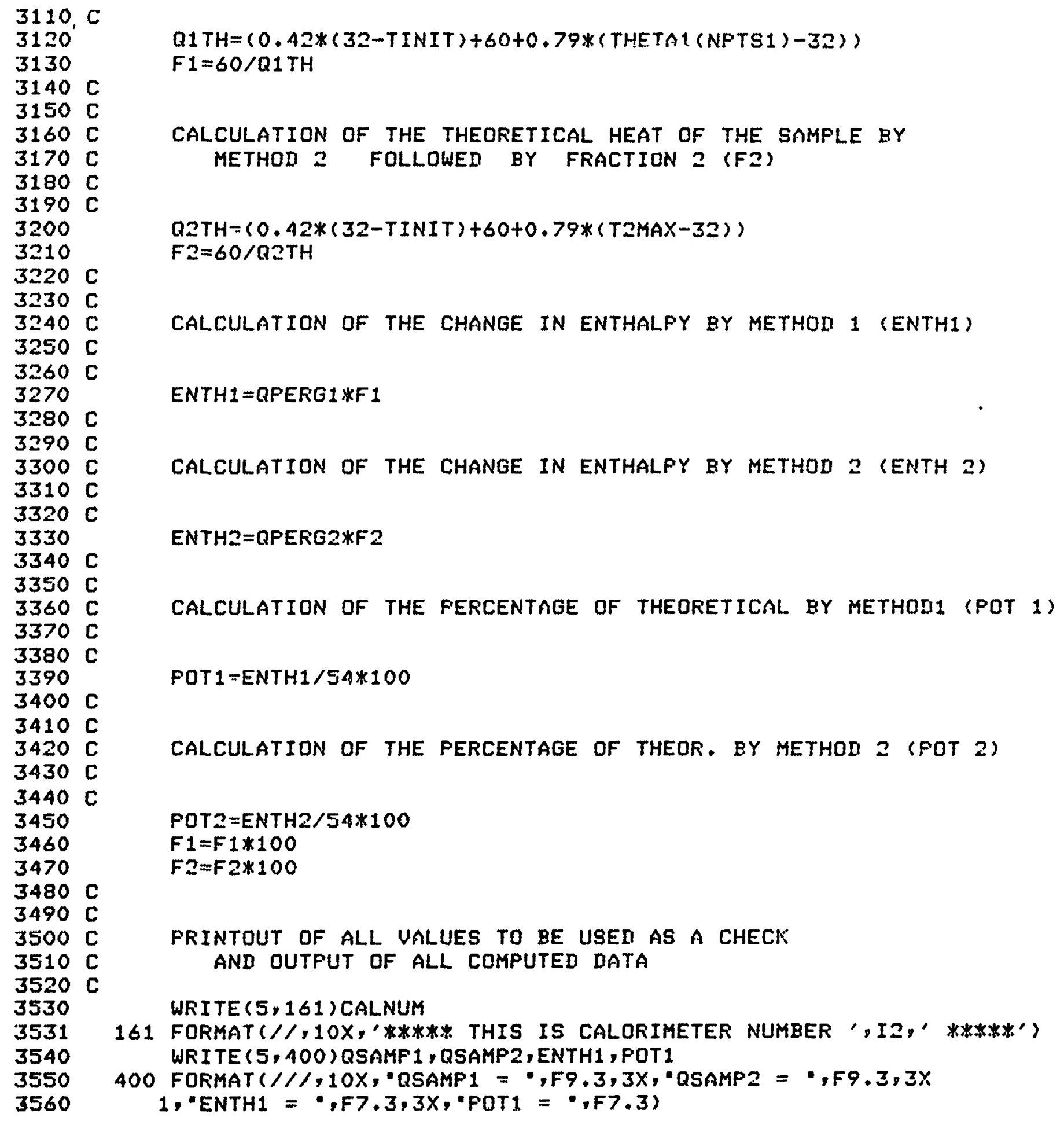


3570

3580

3590

3600

3610

3620

3630

3640

3650

3660

3670

3680

3690

$370 \mathrm{C}$

3710

3720

3730

3740

3750

3760

3770

3780

3790

3800

3810

3820

3830

3840

3850

3860

3870

3880

3890

3900

3910

3920

3930

3940

3950

4020

4030

4040

4050

4060

4070

4210

4220

4230

4240
WRITE (5, 405) QFERG1, QFERG2, ENTH2, POT2

AO5 FOFMAT ( $10 X$, OPERG1 $=$ OF9.3,3X,"QPERG2 $=", F 9.3,3 X$,

$1 \cdot$ ENTH2 $=-, F 7.3,3 X, \cdot F O T 2=\because, F 7.3,1 / 1)$

WRITE $(5,101)$ BATCH

101 FORMAT (10X,"BATCH NO.",F7,2)

WRITE $(5,102) \mathrm{MON}, \mathrm{DAY}, \mathrm{YR}$

102 FORMAT $(10 X$, DATE',I2, $1 \cdot, 12, \cdot 1,12)$

WRITE $(5,103)$ PAGE

103 FORMAT $(10 X$, "FAGE NO.',I3)

WRITE $(5,104) N T B K$

104 FORMAT (10X,"NOTEBOOK NO.",I4)

WRITE $(5,105)$ CYCLE

105 FOFMAT (10X,"CYCLES", I 4)

WFITE (I:10S)CTIME

106 FORMAT(10X,"FINAL COOLING TIME" II,X,"MINS.")

WRITE $(5,109)$ HTIME

109 FORMAT(10X,"HEATING TIME",F5.2,X,"MINS.")

WRITE $(5,110)$ ETIME

110 FORMAT (1OX,"ELECTRICAL 'ON' TIME",FS.2,X,"MINS.")

DO $201 \mathrm{I}=1$, NU

201 WRITE $(5,202) I, E E(I)$

202 FORMAT $(10 X, \cdot E E(", I 2, ")=", F 8.3)$

WRITE $(5,206) E$

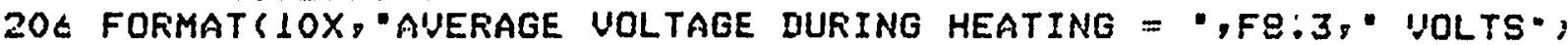
DO $203 I=1$, NA

203 WRITE $(5,204) I$, AMP (I)

204 FORMAT $(10 X$, AMP $(", I 2, ")=", F 6.4)$

WRITE (5,205) AMFS

205 FORMAT (10X,"AUERAGE CURFENT DURING HEATING $=", F 6.1, "$ AMPS", WRITE $(5,120)$ TINIT

120 FORMAT $(10 X$, "INITIAL SAMPLE TEMPERATURE",F $7,2, X, 0 D E, C . \cdot)$ WRITE $(5,121)$ HH2O

121 FORMAT ( $10 X$, "MASS OF WATER",F8, 2, $X$, "GRAMS")

WRITE $(5,122) M S A M P$

122 FORMAT(10X,"MASS OF SAMFLE",F8,2,X,"GRAMS")

WRITE $(5,123)$ THETA1 (NPTS1)

123 FORMAT $(10 X$, 'EQUIL TEMF OF SAMPLE AND DEWAR=',F7, $2, X$, 'DEG $C$ ') WRITE $(5,121)$ AMBOT

124 FOKMAT( $10 X$, 'MASS OF SAKPLE BOTTLE $=\prime, F 7.2, X, '$ GMS') WRITE $(5,111)$ T2MAX

111 FORMAT(10X,"MAX TEMP. AFTER ELEC, HTG.",F7.2,X,"nEG, c.") WRITE $(5,140) K 1 H L$

140 FORMAT $(10 X, " K 1 H L=", F 10.6, "$ HEAT LOSS COEFF.")

WRITE $(5,150) M C A L$

150 FORMAT $(10 X, " M C A L=", F 10.3, X$, MASS EQUI' OF CALORIMETER") WRITE $(5,182) F 1$

182 FORMAT $(10 X, " F 1=$ "F6.3," 1 REPRESENTS FRACTION 1") WRITE $(5,183) F 2$

183 FOFMAT $(10 X, " F 2=" F 6.3, "$, REPRESENTS FRACTION 2") 
The heat for the container, water and Dewar flask are calculated as:

$$
Q_{i}=M_{i} C_{i}\left(T_{\text {final }}-T_{\text {initial }}\right)
$$

where $M_{i}$ is the mass, $C_{i}$ is the specific heat and $T_{f i n a l}$ and $T_{\text {initial }}$ are the final and initial temperatures. The value for $Q_{\text {Dewar }}$ is calculated by determining an equivalent water mass for the Dewar in a previous calibration experiment. The $Q_{\text {heat loss }}$ term is calculated by the following equation:

$$
Q_{\text {heat loss }}=\left(k_{h l}\right)(\Delta t)\left[T_{a v}-T_{\text {room }}\right]
$$

where $k_{h l}$ is a heat loss coefficient assumed to be constant for a given calorimeter and determined in a calibration experiment, $\Delta t$ is the elapsed time over which the loss is being calculated, $T_{a v}$ is the average temperature in the calorimeter during the time $\Delta t$ and $T_{\text {room }}$ is the average room temperature during the same period. Thus every quantity on the right hand side of eqn. (1) is known and $Q_{\text {sample }}$ can be calculated.

As a check, after the sample has reached thermal equlibrium with the water in the calorimeter, the contents of the Dewar are heated to a temperature close to the initial temperature in the Dewar at the beginning of the experiment and an enthalpic balance is made: 


$$
\begin{aligned}
& \underset{\text { sample }}{H_{\text {initial }}^{T}}+\Delta H_{\text {calorimeter }}^{T^{\prime}}+Q_{\text {elec }}= \\
& \underset{\text { calorimeter }}{\mathrm{T}^{\prime} \text { final }}+\mathrm{H}_{\text {sample }}^{\mathrm{T}_{\text {final }}}+\mathrm{Q}_{\text {heat loss }}
\end{aligned}
$$

If $T^{\prime}$ initial and $T^{\prime} f i n a l$ for the calorimeter are the same, then:

$$
\underset{\Delta H_{\text {calorimeter }}^{T^{\prime}}}{\text { initial }}=\Delta H_{\text {calorimeter }}^{T^{\prime}} \text { final }
$$

$0_{\text {elec }}$ is calculated from the averaqe values for the voltage and current and elapsed time during the heating run:

$$
Q_{\text {elec }}=(\bar{V} \cdot T \cdot \Delta t \cdot 60) / 4.184
$$

where $\bar{V}$ is in volts, $T$ is in amps, $\Delta t$ is in minutes and $Q_{e l e c}$ is in calories. If, in fact, the requirements of equation (5) are not strictly met, a small correction based on the mass of the water and calorimeter is applied.

Thus rearranging equation (4)

$$
H_{\text {sample }}^{\top} \text { final }-H_{\text {sample }}^{\text {Tinitial }}=Q_{\text {elec }}-Q_{\text {heat loss }}
$$

The above calculations are done by a computer. A sample of the output is shown in Table VIII. The terms QSAMP1 and QSAMP2 refer to the calculations of equations (1) and (7) respectively. QPERG1 and QPERG2 are the respective heat values per unit mass (in grams) of sample. The slight discrepancy in values reflects the different 
TABLE VIII

******* THIS IS CALOFIMETEF NUMEEF 2 * $* * * * *$

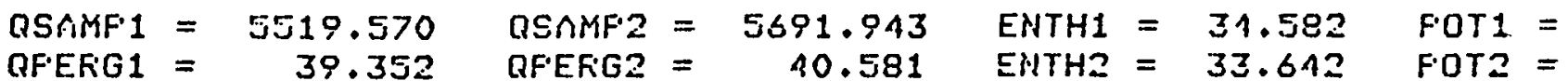

BATCH NO. 9.10

IIATE S/ $4 / 79$

FAGE NO. 55

NOTEEOOK NO. 198

CYCLES 4

FINAL COOLING TIME 88 MINS.

HEATING TIME 7.44 MINS.

ELECTFICAL 'ON' TIME 5.44 MINS.

$\operatorname{EE}(1)=120.050$

$\operatorname{EE}(2)=120.050$

$E E(3)=120.050$

$E E(4)=120: 050$

$E E(5)=120.050$

$E E(6)=120.050$

AUEFIAGE VOLTAGE IIUFIING HEATING $=120.050$ VOLTS

$A M F(1)=0.7705$

AMF ( 2) $=0.7705$

$\operatorname{AMF}(3)=0.7695$

AMF $(A)=0.7695$

$\operatorname{AMF}(5)=0.7695$

$A M P(S)=0.7595$

AUERAGE CUFFENT IUUFING HEATING $=0.7698$ AMF'S

INITIAL SAMFLE TEMFEFATUFE 10.00 IIEG. C.

MASS OF WATER 1200.00 GFAMS

MASS OF SAMPLE 140.26 GRAMS

EQUIL TEMF OF SAMFLE AND IIEWAR $=30.78$ IEG $C$

MASS OF SAMFLE ROTTLE $=23.66$ GMS

MAX TEMF. AFTER ELEC. HTG. 35.97 DEG. $C$.

K1HL $=0.958500$ HEAT LOSS COEFF.

MCAL $=128.175$ MASS EQUIV OF CALOFIMETER

$F 1=87.878$, FEPFESENTS FRACTION 1

$F 2=82.900$, FEFFESENTS FRACTION 2

TAVG1 $=21: 143$ IIEG $+C$

TAVGA $=21.089$ NEG. C

QELEC $=7209.703$ CALORIES

QHL1 $=1027.961$ CALORIES

Q2HL $=1115.576$ CALORIES

Q1TH $=68.276$ CALORIES PER GKAM

$Q 2 T H=72.376$ CALORIES PER GRAM

:QUEUED

$\neq E T=1: 32.6 \quad$ FT $=0.4 \quad$ IO $=0.3$

$$
+
$$


approaches to the calculations and the various approximations made. Reported values are an average of the two. The data to the right are used in a ditferent application of the program and are of no interest here. The other infomation listed are pertinent raw data which serve as a check and are included for the sake of convenience.

Since values of the specific heat for the sample are not known precisely, experiments are performed by splitting a batch of the mixture into two halves and measuring the heat content of the first half maintained at a temperature of $50^{\circ} \mathrm{F}\left(10.0^{\circ} \mathrm{C}\right)$ and of the other half maintained at a temperature of $60^{\circ} \mathrm{F}\left(15.6^{\circ} \mathrm{C}\right)$. The difference between the two represent the latent heat of transition stored in the material with a small amount of heat (about 10-15\% of the total) due to specific heat effects. The data are normalized to a $\Delta T$ of $30^{\circ} \mathrm{F}$ by assuming a specific heat of 0.35 for the solid and 0.65 for the liquid. Samples for this calorimeter are stored in a sealed plastic bottle. After a calorimetric measurement, the samples are placed in a cycling chamber. The cycling chamber is a freezer which has been modified so that the air temperature varies between $5^{\circ} \mathrm{F}$ to $75^{\circ} \mathrm{F}$ in a roughly sawtooth manner, such that a complete thermal cycle lasts eight hours (four hours cooling and four hours heating). Calorimetric data as a function of thermal cycling are presented for two samples in Tables $I X$ and $X$. The data have been normalized to a standard $\Delta T$ of $30^{\circ} \mathrm{F}$. The decline in thermal energy storage capacity with cycling is disturbing, however, the fact that initially the performance is high suggests that a thorough analysis of the failure mechanism will lead to a means of maintaining the material's initial acceptable performance. 
TABLE IX

$\frac{\text { THERMAL ENERGY STORAGE CAPACITY }}{\text { OF 55 } 5^{\circ} \mathrm{F} \text { MATERIALS AS MEASURED BY }}$
THE LABORATORY CALORIMETER OVER AN
OPERATING TEMPERATURE RANGE OF $30^{\circ} \mathrm{F}$

Cycles

Energy/Lb

(Btu/Lb)

$\begin{array}{rr}1 & 65.7 \\ 1 & 60.7 \\ 6 & 55.8 \\ 11 & 52.6 \\ 20 & 48.1 \\ 98 & 46.8 \\ 102 & 45.6 \\ 135 & 43.6 \\ 151 & 44.5\end{array}$


TABLE $X$

THERMAL ENERGY STORAGE CAPACITY OF A $55^{\circ} \mathrm{F}$ MATERIAL AS MEASURED BY

THE LABORATORY CALORIMETER OVER AN OPERATING TEMPERATURE RANGE OF $30^{\circ} \mathrm{F}$

$\begin{array}{cc}\text { Cycles } & \begin{array}{r}\text { Energy/Lb } \\ (B t u / L b)\end{array} \\ 0 & 70.2 \\ 3 & 64.9 \\ 38 & 53.2 \\ 54 & 52.7 \\ 80 & 4 \% .0 \\ 135 & 40.4 \\ 229 & 37.2 \\ 302 & 35.6 \\ 101 & 37.2\end{array}$




\section{Differential Scanning Calorimeter (DSC)}

A Mettler TA2000(B) thermal analysis system equipped with a TA34 coolant controller has been used in these studies. The system in this configuration is capable of scanning from $-170^{\circ}$ to $550^{\circ} \mathrm{C}$. The advantage of using a DSC lies in its ability to collect calorimetric data over relatively large temperature ranges in a short period of time (minutes to hours). It does this by using small samples ( $10 \mathrm{mg}$ ) and this fact must be borne in mind when interpreting DSC data. The differential scanning calorimeter records the differences in assimilation of thermal energy between the sample being measured and a reference material. The reference and sample are contained in small individual crucibles and placed on the ends of a thermopile in a well-insulated oven. The temperature of the oven is changed at a precisely controlled rate and the difference in temperature between the reference and sample is recorded. From the area under a peak it is possible to determine the amount of energy involved in an observed thermal transition. In addition, it is sometimes possible to derive values for the heat capacity of the sample from the recorded data.

A measurement consists of weighing a known amount of sample into a crucible and placing it on the thermopile in the oven along with the reference sample, which is usually an empty crucible. The sample and 
reference are brought to the oven temperature and then the experimental scan is initiated. The temperature of the oven is changed at a rate of $1^{\circ} \mathrm{C} / \mathrm{min}$ over the range -20 to $35^{\circ} \mathrm{C}$ and the temperature difference between the sample and reference are recorded. A complete run consists of a cooling and heating scan between the above temperatures. The area under the peaks is measured and the amount of energy stored or released is computed. The temperature in the oven is known to an accuracy of $\pm 0.5^{\circ} \mathrm{C}$ and is reproducible within $\pm 0.1^{\circ} \mathrm{C}$. The calorimetric measurements are typicalily accurate to $\pm 2 \%$ with a repeatability of $\pm 0.5 \%$.

\section{Differential Scanning Calorimeter (OSC) - Sample Calculations}

The procedure for calculating the energy involved in a thermal transition consists of integrating the area under the desired recorded peak and comparing the area to that obtained for a known substance, whose thermal characteristics are well known. The manufacturer of the DSC (Mettler Corp.) recommends using indium metal as the calibration standard. The desired equation is:

$$
\Delta H_{\text {sample }}=\Delta H_{\text {ref }} \frac{\text { (area of sample peak) }}{\text { (reference area) }}
$$

The reference area is a known area of graph paper which has been measured by the same instrument used to measure the area under the sample peak. The sample peak area and reference area were measured with a KEE Co. compensating polar planimeter and values of 0.6614 and 0.5000 , respectively, were obtained (in arbitrary units). The value for $\Delta H$ is obtained as follows: 


$$
\Delta H_{\text {ref }}=(\text { reference area in } \mu V \cdot \sec ) / E_{\text {ref }}
$$

The values for the reference area in $\mu \mathrm{V} \cdot$ sec are obtained from the scan speed of the recorder and the sensitivity reading obtained from the DSC instrument. In this case, the chart paper moved at $1 \mathrm{~cm} / \mathrm{min}$ and full scale deflection of the pen was $200 \mu \mathrm{V}$. The value for $E_{r e f}$ was obtained from calibration data recorded earlier.

$$
\Delta H_{\text {ref }}=(30,000 \mu \mathrm{V} \cdot \mathrm{sec}) /(54.684 \mu \mathrm{V} / \mathrm{mcal} \cdot \mathrm{sec})=
$$$$
548.6 \mathrm{mcal}=0.5486 \mathrm{cal}
$$

Therefore,

$$
\Delta H_{\text {sample }}=(0.5486) \frac{0.6614}{0.5000}=0.726 \mathrm{cal}
$$

The sample's mass was $0.0440 \mathrm{~g}$

$$
\Delta H_{\text {sample }} / \text { mass }=\frac{0.726}{0.0440}=16.5 \mathrm{cal} / \mathrm{g}=29.7 \mathrm{Btu} / \mathrm{lb}
$$

Adding in the contribution for specific heat for a $30^{\circ} \mathrm{F}$ range and assuming an average specific heat of 0.5 we have:

$$
\Delta H / \text { mass }=29.7+15.0=44.7 \mathrm{Btu} / 1 \mathrm{~b}
$$


Use of Differential Scanning Calorimeter to Study the Effects of Vibration on Phase Change Material

Differential scanning calorimetry data are shown in Figure 16 for a series of four samples with different thermal and physical histories. All samples were measured under the same conditions, at sample sizes of 40 to $50 \mathrm{milligrams}$ and at a heating rate of $1^{\circ} \mathrm{C}$ per minute. Samples had been cooled in the instrument to a temperature of $-20^{\circ} \mathrm{C}$ at a cooling rate of $1^{\circ} \mathrm{C} / \mathrm{min}$ before the heating-curve data were collected.

For samples $A$ and $B$, taken from the upper and lower sections of a control Chub, the heating curves were similar. The onset of melting corresponding to the major thermal effect was in the range of $10-12^{\circ} \mathrm{C}$ $\left(50-55^{\circ} \mathrm{F}\right)$. It is to be noted that the melting temperature is determined by extrapolating the slope of the rise portion of the peak to the baseline. The area under the peak indicates the magnitude of the thermal effect, but the temperature on the chart where the peak is recorded is of no significance.

Samples $C$ and $D$ were taken from the upper and lower sections of a Chub that had been vibrated for a week on the Travelometer. The lower, closely consolidated layer of the vibrated Chub, representing most of the cross-sectional area of the chub, had a melting curve similar to that of the control (unvibrated) Chub.

All of the samples exhibit secondary thermal transitions which start at a temperature near the freezing point of water. 


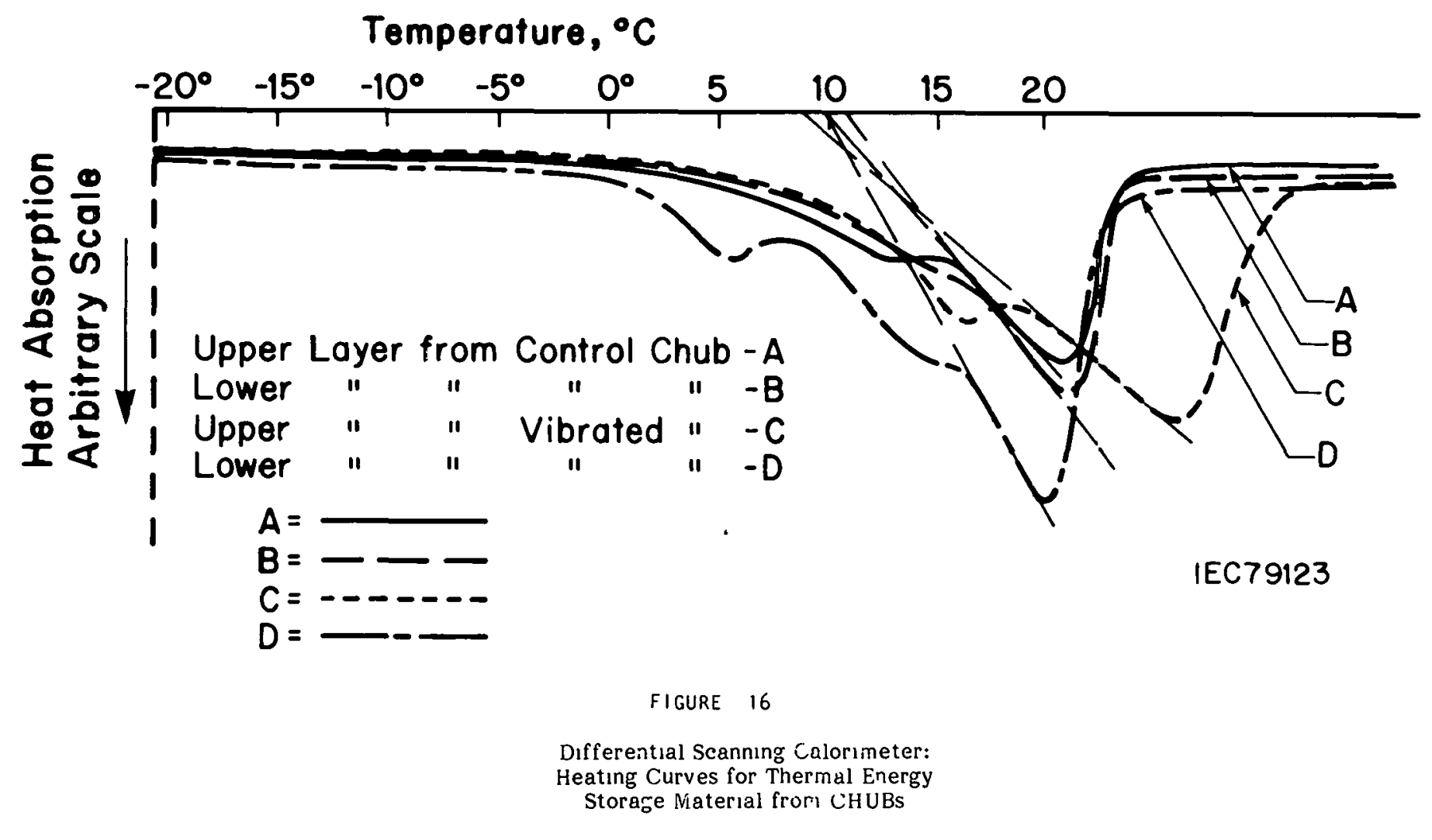


The data indicate that changes occur in the thermal energy storage mixture during an accelerated vibration test. In particular curve $\mathrm{C}$ which was taken from the upper layer of the vibrated Chub appears to differ appreciably from the other curves. Note, however, that the extrapolated transition temperature is the same as for the control sample. This suggests that the difference in curve $C$ is due to changes in the thermal conductivity of the material. The fact that the transition temperature is unchanged suggests that the composition of the material is not appreciably changed, however, physical characteristics such as crystal size, etc., may have altered appreciably. This interpretation is consistent with the visual observation described in Section $1-F-1$.

\section{Differential Scanning Calorimetry as a Function of Cycling}

Table XI presents data from the differential scanning calorimeter on laboratory samples that were cycled in the Institute's cycling chamber. The data are normalized to the standard $\Delta T$ of $30^{\circ} \mathrm{F}$. Note that the energy computed from the cooling half of the scan, listed separately from that obtained during the heating portion of the measurement is significantly different. Due to the overlapping nature of the peaks during a heating run (see Figure 16), it is difficult to separate the desired thermal peak from other peaks that are overlapping with it. Similarly, on a cooling run, due to supercooling, several thermal events are present in what appears to be one large peak. For these reasons and the difficulties in obtaining representative samples, differential scanning calorimetry is not considered a good technique for measuring thermal energy storage capacity as a function of thermal cycling. 
TABLE $\quad X 1$

$$
\begin{aligned}
& \text { DSC DATA } \\
& \text { Normal ized to } \triangle \mathrm{T}=30^{\circ} \mathrm{F} \\
& 55^{\circ} \mathrm{F} \text { Material }
\end{aligned}
$$

Cycles

0

0

0

0

0

48

48

48

56

100

101

101

101

101
$\Delta H / m(B t u / I b)$

Cooling

Heat ing

48.3

37.1

45.4

60.1

40.7

30.7

49.7

38.9

49.6

42.4

36.8

35.5

43.1

38.9

49.9

37.0

49.0

35.7

46.1

34.1

40.6

31.4

42.5

30.5

42.7

29.3

41.5

28.3 


\section{E. Chub Test Results}

The thermal energy storage capacity (Btu's per pound) which is of interest is that amount of heat which can be stored under actual field conditions in a practical system. The fact that the system must be carefully specified in order to make meaningful measurements was recognized when the ASHRAE Standard 94-77, "Methods of Testing Thermal Storage Devices Based on Thermal Performance" was developed. The air calorimeter constructed at the Institute of Enerqy Conversion conforms to this standard and is useful for measuring the heat content of an array of Chubs. It is not surprising, therefore, that the air calorimeter gives the best correlation between laboratory measured capacities and those obtained in Solar One during the summer of 1978 in the first field demonstration of the Chub thermal energy storage material configuration. As mentioned in the description of the air calorimeter, it is calibrated against water as the standard reference material. In one of these calibrations, water contained within chub film laminate fabricated on the Chub machine was used as the reference.

As a base measurement, the air calorimeter was used to measure the capacity of 183 pounds of $55^{\circ} \mathrm{F}$ phase change material contained in 1.5-inch diameter plastic tubes. The results of five measurements of the material initially in frozen and thawed states is given in Table XII. Similarly, in Table $x \mid 11$, a measurement was made of the thermal energy storage capacity of 218 pounds of $55^{\circ} \mathrm{F}$ phase change material contained 
TABLE XII

\section{THERMAL ENERGY STORAGE CAPACITY}

AS MEASURED IN THE AIR CALORIMETER

183 Lbs. of $55^{\circ} \mathrm{F}$ Phase Change Material

Contained in 1.5-Inch Diameter Tubes

\begin{tabular}{|c|c|c|c|}
\hline $\begin{array}{l}\text { Measurement } \\
\text { (\#) }\end{array}$ & $\begin{array}{c}\text { Flow Rate } \\
\text { fm }\end{array}$ & $\begin{array}{l}\text { Total Energy } \\
\left(\text { Btu } \times 10^{-3}\right)\end{array}$ & $\begin{array}{c}\text { Total Energy/Lb } \\
\text { Btu/lb }\end{array}$ \\
\hline $\begin{array}{l}1 a \\
1 b\end{array}$ & $\begin{array}{l}183 \\
175\end{array}$ & $\begin{array}{l}14.2 \\
13.8\end{array}$ & $\begin{array}{l}77.4 \\
75.2\end{array}$ \\
\hline $\begin{array}{l}2 a \\
2 b\end{array}$ & $\begin{array}{l}171 \\
181\end{array}$ & $\begin{array}{l}13.3 \\
14.2\end{array}$ & $\begin{array}{l}72.5 \\
77.4\end{array}$ \\
\hline $\begin{array}{l}3 a \\
3 b\end{array}$ & $\begin{array}{l}169 \\
182\end{array}$ & $\begin{array}{l}14.2 \\
12.6\end{array}$ & $\begin{array}{l}77.4 \\
68.7\end{array}$ \\
\hline $\begin{array}{l}4 a \\
4 b\end{array}$ & $\begin{array}{l}173 \\
180\end{array}$ & $\begin{array}{l}11.3 \\
11.9\end{array}$ & $\begin{array}{l}61.6 \\
64.9\end{array}$ \\
\hline $\begin{array}{l}5 a \\
5 b\end{array}$ & $\begin{array}{l}172 \\
181\end{array}$ & $\begin{array}{l}10.9 \\
11.3\end{array}$ & $\begin{array}{l}59.4 \\
61.7\end{array}$ \\
\hline
\end{tabular}

\footnotetext{
a) Freezing of thermal energy storage material

b) Thawing of thermal energy storage material

c) Includes contributions for specific heat over the normal operating rangc of $30^{\circ} \mathrm{F}$ and the latent heat at the transition point
} 
TABLE $\quad X \mid I I$

\section{THERMAL ENERGY STORAGE CAPACITY}

AS MEASURED IN THE AIR CALORIMETER

(218 Lbs. of $55^{\circ} \mathrm{F}$ Phase Change Material

Contained in 2-Inch Diameter CHUBs)

\begin{tabular}{|c|c|c|c|}
\hline $\begin{array}{l}\text { Measuremenl } \\
\text { (H) }\end{array}$ & $\begin{array}{c}\text { Fluw Rule } \\
(\mathrm{fm})\end{array}$ & $\begin{array}{l}\text { Tutal Energy } \\
\left(\text { Dtu } \times 10^{-3}\right)\end{array}$ & $\begin{array}{c}\text { Total Energy } / \mathrm{Lb}^{\mathrm{C}} \\
\text { Dtu/Lb }\end{array}$ \\
\hline $\begin{array}{l}1 a \\
1 b\end{array}$ & $\begin{array}{l}181 \\
185\end{array}$ & $\begin{array}{l}15.6 \\
17.0\end{array}$ & $\begin{array}{l}71.6 \\
78.0\end{array}$ \\
\hline $\begin{array}{l}2 a \\
2 b\end{array}$ & $\begin{array}{l}180 \\
178\end{array}$ & $\begin{array}{l}14.0 \\
14.4\end{array}$ & $\begin{array}{l}64.2 \\
66.1\end{array}$ \\
\hline $\begin{array}{l}3 \mathbf{a} \\
3 \mathbf{b}\end{array}$ & $\begin{array}{l}178 \\
176\end{array}$ & $\begin{array}{l}12.9 \\
13.2\end{array}$ & $\begin{array}{l}59.2 \\
60.6\end{array}$ \\
\hline $\begin{array}{l}4 a \\
4 b\end{array}$ & $\begin{array}{l}178 \\
177\end{array}$ & $\begin{array}{l}13.8 \\
14.2\end{array}$ & $\begin{array}{l}63.3 \\
65.1\end{array}$ \\
\hline $\begin{array}{l}5 a \\
5 b\end{array}$ & $\begin{array}{l}180 \\
177\end{array}$ & $\begin{array}{l}13.2 \\
13.8\end{array}$ & $\begin{array}{l}60.6 \\
63.3\end{array}$ \\
\hline
\end{tabular}

\footnotetext{
a) Freezing of thermal energy storage material

b) 'Thawing of thermal energy storage material

c) Includes contributions from specific heat over the normal operating range of $30^{\circ} \mathrm{F}$ and the latent heat at the transition point
} 
in 2-inch diameter Chubs. The measured thermal energy storage capacities in both of these cases were roughly identical. These values are consistent with, and slightly higher than, previously reported data for the full house testing. (2) It should be noted that the data in Tables $x \mid 1$ and $\mathrm{XIII}$ are for material that had not been previously thermally cycled.

Tables XIV presents results for a portion of the material (206.5 lbs) taken from the 100 -cycle test at the end of 71 cycles. Table XV shows data from the air calorimeter for the materlal cycled 405 times in the accelerated cycle test. The reason for the discrepancy between the two sets of data is not clear at this time.

(2) Experimental Study of Coolness Storage Using Sodium Sulfate Decahydrate, William J. Rice and Joseph J. Sliwkowski, ISES Conference, Atlanta, 1979. 
TABLE XIV

THERMAL ENERGY STORAGE CAPACITY

AS MEASURED IN THE AIR CALORIMETER

206.5 Lbs. of $55^{\circ} \mathrm{F}$ Phase Change Material Contained in 12 " Long by 2" Diameter CHUBs After 71 Cycles on the Diurnal Test Schedule

$\begin{array}{lcc}\begin{array}{c}\text { Measurement } \\ (\#)\end{array} & \begin{array}{c}\text { Total Energy }^{c} \\ \left(B t u \times 10^{-3}\right)\end{array} & \begin{array}{c}\text { Total Energy } / \mathrm{Lb}^{\mathrm{c}} \\ \text { Btu/lb }\end{array} \\ \text { 1a } & 8.86 & 42.9 \\ \text { 1b } & 9.43 & 45.7 \\ \text { 2a } & 8.68 & 42.0 \\ 2 \mathrm{~b} & 9.02 & 43.7 \\ \text { 3a } & & \\ \text { 3b } & 8.75 & 42.4 \\ & 9.55 & 46.2\end{array}$

\footnotetext{
a) Freezing of thermsl energy storage material

b) Thawing of thermal energy storage material

c) Includes contributions for specific heat over the normal operating range of $30^{\circ} \mathrm{F}$ and the latent heat at the transition point
} 


\section{THERMAL ENERGY STORAGE CAPACITY}

\section{AS MEASURED IN THE AIR CALORIMETER}

204 Lbs. of $55^{\circ} \mathrm{F}$ Phase Change Material Contained in 12 " Long by 2" Diameter CHUBs After Being Cycled

For 405 Cycles on the Accelerated Test Schedule

$\begin{array}{lcc}\begin{array}{l}\text { Measurement } \\ (\#)\end{array} & \begin{array}{c}\text { Total Energy } \\ \left(B t u \times 10^{-3}\right)\end{array} & \begin{array}{l}\text { Total Energy/Lb } \\ \text { Btu/lb }\end{array} \\ \text { 1a } & 15.2 & 74.5 \\ \text { 1b } & 17.8 & 87.3 \\ 2 a & 14.3 & 70.1 \\ 2 b & 16.0 & 78.4 \\ 3 a & 14.5 & 71.1 \\ 3 b & 14.0 & 68.9\end{array}$
a) Freezing of thermal energy storage material
b) Thawing of thermal energy storage material
c) Includes contributions for specific heat over the normal operating range of $30^{\circ} \mathrm{F}$ and the latent heat at the transition point




\section{SPECIFICATION AND TESTING}

A. For blue Chubs containing $55^{\circ} \mathrm{F}$ phase change material.

1. Contents

The contents of blue Chubs shall be a uniform mixture of the following components:

$\begin{array}{lrl}\text { Water } & 41.84 & \text { parts by weight } \\ \text { Sodiuin Sulfale-dlliydruus } & 32.90 & \text { parts by weight } \\ \text { Sodium Chloride } & 6.75 & \text { parts by weight } \\ \text { Ammonium Chlelide } & 6.23 & \text { parts by welght } \\ \text { Borax - nucleating agent } & 2.63 & \text { parts by weight } \\ \text { Boric Acid - stabilizer } & 1.75 & \text { parts by weight } \\ \text { Min-U-Gel FG - thickener } & 7.90 & \text { parts by weight } \\ \text { TOTAL. } & 100.00 & \text { parts by weight }\end{array}$

The order of addition and the conditions and temperature of mixing shall be arranged to produce a mixture which has a consistency of 25 to 35 Zahn grams at $25^{\circ} \mathrm{C}$, as measured with a Zahn-Gardco Consistency Meter. The consistency meter, and instructions for its use, can be obtained from Paul N. Gardner Company, P. 0. Box 6633. Station 9, Fort Lauderdale, FI 33316.

Mixing temperatures should not exceed $160^{\circ} \mathrm{F}$. For routine quality control, the differential scanning calorimeter profile of the chub contents shall match the profile of a standard sample. 


\section{Dimensions}

The standard blue Chub shall have a nominal diameter of $50.8 \mathrm{~mm}$ (2.0 inches) and a nominal tip-to-tip length of $508 \mathrm{~mm}$ (20.0 inches). The tolerance on Chub length shall be 495 to $508 \mathrm{~mm}$ (19.5 to 20.0 inches). Chub length tip-to-tip shall be determined using a metric scale graduated in units of $1 \mathrm{~mm}$. Care should be taken to avoid errors in length measurement due to parallax.

\section{Sag}

Large variations in the rigidity of the Chub package due to variations in strength, length or filling pressure may lead to difficulties in stacking the Chubs in standard stacking hardware. A pass/fail test for sag in Chubs has been developed using the Chub Sag Tester (Figure 17). This device consists of $102 \mathrm{~mm}$ ( 4 inch) sections of $127 \mathrm{~mm}(1 / 2 \mathrm{inch})$ diameter wooden dowels cemented to a smooth wooden base approximately $51 \mathrm{~mm} \times 102 \mathrm{~mm} \times 508 \mathrm{~mm}$ $\left(2^{\prime \prime} \times 4^{\prime \prime} \times 20^{\prime \prime}\right)$. The dowels are aligned parallel to a $102 \mathrm{~mm}$ edge of the base, at intervals of $76 \mathrm{~mm}, 254 \mathrm{~mm}$ and $432 \mathrm{~mm}$ from one end. The base of the Sag Tester is placed horizontally on an appropriate level surface. When a Chub is laid horizontally across the three parallel dowels, with one end positioned flush with the base of the Sag Tester, no parts of the Chub shall touch the base, i.e., the Chub shall not sag more than $12.7 \mathrm{~mm}(1 / 2$ inch) at any point. In questionable cases, the sag of the Chub shall be checked at four orientations around its circumference, i.e., with the heat seal up, down, at $90^{\circ}$ to the left and at $90^{\circ}$ to the right. A Chub shall be considered to have acceptable sag if it passes the test in at least three of the four orientations. 


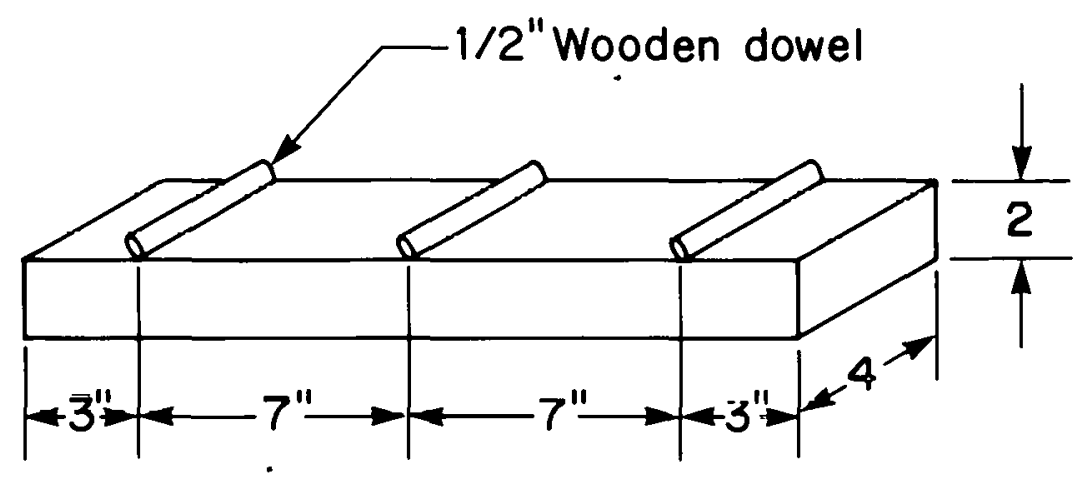

Chub Sag Tester

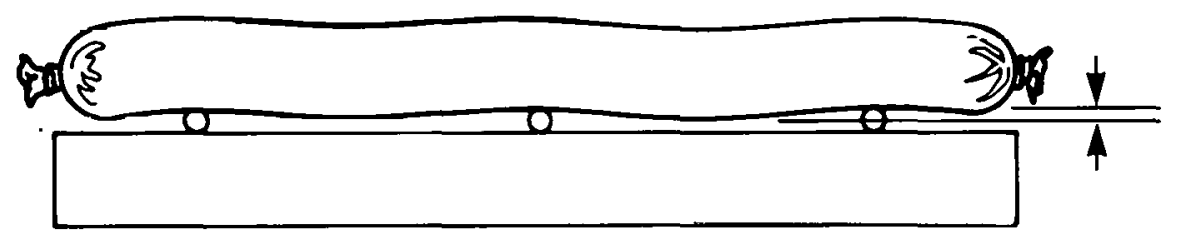

Suy less than $0.50^{\prime \prime}$ is acceptable

FIGURE 17

C:AUB Sag I cster

IEC79142 
4. Heat Seal Uniformity

A uniform and strong heat seal down the length of the Chub is necessary to ensure retention of the chub contents during handling and use. For the standard 2-inch diameter chub, made from a 2-inch wide sheet of laminate, the nominal overlap available for heat sealing is $18 \mathrm{~mm}$.

Heat seals in the Chub package shall have a visually uniform sealed width of at least $10 \mathrm{~mm}$. The seal area shall be essentially free of visible unsealed areas, including wrinkles that traverse the width of the seal area. If an unsealed flap is exposed on the outside of the Chub along the seal area, it must not be peelable as determined by running a thumbnail under the flap and applying moderate inward pressure at the junction of the two layers of $\mathrm{fi} \mathrm{lm}$.

\section{End Closure.}

The primary end closure of the Chub package is a clip of heavy wire, comprising one and a half laps around the gathered film. The tightened clip must grip the gathered film so as to achieve a liquid-tight closure without cutting through the film. The ends of the wire clip must be free of sharp burrs. A plastic adhesive or wax, applied to cover the exposed end of the gathered film, serves as a secondary. end closure. The end closure must exhibit no visible build-up of white salts, or wet salt solution, around the closure and clip when observed after storage at room temperature for at least seven days. 


\section{Punctures}

An acceptable Chub must be free of pinholes, scratches, or punctures which allow exudation of visible accumulations of white and/or wet salt during handling and storage. These defects are most likely to occur in the creased hemispherical areas at each end of the Chub.

\section{Weight}

Chub weights shall be determined using a balance sensitive to \pm 1 gram. An Ohaus Heavy Duty Balance, or its equivalent, is suitable. For routine sampling, the weights shall be determined and averaged for at least five percent of the chubs selected at random in a production lot.

\section{Appearance}

Chubs ready to be packaged for shipment shall be clean, and free of obvious foreign materials.

\section{Color}

Chubs for use in cooling applications shall be blue in color. The blue pigmented outer layer of the Chub package shall visually match the Etandard "Blue" color. 
10. Drop Impact

A standardized drop test onto a smooth surface from a height of one meter is used as a measure of the ability of the filled chub package to withstand dropping and similar abuse during handling as individual chubs.

An acceptable Chub shall withstand ten drops of one meter onto a smooth hard surface from a horizontal position with the heat seal up, followed by ten similar drops of the same Chub with the heat seal down. For more rigorous testing, to represent extremely rough handing, the test may be continued with the chub dropped vertically with its bottom end one meter above the smooth flat surface for ten drops, followed by ten vertical drops with the top end of the Chub (as manufactured) down and one meter above the smooth flat surface. In this more rigorous test, the laminate package may become stretched and distorted, so as to be unusable, but should not allow the chub contents to leak from the package. The more rigorous test will detect weaknesses in the heat seals, and may cause punctures of the laminate by the exposed ends of the wire clips.

\section{Delamination}

If adhesion between adjacent layers of the laminate, especially those involving the metallized layers, is inadequate, e.g., due to insufficient cure, the laminate layers involved may separate. This will result in a dimpled or bubbly appearance in the laminate, especially adjacent to the cut edge. The chub contents may then attack the metallized interior layers of the laminate, leading to a marked increase in water vapor transmission rate, and an associated loss of Chub performance. 


\section{B. Qualified Chub Fabrication}

Based on the specifications of the film laminate developed in cooperation with Du Pont and the use of the Chub Machine (Kartridg Pak, Inc.) by Du Pont to prepare sample Chubs for research evaluation, and the extensive tests conducted both at the University of Delaware and Du Pont, the materials for and the procedure for the preparation of a qualified chub was completed. Based upon this background, a prototype fabrication facility was set up in 2000 square feet of space located in a building adjacent to the campus of the University of Delaware. In this space, the materials for the preparation of the Chubs were stored, the process machinery for the Chub preparation was installed and used, and the Chubs were inspected, prepared for packaging, and packaged for shipment to a demonstration site. After initial startup and debugging of the process equipment in May 1979, the qualified Chub materials required for life testing under this contract were prepared during the first week of June $1 y / y$. I hese lhubs were 12 inches long by 2 -inch diameter. This size was chosen as representative of the Chub thermal energy storage materials which would be used in field demonstrations, but with a size convenient for research testing. The Chubs prepared at the prototype fabrication facility after the first week of June 1979 were all 20 inches in length, which has been adopted as the standard for incorporation into modules (Figure 18) for use in demonstration thermal energy storage systems. During the summer of 1979, approximately 25 tons of Chub thermal energy storage materials were prepared for evaluation in several demonstration systems. 


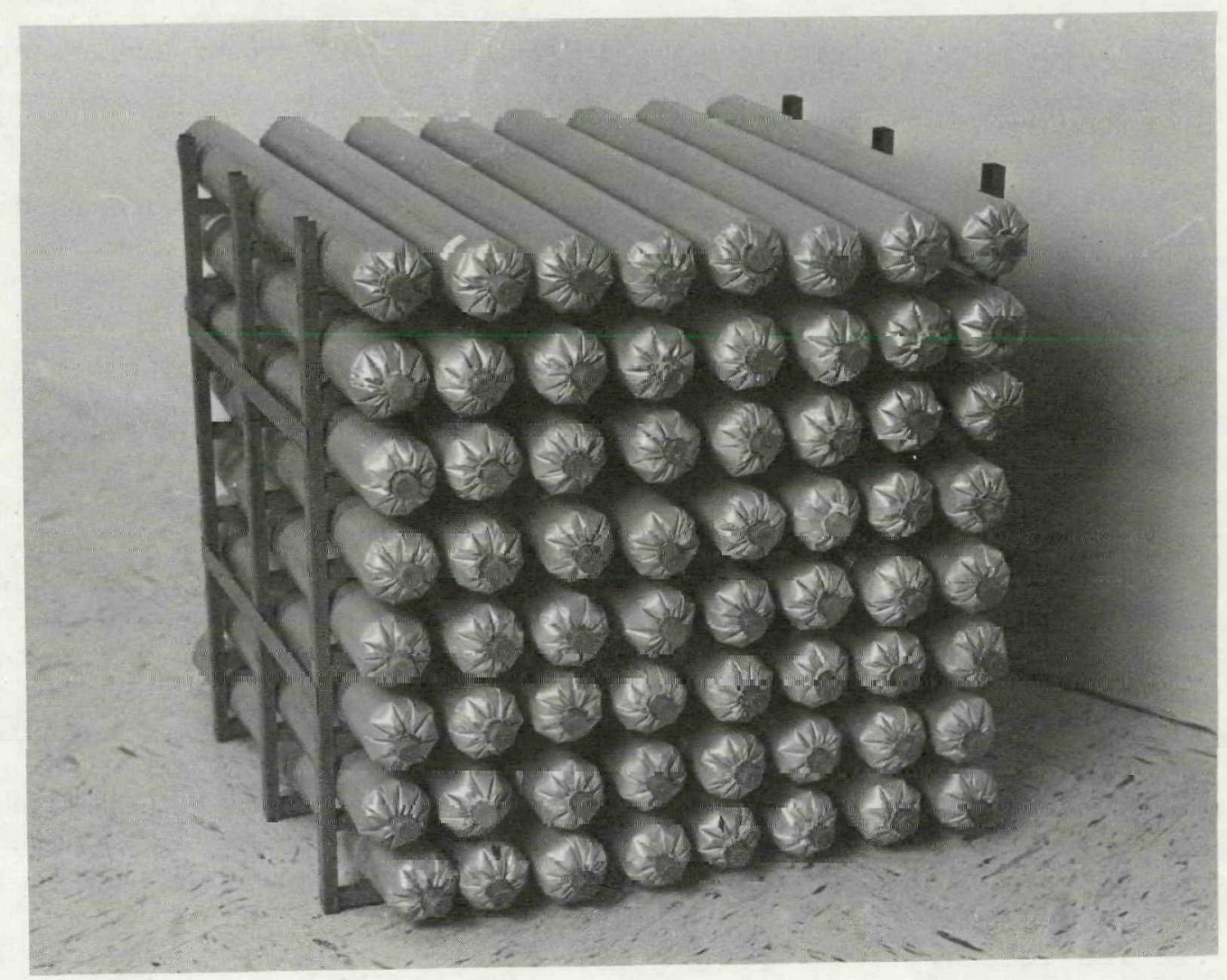

FIGURE 18

CHuB Thermal Energy Storage Module 
A schematic diagram for the manufacture of Chubs from materials is shown in Figure 19. The constituent solid materials (sodium sulfate, sodium chloride, ammonium chloride, Borax, boric acid, and Min-U-Gel) are fed in preweighed portions into the reactor mixer. Here hot water is added through a metering pump, the material agitated and homogenized and metered to the Chub machine which forms the final package. This schematic diagrams the flow pattern in a full-scale manufacturing facility. In the farility for the preparation of the qualified Chubs, the material was taken from bags off of skids, weiqhed on a scale, and premixed, using a ribbon blender such as seen in Figures 20 and 21. The premixed material was added to hot water in the Agi-Mixer (Figure 22) for the dispersion of the materials with the clay gelling agent to create the thixotropic mixture. This can be pumped to a holding kettle such as shown in Figure 23 before going to the Chub machine shown in Figure 24 . In the photograph of the Chub machine, the laminate $f i l m$ roll is shown to the upper left, which is fed in flat form and formed into a tube around a mandrel which is heat sealed along the seam. The hydrated salt is inserted into the tube and the tube sealed at each end with a metal clip. The finished product, the Chub (Figure 25), emerges at the bottom of the machine ready for inspection and packaging. 


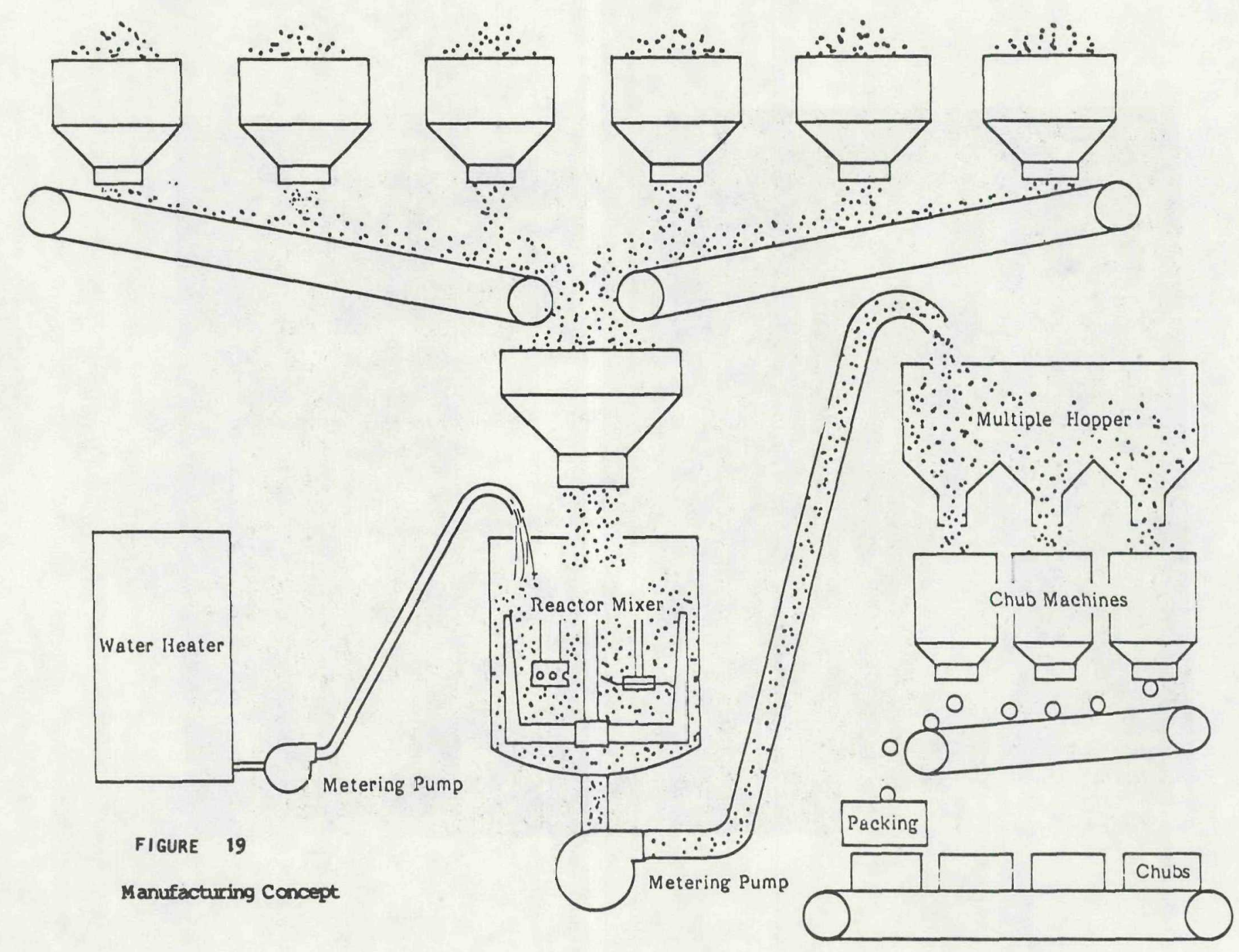




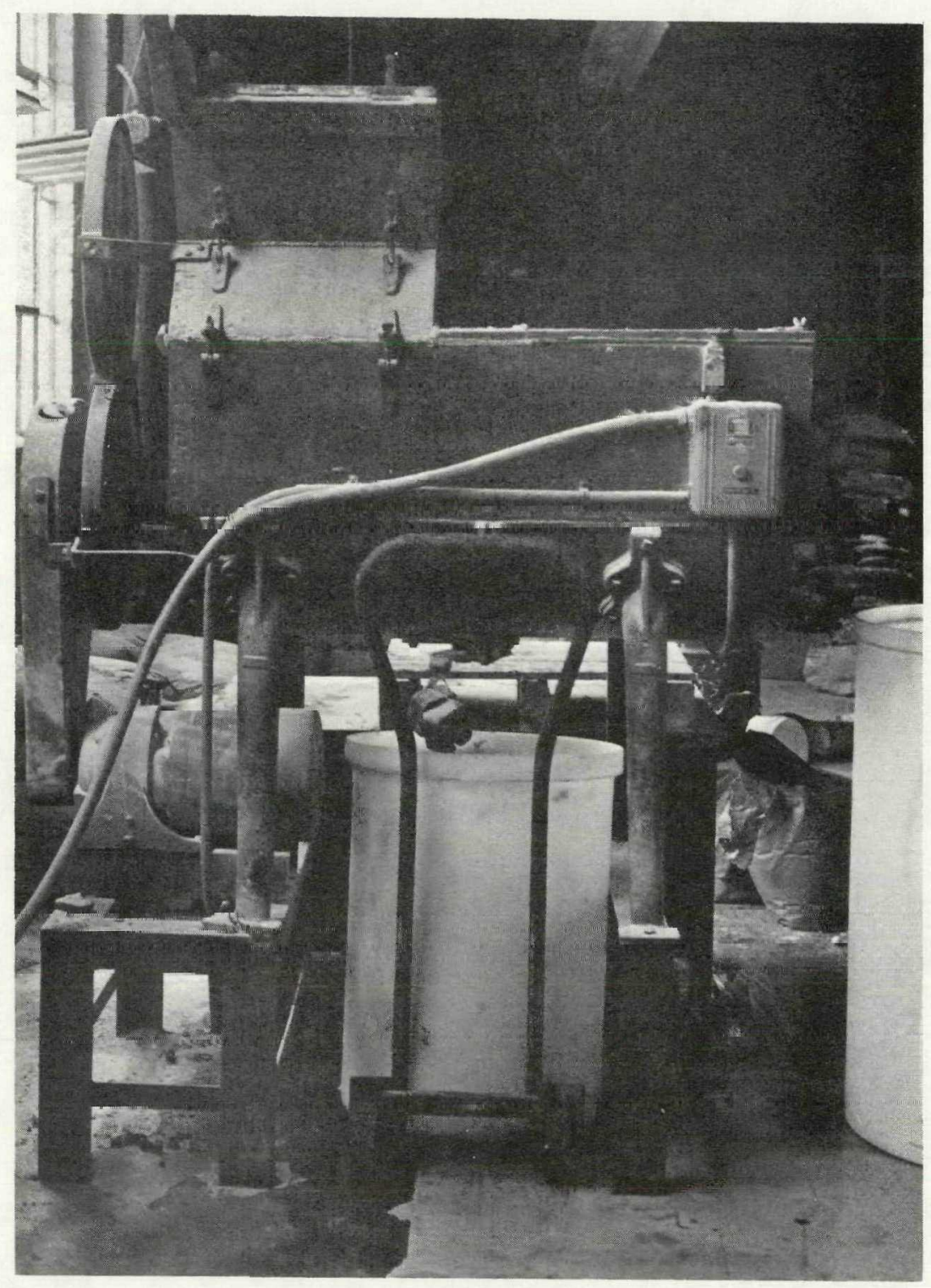

FIGURE 20

Ribbon Blender 


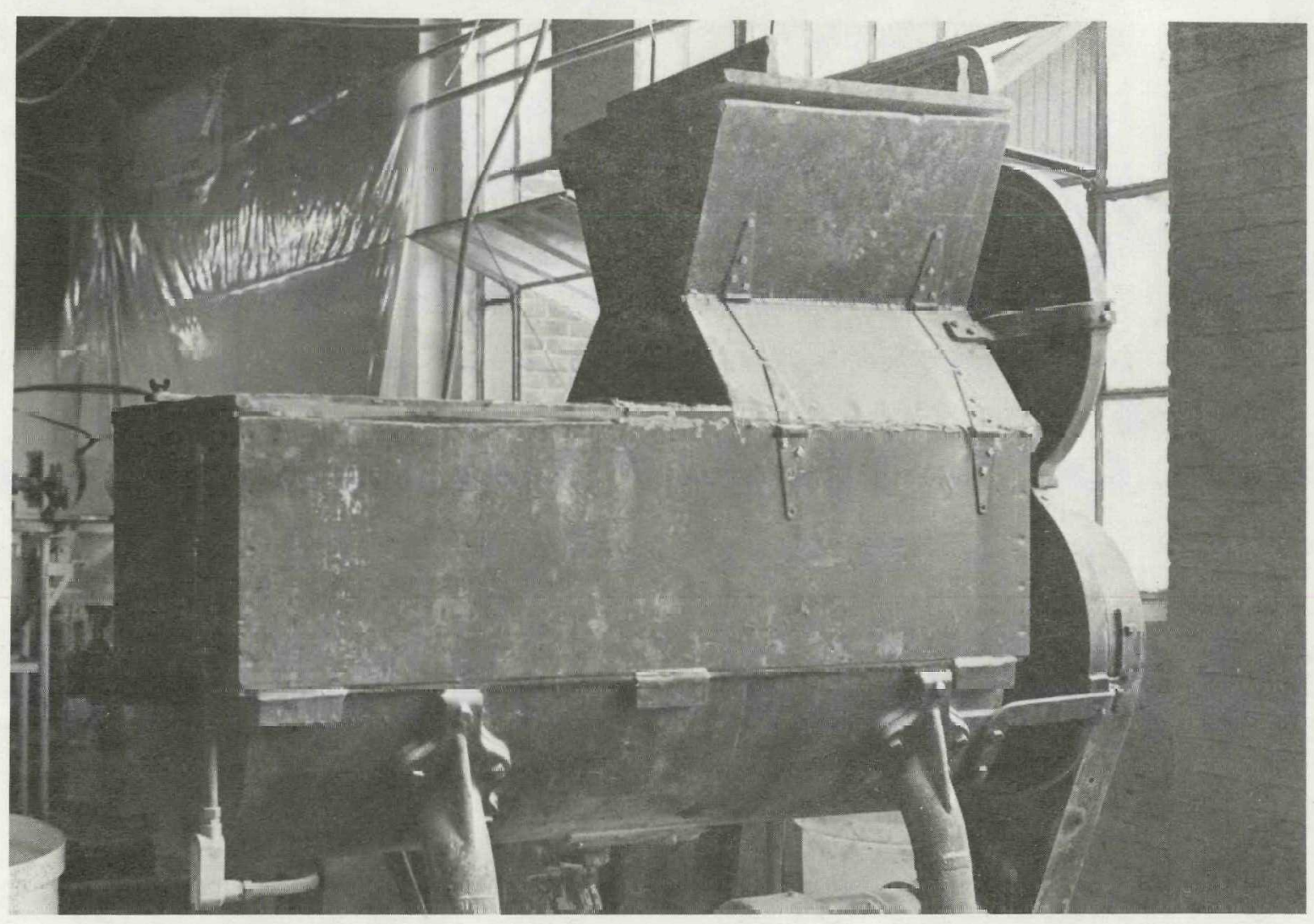

FIGURE 21

$\mathrm{Ribbon}$ Blender 


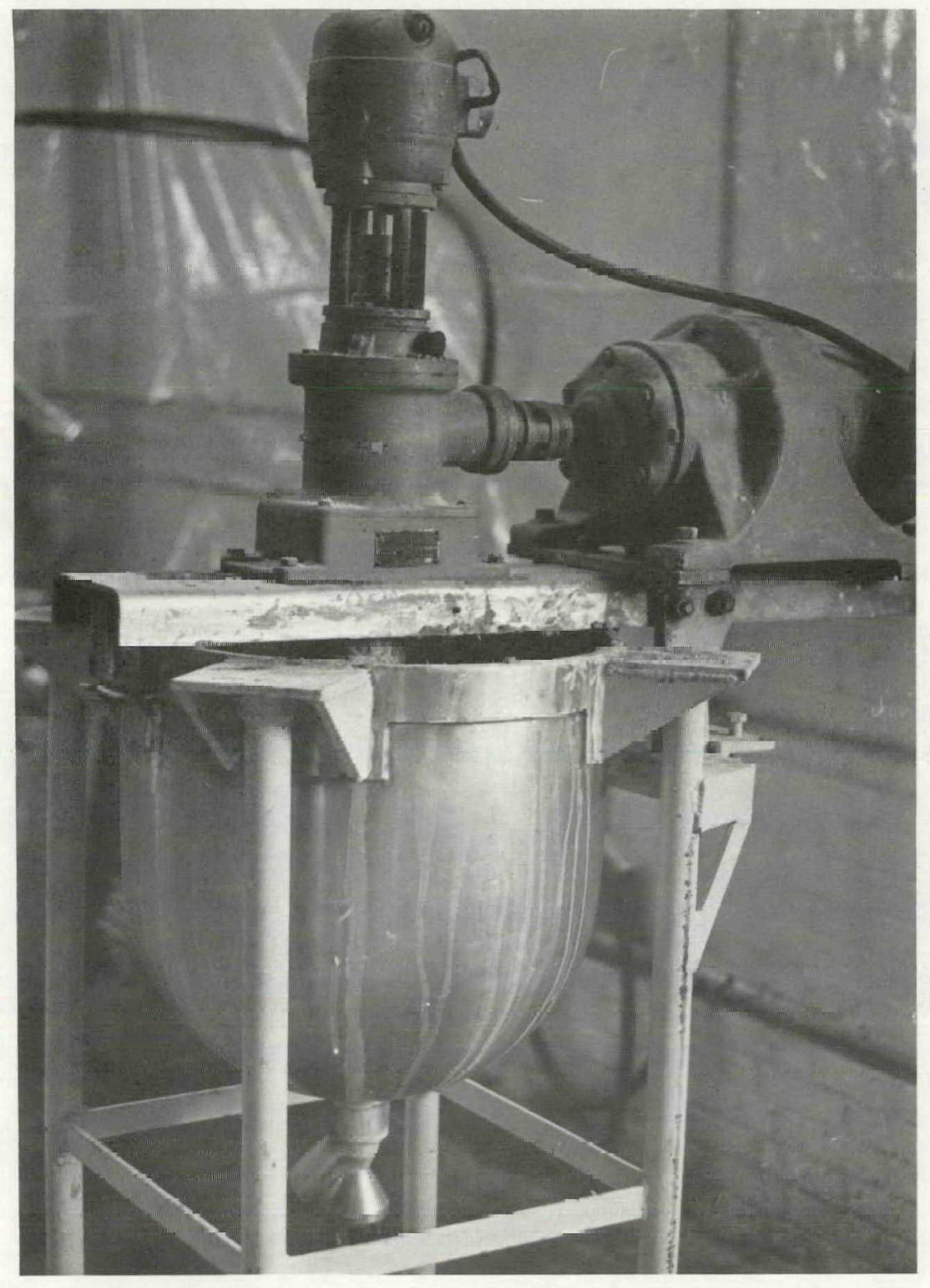

FIGURE 22

Agi-Mixer 


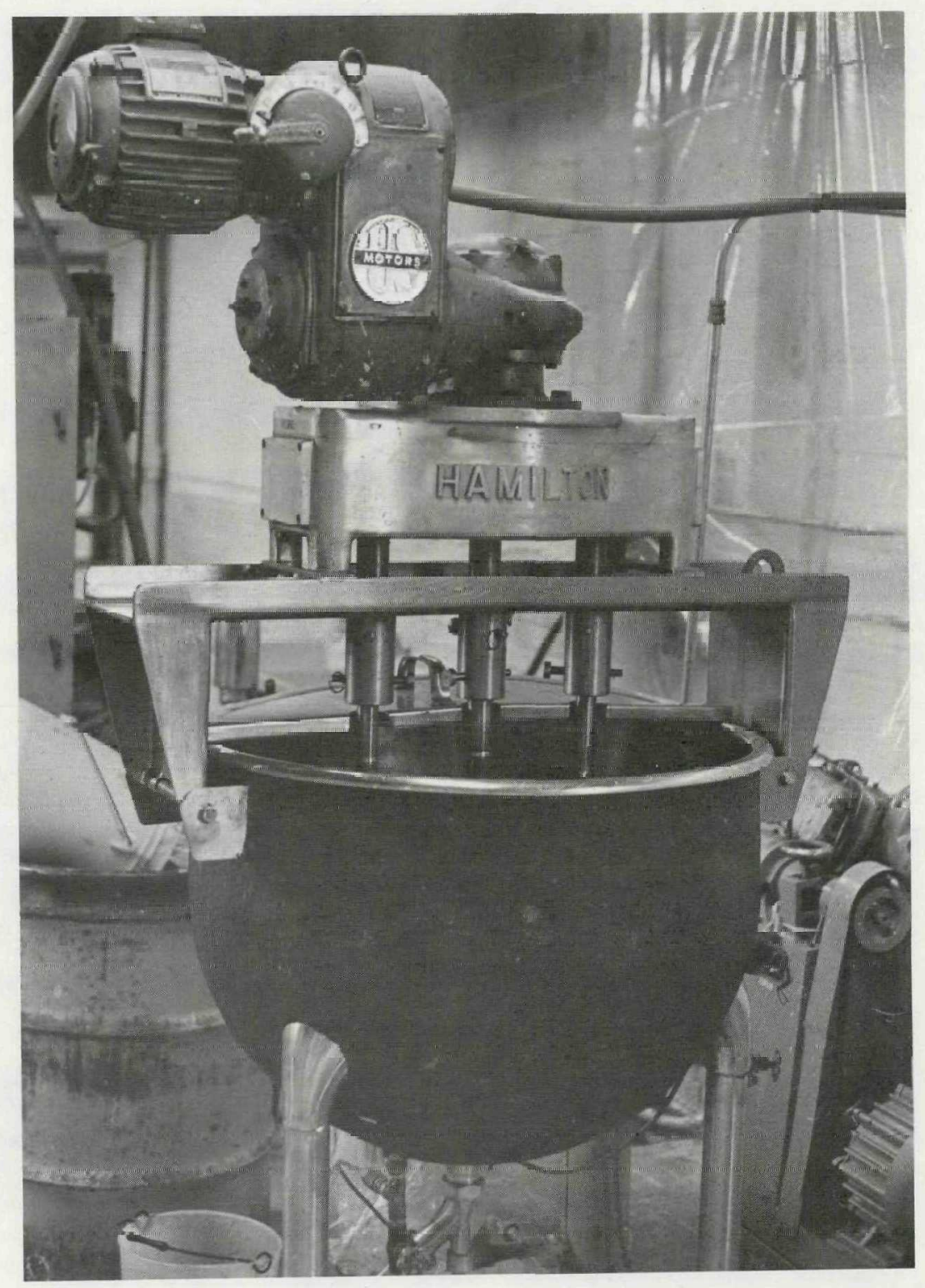

FIGURE 23

Holding Kettle 


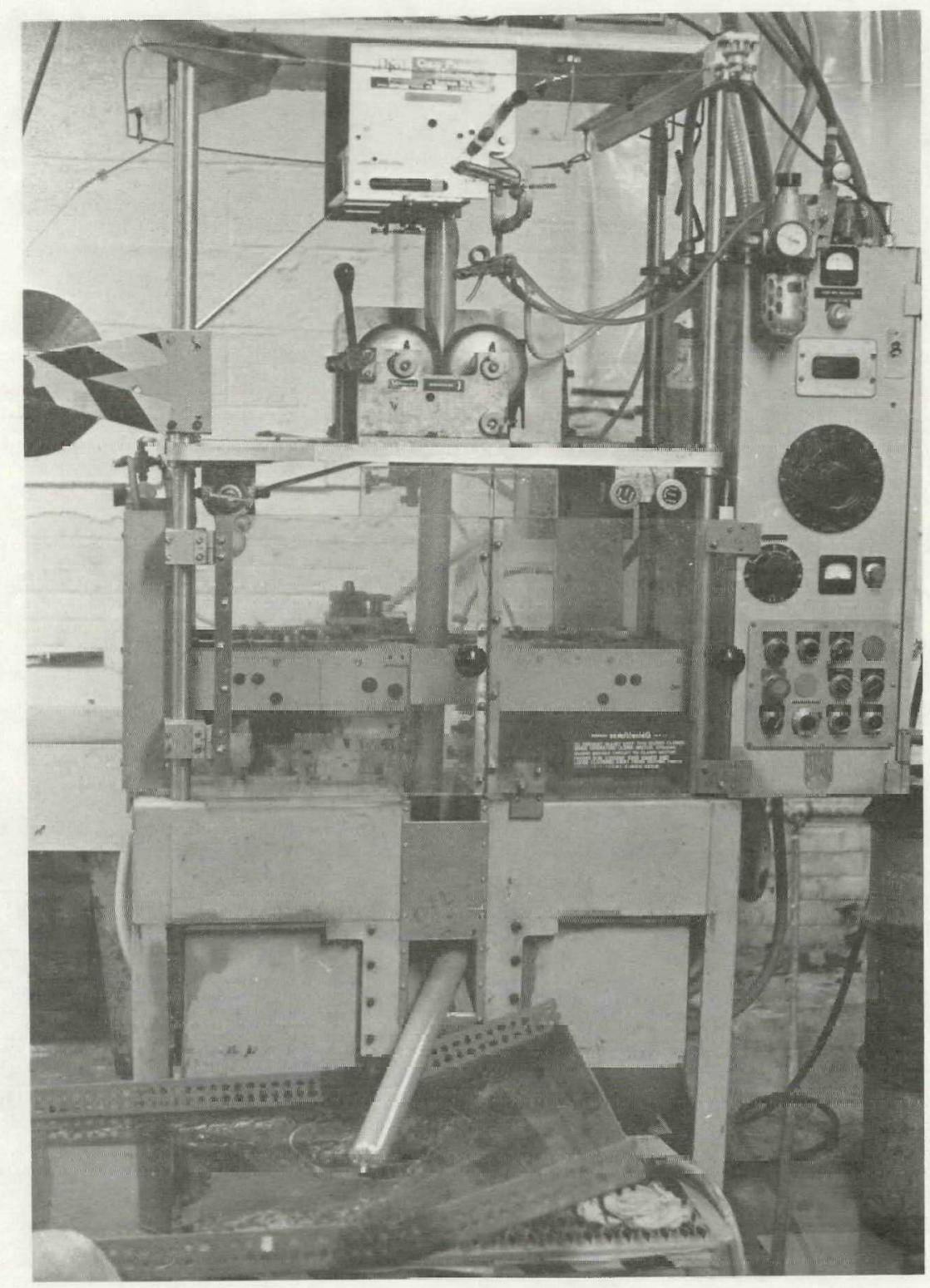

FIGURE 24

CHUB Machine 
FIGURE

NOTES:

MATERIALS LIST MALI

$$
\begin{array}{lrl}
\mathrm{Na}_{2} \mathrm{SO}_{4} & 32.89 \% & \text { MS } 1002 \\
\text { Water } & 41.82 \% & \text { MS } 1001 \\
\text { Borax } & 2.63 \% & \text { MS } 1007 \\
\text { Boric ACid } & 1.75 \% & \text { MS } 1003 \\
\text { Minugel } & 7.89 \% & \text { MS } 1006 \\
\mathrm{NaCl} & 6.75 \% & \text { MS } 1005 \\
\mathrm{NH}_{4} \mathrm{Cl} & 6.23 \% & \text { MS } 1004 \\
\mathrm{Film} & & \text { MS } 1008 \\
\mathrm{Clamps} & & \text { MS } 1009
\end{array}
$$

PARTS LIST PILI

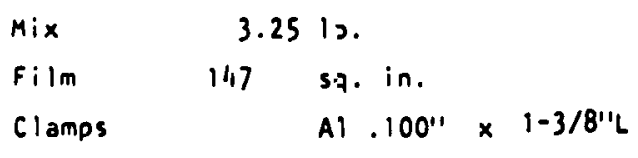

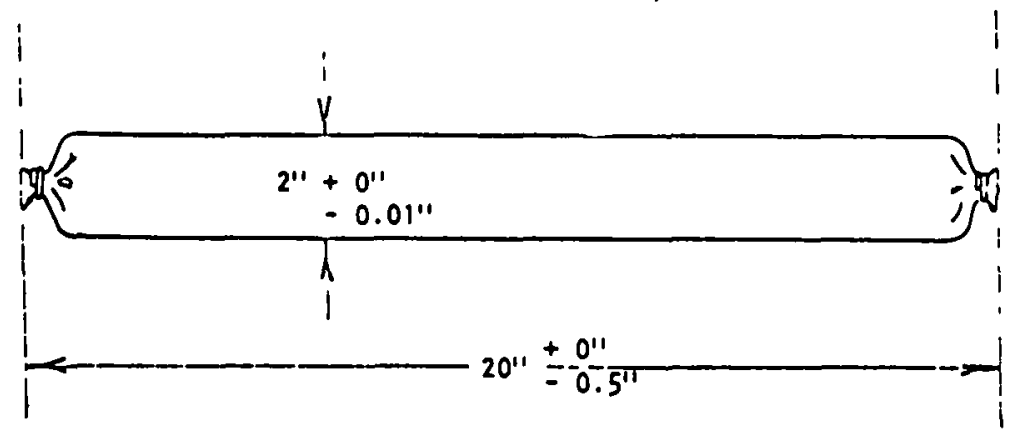

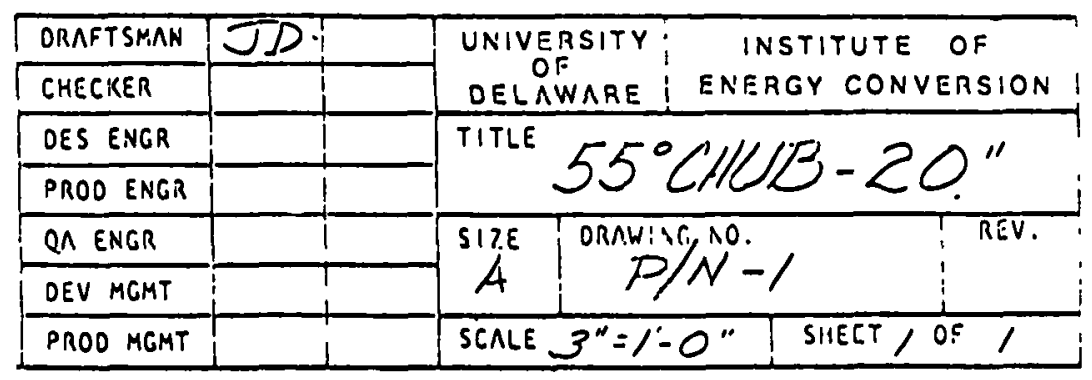

苫 
- THIS PAGE WAS INTENTIONALLY LEFT BLANK 
ORNL/Sub-7585/1

Dist. Category UC-94a

\section{Internal Distribution}

$\begin{aligned} \text { 1. } & \text { T. D. Anderson } \\ 2 . & \text { R. S. Carlsmith } \\ \text { 3. } & \text { D. M. Eissenberg } \\ \text { 4. } & \text { H. L. Falkenberry } \\ 5 . & \text { E. C. Fox } \\ 6 . & \text { H. W. Hoffman } \\ \text { 7. } & \text { A. S. Holman } \\ \text { 8. } & \text { L. Jung } \\ 9 . & \text { R. J. Ked1 } \\ 10 . & \text { H. M. Long } \\ 11-25 . & \text { J. F. Martin } \\ 26 . & \text { M. Olszewski }\end{aligned}$

27. J. L. Rich

28. M. W. Rosenthal

29. A. Solomon

30. W. Stockdale

31. M. P. Ternes

32. H. E. Tramme11

33. D. B. Trauger

34. ORNL Patent office

35. Central Research Library

36. Document Reference Section

37-38. Laboratory Records Department

39. Laboratory Records (RC)

\section{External Distribution}

40. Fred Avril, Long Island Lighting Company, 250 01d Country Road, Mineola, NY 11501

41. Allen M. Barnett, University of Delaware, Instituce of Energy Conversion, Newark, DE 19711

42. Frank Baylin, Solar Energy Research Institute, 1536 Cole Boulevard, Golden, CO 80401

43. Ralph M. Deal, Chemistry Department, Kalamazoo College, Kalamazoo, MI 49007

44. Jay Eliason, Battelle Pacific Northwest Laboratories, P.0. Box 999, Battelle Boulevard, Richland, WA 99352

45-47. William Frier, Division of Energy Storage Systems, Department of Energy, $600 \mathrm{E}$ Street, NW, Washington, DC 20585

48. Galen R. Frysinger, University of Delaware, Institute of Energy Conversion, Newark, DE 19711

49. John S. Gahimer, Chemical and Thermal Storage Branch, Division of Energy Storage Systems, Department of Energy, 600 E Street, NW, Washington, DC 20585

50. Jay Gilson, Sandia Laboratories, P.0. Box 969, Livermore, CA 94550

51. Larry Gordon, NASA-Lewis Research Center, Cleveland, OH 44101

52-61. Mike Guervich, Division of Energy Storage Systems, Department of Energy, 600 E Street, NW, Washington, DC 20585

62. Herb Hersh, Argonne National Laboratory, 9700 S. Cass Ave., Argonne, IL 60439

63. Maurice Lang, Institute of Energy Conversion, One Pike Creek Center, Wilmington, DE 19808

64. T. Mahefkey, AFAPL/POE, Building 18, Wright-Patterson Air Force Base, Dayton, OH 45433 
65. Arnold Mancker, Tennessee Valley Authority, 1360 Commerce Union Bank, Chattanooga, TN 37401

66. Allan Michaels, Argonne National Laboratory, 9700 South Cass Avenue, Argonne, IL 60439

67. James Minor, Battelle Pacific Northwest Laboratories, P.0. Box 999, Battelle Boulevard, Richland, WA 99352

68. David Namkoong, NASA-Lewis Research Center, Cleveland, OH 44101

69. William Nice, NASA-Lewis Research Center, Cleveland, OH 44101

70. George Pezdirtz, Director, Division of Energy Storage Systems, Department of Energy, $600 \mathrm{E}$ Strcet, NW, Washington, DC 20585

71. Joseph E. Rizzuto, New York State Energy Research and Development Authority, Empire State Plaza, Albany, NY 12223

72. Ival Salyer, University of Dayton, Research Institute, Dayton, OH 45469

73. Regis Scheithauen, Division of Energy Storage Systems, Department of tinergy, Washingron, DC 20545

74. Tom Schneider, Electric Power Research Institute, 3412 M1llview Ave., P.O. Box 10412, Palo A1to, CA 94303

75. Robert J. Schoenhals, Ray Herrick Laboratorles, Purdue University, West Lafayette, IN 47907

76. Tony W. Sigmon, Research Triangle Institute, P.0. Box 12194, Research Triangle Park, NC 27709

77. James H. Swisher, Division of Energy Storage Systems, Department of Energy, $600 \mathrm{E}$ 'Street, NW, Washington, DC 20585

78. Susan Waddle, Department of Energy, Oak Ridge Operations, P.o. Box E, Oak Ridge, IN 37830

79. Charles Wyman, Solar Energy Research Institute, 1536 Cole Boulevard, Golden, CO 80401

80. Director, Reactor Division, DOE, ORO, Oak Ridge, TN 37830

81. Office of Assistant Manager for Energy Research and Development, DOE, ORO, Oak Ridge, TN 37830

82-316. Given distribution as shown in DOE/TIC-4500 under category UC-94a 